University of Louisville

ThinkIR: The University of Louisville's Institutional Repository

Electronic Theses and Dissertations

8-2011

\title{
Assisted living facilities in Louisville Kentucky : a case study to examine aging in place.
}

James Luther Wilson

University of Louisville

Follow this and additional works at: https://ir.library.louisville.edu/etd

\section{Recommended Citation}

Wilson, James Luther, "Assisted living facilities in Louisville Kentucky : a case study to examine aging in place." (2011). Electronic Theses and Dissertations. Paper 1581.

https://doi.org/10.18297/etd/1581

This Doctoral Dissertation is brought to you for free and open access by ThinkIR: The University of Louisville's Institutional Repository. It has been accepted for inclusion in Electronic Theses and Dissertations by an authorized administrator of ThinkIR: The University of Louisville's Institutional Repository. This title appears here courtesy of the author, who has retained all other copyrights. For more information, please contact thinkir@louisville.edu. 
ASSISTED LIVING FACILITIES IN LOUISVILLE KENTUCKY:

A CASE STUDY TO EXAMINE AGING IN PLACE

\author{
By \\ James Luther Wilson \\ B.S. University of Louisville, 1989 \\ M.A. Spalding University, 1998

\begin{abstract}
A Dissertation
Submitted to the Faculty of the

Graduate School of the University of Louisville

in Partial Fulfillment of the Requirements

for the Degree of
\end{abstract} \\ Doctor of Philosophy \\ Department of Urban and Public Affairs \\ University of Louisville \\ Louisville, Kentucky
}

August 2011 


\title{
ASSISTED LIVING FACILITIES IN LOUISVILLE KENTUCKY: \\ A CASE STUDY TO EXAMINE AGING IN PLACE
}

\author{
By \\ James Luther Wilson \\ B.S. University of Louisville, 1989 \\ M.A. Spalding University, 1998 \\ A Dissertation Approved on
}

May 31, 2011

By the following Dissertation Committee:

Dissertation Co-Chair (Steven Bourassa)

$\overline{\text { Dissertation Co-Chair (Steven Koven) }}$

\begin{tabular}{c}
\hline Noell Rowan \\
\hline John S. Gilderbloom \\
\hline Leonard Bright
\end{tabular}




\section{DEDICATION}

This dissertation is dedicated to my Lord and

Savior Jesus Christ. Without Him, I am nothing.

This dissertation is also dedicated to the love

of my life, my wife, Andrea Marie Wilson. Your love and support during the completion of my studies has been vital.

I love you! 
ACKNOWLEDGEMENTS

Many thanks to my co-Chairs, Dr. Steven Bourassa and Dr. Steven Koven for their direction and corrections to the numerous draft editions of this dissertation. Their patience and rigorous attention to scholarship has made me a better social scientist.

To my committee members, Dr. Leonard Bright, Dr. John Gilderbloom and Dr. Noell Rowan, thank you for engaging with me in this work. Your thoughtful criticism, time and attention to this dissertation in the midst of busy semesters is deeply appreciated.

To Christian Care Communities for tuition assistance and encouragement as I hopped, skipped and jumped my way through completing this work. Your dedication to employees is evident in your investment in me.

To the Oakland Missionary Baptist Church, thank you for the time off to ponder and pray my way through my studies and my writing. I thank the Lord for allowing our paths to intersect.

To Dr. F. Bruce Williams, I love you. You believed in me when I often didn't believe in myself. Good looking out! 
Finally, to my children, Ashley, Joshua, April and niece, Teonnie, I hope that my work inspires your life to deeper depths and higher heights. 


\section{ASSISTED LIVING FACILITIES IN LOUISVILLE, KENTUCKY:}

A CASE STUDY TO EXAMINE AGING IN PLACE

\section{JAMES LUTHER WILSON}

\section{MAY 31, 20111}

ABSTRACT

As the older adult population in the United States continues its accelerated growth, there is a growing concern about the long-term care options for these elders. While nursing homes are no longer desirable and costly for federal and state governments, viable alternatives are being sought to meet this need. The development and rapid expansion of the numbers of assisted living communities have grown as older adults, family caregivers and government bureaucrats are looking for lower cost options. How beneficial are assisted living communities for the older adults that live in them? Most older adults seek to avoid multiple moves to meet their care needs and desire to age in place within a residential setting.

This research examines assisted living communities (ALCs) in the Louisville, Kentucky to explore their benefit to older adults and to examine their ability to accommodate 
residential aging in place. The analysis consisted of examining four characteristics of the ALCs which are personal services, meals and social interaction, community policies and the physical configuration.

The findings of this study conclude that assisted living communities provide significant benefits to older adults by the provision of supportive services to help in areas of activities of daily living. There are some assisted living communities that are more able to accommodate residents to age in place based on the provision of necessary services, highly personalized service and reasonable accommodations that are needed to help with physical decline. Finally, the assisted living communities operate along the continuum of care and facilitate residents to move to more intensive care when their supportive services needs are beyond the capacity of the ALC. 


\section{LIST OE TABLES}

TABLE

PAGE

1. Physical Characteristics. . . . . . . . . . 72

2. Meals and Social Interaction. . . . . . . . . . 74

3. Available Services. . . . . . . . . . . . 79

4. Units and Staff Ratio. . . . . . . . . . 83

5. Monthly Fees. . . . . . . . . . . . . . . 84

6. Community Policies. . . . . . . . . . . . 85

7. HUD Assisted Living Conversion Program. . . . . .135

8. States Allowing ALC Medication Administration. - 142 


\section{LIST OF FIGURES}

EIGURE

PAGE

1. Chart of Sources of Funding for Residents . . . . .52

2. Photo of ALC Indoor Sitting Area. . . . . . . . 69

3. Photo of Typical Hallway Width. . . . . . . . . . 69

4. Photo of Piano in Dining Room. . . . . . . . 70

5. Photo of Theatre in ALC. . . . . . . . . . . 71

6. Photo of Beauty Salon. . . . . . . . . . 72

7. Photo of Typical Dining Room. . . . . . . . . . 73

8. Photo of Typical Apartment Bedroom. . . . . . . .84

9. Chart of U.S. Population 65+. . . . . . . . . . 98

10. Chart of KY Population 65+. . . . . . . . . . . 98

11. Chart Comparing KY Population $65+$ and Available Long-Term Care Units. . . . . . . . . . . 100

12. Chart of Kentucky Aged Population by Cohort. . . 101 
TABLE OF CONTENTS

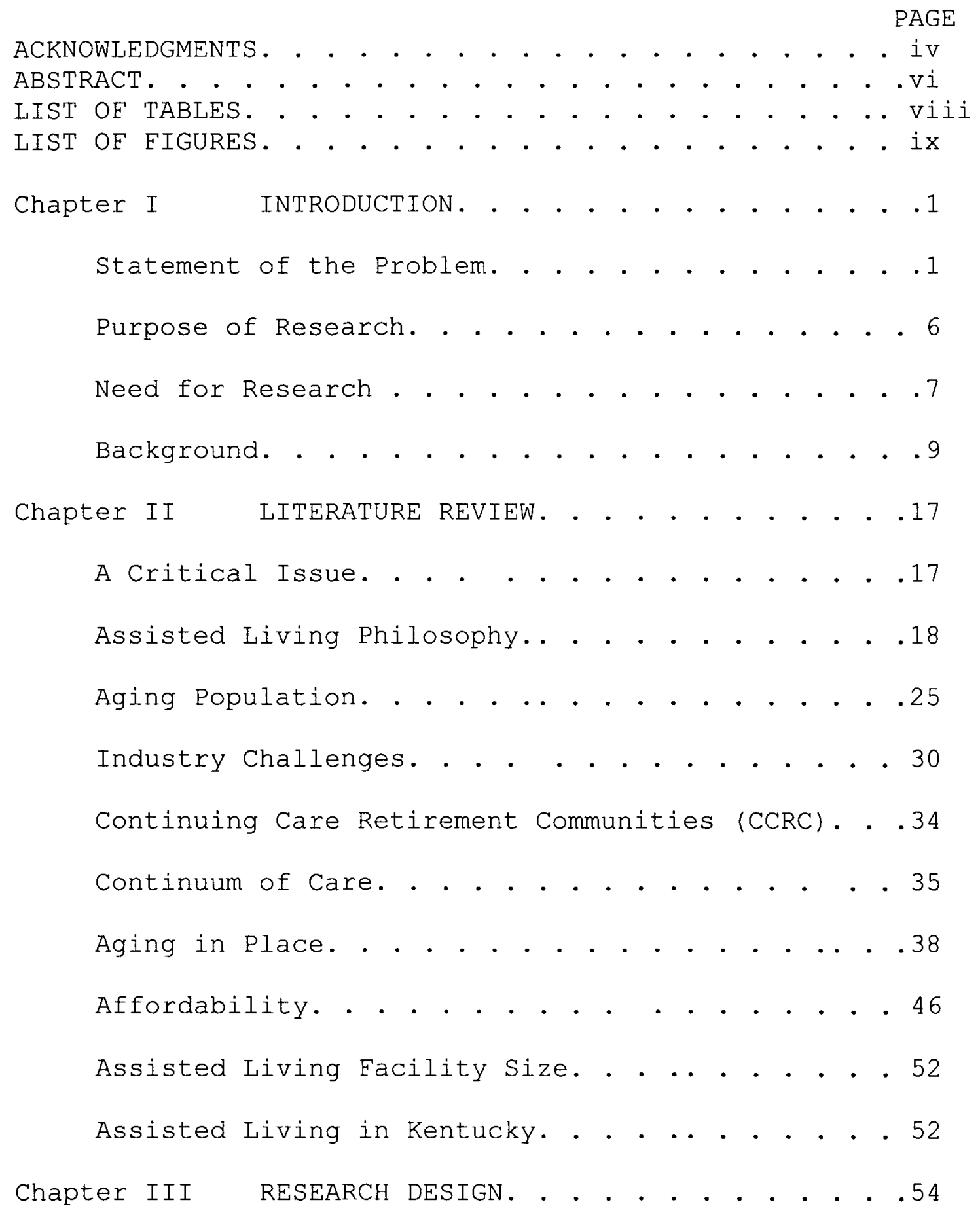


Case Study. • . . . . . . . . . . . . . . 55

Methodology. . . . . . . . . . . . . . 55

Grounded Theory. . . . . . . . . . . . 56

Data Collection. . . . . . . . . . . . . . 58

Design Tests. . . . . . . . . . . . . 60

Research Question. . . . . . . . . . . . 62

Chapter IV DATA REVIEW. . . . . . . . . . . . 62

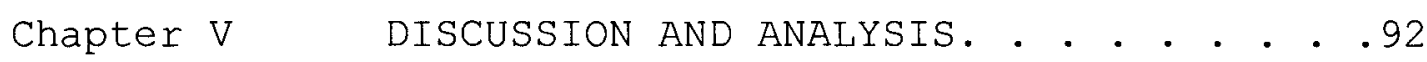

Aging in Place Capacity. . . . . . . . . . 111

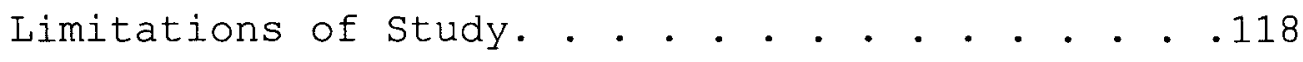

Chapter VI ASSISTED LIVING COMMUNITY AFFORDABILTY

AND COST. . . . . . . . . . . . . 120

Chapter VII POLICY RECOMMENDATIONS. • • • • . • . . . . 132

Hypotheses. . . . . . . . . . . . . 140

Chapter VIII SUMMARY AND CONCLUSION. • . . . . . . . . 144

REEERENCES. . . . . . . . . . . . . . . . . . . 154

APPENDICES. . . . . . . . . . . . . . . . . . . 160

CURRICULUM VITAE. . . . . . . . . . . . . . . 209 


\section{CHAPTER I}

\section{INTRODUCTION}

Statement of the Problem

The population of the United States is experiencing a significant increase in the numbers of aging citizens with the most dramatic growth occurring in the oldest age groups. The U. S. Census Bureau reports that in 2000 there were nearly 35 million people aged 65 years and older in the U.S., which amounts to $12.6 \%$ of the total population. By 2015, it is projected to be $14.7 \%$ and to exceed $20 \%$ by 2030. With a projected U.S. population of 351 million by 2030, the number of persons aged 65 years and over is estimated to rise to over 70 million people, which is more than twice the amount in 2000 (Spitzer, Newman \& Holden, 2004).

As the nation experiences unprecedented growth in the older adult population, the provision of long-term care services and housing for older adults has emerged as an increasingly urgent public policy issue. In recent years, 
assisted living communities (ALCs) have proven to be the fastest growing long-term care and housing option for older adults in the U.S. ALCs are a type of residence where daily services are provided to assist with normal activities. These communities are an alternative for older adults who need more assistance than is typically available in a housing only retirement community, but do not need intensive medical and nursing care provided in nursing homes. The popularity of assisted living communities is on the rise as communities, legislatures and federal and state governments look for better and more economical ways to provide a supportive environment where social, physical and emotional needs of older adults are met but the limitations or restrictions on their independence are minimized (Gillespie \& Sloan, 1990). A typical aging progression includes a diminished ability to perform routine and necessary tasks on a regular basis. This decline is normally due to physiological and psychosocial changes (Aud \& Rantz, 2005). The provision of supportive care services in assisted living communities is designed to optimize independence while meeting care needs (Stefanacci \& Podrazik, 2005)

Operators of assisted living communities believe that the housing and care setting of the assisted living 
community can accommodate physically and mentally frail older adults by providing a protective environment and assistance with the everyday activities to meet their needs.

Assisted living communities were developed as a model of residential long-term care, which emphasizes the importance of the social aspects of care (Barton, 1997). ALCs depart from what is generally termed a medical model which puts treatment of the disease primary and social aspects secondary. Essentially, the goal of a social model is to create a normal, homelike living environment that is organized around promoting independence rather than the provision of heath care services or performance of personal care assistance tasks (Hawes, Rose \& Philips, 1999). Feingold and Werby, (1990) demonstrate that the best way to prolong independence in older adults is by reinforcing the sense of competence of older adults by exercising control over one's life and having access to choices.

One of the central views of the assisted living community is that as changes occur in the health status of older adults, residents choose supportive services that allow them to remain in their homes and thereby "age in place." 
Traditionally, the term "aging in place" meant that individuals grow old in their own personal residences. However, the concept has been expanded to include a wide range of housing alternatives, including assisted living communities (Ball et al., 2005). Erom the perspective of some in the assisted living industry, aging in place provides for older adults to remain in the community for longer periods of time by having daily support services to meet their care needs and delays traditional nursing home placement or hospitalization (Frank, 2002). However, there is disagreement among proponents of the assisted living industry as to the role of ALCs with regard to aging in place. The disagreement stems from opposing philosophical views of the ALC.

Eor some, assisted living communities are an option that fits along the continuum of long-term care. Under this perspective, the ability of residents to age in place is hampered as managers are less likely to make accommodations or modifications to the facility. Simply put, the ALC makes no attempts to provide additional services, modification or accommodations to meet the needs of residents. When residents decline, they must relocate to another community setting that can meet their care needs. 
However, others believe that the ALCs are an option separate from the entire continuum of care. The continuum of care represents the traditional model of care for older adults where they move in a linear trajectory from one setting to another with each move representing an increase in need for medical care and assistance with daily activities (Frank, 2002). When assisted living is approached as an alternative to the continuum of care rather than as a part of it, ALCs may serve a larger population and allow older adults to age in place (Stefanacci \& Podrazik, 2005).

These differing perspectives on aging in place and how ALCs fit into the long-term care industry are often sources of confusion and anxiety for residents and their families. Residents and ALC managers have different expectations on the level of accommodation to age in place. These differences not only exacerbate confusion for residents and families, but miss opportunities to capitalize on financial, human and community resources (Spitzer, Neuman \& Holden, 2004).

However, assisted living communities have developed and grown to become a vital part of the long-term care industry for older adults, families, policy makers and politicians seeking to access more cost effective ways to 
care for older adults who are unable to live independently but do not require the skilled care of a nursing facility (Gillespie \& Sloan, 1990).

\section{Purpose of Research}

This dissertation will consist of a case study of ALCs in the Louisville, Kentucky metropolitan area. The purpose of this research will be to determine how ALCs are providing supportive services to the older adult population. Because ALCs differ in areas including size, amenities, configuration, staffing levels and care philosophy, how do these characteristics affect the provision of supportive services? How do ALCs in Louisville interpret their care philosophy regarding aging in place? How ALCs approach and interpret their role for providing assistance are significant topics of consideration, especially for an aging society. What are those factors and/or policies that influence the capacity of ALC managers to allow residents to age in place? This research will explore that question by examining personal services, meals and social interaction, facility policies and the physical characteristics of the building. The specific research objectives are: 
1. To explore how ALCs in Louisville, Kentucky are providing care to residents.

2. To examine those factors that research suggests promotes an $\mathrm{ALC}^{\prime}$ s ability to accommodate residents to age in place.

3. To inform the current public policy debate as federal and state governments continue to look for low-cost options for assisting older Americans in their housing and care needs.

4. To increase the general knowledge about assisted living communities. The research question is how are ALCs providing longterm care services to older adults? My hypotheses are: 1. Supportive services to older adults are a benefit to the residents who live in ALCs.

2. Some ALCs are more accommodating to allow aging in place than others.

3. ALCs interpret their services apart from the continuum of care and accommodate aging place.

\section{Need for the Research}

Assisted living is a relatively new type of housing for older adults with physical and mental deficiencies in activities of daily living. Because of the comparatively 
short history of the assisted living industry as compared with nursing facilities, Continuing Care Retirement Communities (CCRCs) and congregate housing facilities, there is still a great concern and need for additional research that examines the contribution ALCs are making. According to the National Center for Assisted Living (NCAL, 2001), there are nearly 33,000 ALCs in the United states, with approximately 1.18 million people living in those residences. When policies and factors influencing managers' ability to manage residents aging in place can be identified and examined, the information can be reflected in community design and policy-making by developers, facility providers, staff, regulators and educators. The need for research on this matter is further justified by the amount of confusion that exists in the general public and the lack of a consistent definition of what defines an assisted living community. Golant (1999) notes that among the problems older adults and/or their families must answer are which types and levels of physical and mental impairments are accepted and tolerated by ALCs. There are no federal or state agencies that rate the quality of service provision or housing standards. This results in potential residents and their families having no 
way of evaluating the quality of housing and the ability of the community to provide needed supportive services.

There are important distinctions that exist among older adults based on age and health conditions, as well as socio-economic differences and lifestyles. Developers need to know what types of amenities are appropriate and desirable (Golant, 1992). This kind of information can lead to building better, more efficient communities that can accommodate aging in place. Managers need to know what types of policies and staffing needs are necessary to maximize independence and autonomy. Older adults and families need to be clear about what to expect from ALCs when inevitable changes in the health of the residents occur.

Although assisted living is a fast growing long-term alternative, it is still evolving in response to economic realities, the needs of diverse older residents, desires of residents and family members and state regulatory agencies.

Background

Long-term care has functioned effectively since the mid-century, meeting the needs of the frail elderly who did not have the assistance of family or the financial ability to afford private in-home nursing. The nursing home has 
traditionally been the foundation of the long-term care system and the elderly who entered the nursing home required 24-hour medical care from professionals. The traditional nursing home setting operated as a medical model of health care, providing skilled nursing, medication administration, and assistance with activities of daily living, based upon the schedules of the facility operation. The staffing rotation, medical record and physician's orders dictated the resident's care and routines. The traditional nursing home mirrors the hospital operation, while placing focus on efficiency and routine rather than the individual resident's needs (Kane \& Kane, 2001; Zimmerman et al., 2003).

Within the past 15 years, an evolution has emerged, which is shifting the focus of long-term care from a medical model to a social model, in which the care is more holistic and resident-centered (Zimmerman et al., 2003). This shift in the long-term care paradigm has introduced new directions in the system of residential-service delivery (Carder, 2002). An alternative to the medical, nursing home institution was introduced in Oregon in the mid-1980s. This new concept of assisted living has been replicated in most U.S. states, although program titles, 
regulation, licensure, and philosophy continue to differ by state (Stefanacci \& Podrazik, 2005).

Although there is not a national consensus on what clearly defines and constitutes an assisted living community, each state regulates and defines the requirements for what it calls an assisted living community. States describe assisted living communities with a number of different labels, including adult homes, board and care homes, sheltered care facilities, personal care homes, residential care facilities, domiciliary care facilities, adult congregate living, enriched housing, homes for the aged, adult foster care homes, catered living communities and community residences (Gillespie \& Sloan, 1990; Frank, 2002; Tinsley \& Warren, 1999).

Several organizations exist that pioneered the concept of dignity, independence, quality care, and leastrestrictive environment within this new alternative to long-term care. Organizations such as the Assisted Living Quality Coalition the Assisted Living Federation of America and the American Association of Retired Persons each champion the resident-centered focus of long term care.

The least restrictive environment of assisted living has many definitions, as varied as each state government defines assisted living communities. The Assisted Living 
Quality Coalition's (Hawes \& Phillips, 2000) definition of this specialized housing with health-care services phenomenon:

A congregate residential setting that provides or coordinates personal services and care, 24-hour on site support and assistance (scheduled and unscheduled), activities and health-related services by qualified individuals. It is designed to minimize the need to move; accommodate individual residents' changing needs and preferences; protect residents' rights; maximize residents' dignity, autonomy, privacy, independence, choice, safety, quality of life, and quality of care; and encourage family and community involvement (Hawes \& Phillips, 2000).

Although the model of assisted living has been in existence since the 1980s, it has evolved with each state's licensure, regulation, and philosophy definition of their specific programs).

Stefanacci and Podrazik (2005) used the Centers for Medicare and Medicaid Services (CMS) assisted-living definition of a type of living arrangement in which personal care services such as meals, housekeeping, transportation, and assistance with $A D L^{\prime} s$ are available as needed to people who still live on their own in a residential facility. 
However, one common aspect of each assisted-living definition is the concepts of independence and dignity.

It is generally understood that an assisted living community is a group setting that is residential in character and includes the delivery of professionally managed personal and health care services for those residents needing help with activities of daily living (ADL) and instrumental activities of daily living (IADL). Activities of daily living are the physical functions a person performs every day that typically include: dressing, eating, bathing, toileting, transferring (moving from bed to chair), and walking (Assisted Living Workgroup, 2003). Instrumental activities of daily living are functions that involve managing one's affairs and performing tasks of everyday living such as: preparing meals, taking medications, walking outside, using the telephone, managing money, shopping and housekeeping (Assisted Living Workgroup, 2003).

Assisted living communities typically offer a more homelike environment for people needing or anticipating the need for help with activities of daily living and instrumental activities of daily living, but for whom 24hour intensive nursing home care is not necessary. Instead of an institutional looking environment of a nursing home, 
assisted living communities look more like apartment buildings with lockable private rooms or suites. Instead of a nurses' desk, there is typically a help or receptionist desk (Gillespie \& Sloan, 1990). Instead of hospital-like lounge areas and stark public spaces, assisted living communities generally have gathering areas with couches, fireplaces, gardens and atriums. Central dining areas look more like banquet rooms and regularly offer entertainment during or after mealtimes (Gillespie \& Sloan, 1990). Meaningful activities and chats with neighbors in pleasant surroundings keep residents active and socially engaged (Day, 2002). Assisted living is an attractive alternative to many older adults because of the sense of independence they have and the provision of supportive care services when they need them. Many of these services are available upon request and residents can typically choose the type and frequency of care they need (Kane, 2001).

\section{Industry Expansion}

Regnier (1999) identifies several factors that have affected the growth of the assisted living community. Among the factors he cites are the growing numbers of people over the age of 85 and the projection that these 
numbers will continue to grow. Public policy discussions and debates on the viability of Social Security and Medicare have well documented the aging of the U.S. (NCAL, 2001). The National Center of Assisted Living (2001) also points out that growth in the industry not only depends on the number of older adults but on the number of older adults that need daily assistance.

The continuing upward spiral of long-term costs has also been a factor promoting growth in the assisted living industry as policy makers seek low cost alternatives (Regnier, 1999). Policy makers have encouraged states and service providers to develop substitutes to nursing home placement as regulators question the cost effectiveness of nursing homes. Hawes and Phillips (2000) also add that the industry's growth is due to the availability of private financing for development and public policies aimed at containing the use of nursing homes.

Another factor affecting growth is the affluence of the typical assisted living resident. Demand is determined not only by what people want but what they can afford. Older consumers who have the financial means to avoid institutional placement are increasingly reluctant to accept nursing home placement. The increased cost and institutional lifestyle typically associated with nursing 
homes are unappealing to the vast majority of older adults and their families (Regnier, 1999). 


\section{CHAPTER II}

\section{LITERATURE REVIEW}

\section{A Critical Issue}

While addressing issues of older adults finding safe, affordable and quality housing in neighborhoods that they find attractive, Gilderbloom and Mullins (1995) evaluated data from the American Housing Survey and concluded that housing the elderly is one of the most crucial issues facing the country. The "graying" of American society is a formidable challenge as the nation seeks to address the housing and care needs for older adults age 65 years and older. Compounding this phenomenon is that historically, legislatures around the country have turned their backs on this segment of this vulnerable population (Gilderbloom, 2008)

The rapid growth in the older adult population as well as changes in their characteristics will increase future needs for care and ways to finance it (Tinsley \& Warren, 1999). Federal and state governments have imposed 
constraints for the funding housing and long-term care for older adults. These trends suggest that access to adequate care may become increasingly problematic for older adults and their families.

\section{Assisted Living Philosophy}

Assisted living communities adopt an operational philosophy that enhances resident quality of life by emphasizing autonomy, privacy, dignity and freedom with opportunities for ample social interaction. The higher degree of autonomy allows residents more discretion on the delivery of services. Privacy is a high priority as residents are not required to share rooms with other residents and their sense of dignity is maintained as residents are receiving many of the services within the confines of their private apartment (Spitzer, Newman \& Holden, 2004). Assisted living communities typically provide many activities for residents to socialize with other residents as well as activities within or away from the community. ALCs try to create a homelike atmosphere through interior and exterior building designs. Living quarters typically include studios, one- and two- bedroom apartments featuring full bathrooms, kitchens and locking doors. This allows residents to control their space and 
furnishings. The common areas of ALCs feature a décor of non-institutional furniture, artwork, patios, wellness and fitness centers, libraries and computer centers (Spitzer, Newman \& Holden, 2004). In this type of community, a spouse or other caregiver could also reside with the resident.

Older adults are attracted to the assisted living option because it adds a greater emphasis on consumer dignity, autonomy and choice (Hawes, Rose \& Phillips, 1999). Whereas nursing homes are designed to promote operational efficiency, they often compromise the residents' desire for privacy and dignity while providing care. The assisted living model seeks to enhance resident quality of life by emphasizing autonomy, privacy, dignity, and freedom with opportunities for ample social interaction (Stefanacci \& Podrazik, 2005).

Assisted living philosophy is consistent with a social model of care. Golant \& Hyde (2008) identify four elements in a social model of care:

1. That residents define what quality of life means to them and care providers recognize and respect their choices; 
2. that residents and their family members are capable of making decisions about their place of residence and care;

3. that positive social interactions and meaningful activities can be therapeutic; and;

4. that residents retain their connections with the community, including family members, friends, and other service providers.

The social model of care can be contrasted with a medical model of care, which is frequently associated with nursing home and hospital care.

In contrast, nursing homes typically use the medical model as their operational philosophy, which views social, spiritual and other needs as secondary to the delivery of care and treating illness and disease (Barton, 1997). This model often results in physical designs that maximize safety and staff efficiency while compromising privacy and appearance. Characteristic aspects of these designs include centralized floor plans, nursing station placements to maximize resident monitoring, wide doors and hallways to accommodate moving patients while in beds and institutional multi-story or multi-wing construction segregating those with higher care needs from other residents (Spitzer, Newman \& Holden, 2004). 
Researchers and advocates debate ways to define assisted living and its distinctive nature. Morgan et al. (2004) note that there are four main domains that are consistently highlighted as an assisted living facility:

$\underline{\text { Privacy }}$

A lockable, private apartment with bath and a personalized home-like environment are hallmarks. Resident autonomy

Resident chooses how their daily life is lived. Flexible provision of non-medical services

To assist people with growing functional dependency supportive services are provided on a scheduled and unscheduled basis.

Age in place

The capacity to age in place by adding services for needed care in deficiencies in activities of daily living.

Mollica's (2002) study found that patients not requiring nursing home care, but needing some form of care and assistance, are attracted to assisted living communities because their operational philosophy gives residents more personal control over their daily activities. Many older adults prefer to have their longterm care needs met through an assisted living community 
rather than in a nursing home. Aud and Rantz's (2005) study of residents who move to nursing homes found that among the reasons many people try to avoid nursing home care is the generally poor reputation of nursing homes; the cost of care in the nursing home; loss of individual freedom; the institutional, hospital-like setting; and loss of personal possessions, privacy, and autonomy. Also, there is the prospect of being separated from one's spouse or other family members.

Although there is some recognition of the significance of the physical environment in an assisted living community, there is less indication in the literature of a general understanding of the assisted living philosophy. Regnier (1994) has suggested the basic qualities and characteristics of the assisted living community. These suggestions are based on the fact that industry definitions are vague and often distorted by marketing descriptions that rarely clarify basic characteristics. He expected that these definitional qualities of an assisted living community can be a loose normative definition and can provide appropriate targets for the development of highly supportive, humane residential housing for the mentally and physically frail: 
Appear residential in character

The character, appearance, precedent, imagery and memory of assisted living should be related to residential housing. Be perceived as small in size

Most settings will require more than forty units to offer competitive rental rates and provide reliable twentyfour hour care.

Privacy and completeness

A small kitchenette in a private room and a full bathroom make the dwelling unit complete. Privacy should be achieved through a combination of efforts, including leasing policies that encourage single occupancy, design features such as locks and doors, and management practices that require staff to identify themselves before entering. Recognize the uniqueness of each resident

Each older person who enters assisted living has lived a life in a unique way. Each has a multiplicity of different experiences, which have nurtured diverse interests, abilities and values. Capturing that diversity within a group setting is important. Foster independence, interdependence and individuality Resident assessments should inventory the unique capabilities and competencies of each person and devise a 
treatment plan that treats each person as an individual, with respect and dignity.

Focus on health maintenance, physical movement and mental stimulation

Avoiding institutionalization as long as possible is a major motivation provided by assisted living. Monitoring health through preventive checks, good nutritional habits and careful attention to pharmaceuticals constructs a safety net of assurances.

Support family involvement

The purpose of family-based assessments is to develop a caregiving partnership that allows family members a more important role in making critical decisions and in managing care. The building should also provide places for residents and family members to gather and share activities.

An assisted living community is described in most provider trade publications as a residential option for the elderly who need some help with activities of daily living and possible some minimal nursing care. Most definitions from the literature refer to the provision of supportive personal care services and explicitly mention either that assisted living residents do not require the intensity of 
care found in nursing homes or that residents have limited medical needs or require minimal medical care.

\section{Aging Population}

The importance of studying assisted living as a care option is increasing because the population is aging. Populations are said to be aging when the proportion of people over age 65 increases relative to other age groups (Spitzer, Neuman \& Holden, 2004). In 2008, approximately $10 \%$ of the population was over age 65 . This percentage is expected to increase to $11.8 \%$ in 2011, and continue to increase to $21.4 \%$ in 2031 (U.S. Census, 2011).

The two main reasons for the aging population have been a decrease in birthrates and increased life expectancy. In addition, the generation born between 1946 and 1965, commonly known as the Baby Boom generation, is the most populous generation. Starting in 2011, the first of the Baby Boom generation will reach age 65 . In the following years, the percentage of the population over 65 will rise dramatically. In addition, improved life expectancy will continue to result in increases in the percentage of the population over age 80. Although immigration has had a minimal effect on population aging, changes to immigration patterns and increased immigration 
in mid to late life has led to increased cultural diversity among the older population.

As the population ages and individuals live longer, the prevalence of people with long-term chronic illness and progressive cognitive decline is expected to increase. The most common chronic illnesses among people over age 65 in the United States are arthritis, hypertension, hearing impairments, orthopedic impairments, heart disease, and cataracts (Spitzer, Neuman \& Holden, 2004). The physical declines associated with these chronic conditions and the cognitive declines resulting from Alzheimer Disease and other types of dementia can diminish an individual's ability to provide self-care, thereby increasing his or her needs for care-giving support.

Although age is not a good predictor of health and ability, and many older adults remain very active and in good health, the risk of physical and cognitive illness increases after age 65 and rises quickly after age 80 (Spitzer, Neuman \& Holden, 2004). Advances in disease prevention and treatment, pharmaceuticals, and technological aids may mitigate potential increases to agerelated disability. However, it is expected that such advances will not be sufficient to address the sheer 
increases in numbers of older adults in the coming years (Golant \& Hyde, 2008).

In addition, the capacity of family members to be available to provide care has changed. As birth rates have declined, fewer adult children are available to be caregivers. Increased migration has resulted in fewer older adults living in the same community as their adult children. Golant \& Hyde (2008) notes that increases in the divorce rate may result in fewer spousal caregivers. The participation of women in the labor force, which increased sharply starting with the Baby Boom generation, has caused many women to be less available to provide care for older family members. The trend to start having children later in life has resulted in more middle-aged adults, predominantly women, in the "sandwich generation", providing care for both young children and older parents. These factors may result in less availability of care for older adults by family members, and increased caregiver stress for family members who may be juggling with distance, other responsibilities including work and child care, and lack of support from other family members. While it is expected that family members, especially spouses, daughters, and daughters-in-law will continue to provide care for older family members, the availability of family 
members to provide care and the increasing demands placed on family caregivers may result in increased caregiver stress and interest in different community care options. Since more women than men tend to assume the role of family caregiver, Golant \& Hyde (2008) suggests that the availability of family caregivers will largely depend on how women of the future balance their desire to assume this responsibility.

The appeal of assisted living as a community care option may increase as older adults and their family members seek out community care options that suit their needs. Although assisted living care does not substitute for family caregiving, and frequently family involvement in care is often necessary to retain a resident in an assisted living facility (Golant \& Hyde, 2008), the services and residential environment of assisted living may serve as a supplement to family caregiving and result in reduced caregiver stress. According to Golant \& Hyde (2008), many family members want to remain involved in caregiving and the monitoring of care when an older family member moves to assisted living. As the population ages, it is important to recognize the essential contributions of and impacts on family caregivers. The services provided through a continuum of care will need to adapt not only to increasing 
numbers and diversity of older adults, but also to the increasing and diverse needs of family caregivers, who play a significant and pivotal role in both community-based and institutional care.

The aging of the population raises the question of the role of assisted living within the continuum of care options for older adults, and the extent to which it will be accessible and be able to meet the care needs of the increasing older adult population. Since assisted living is still a relatively new model of care, it remains to be seen how it will continue to respond to a rapidly aging and increasingly diverse population. According to Golant \& Hyde (2008), the Baby Boom population born 1945 to 1964 is likely to show a preference for assisted living as a care option because of the values of independence and consumer choice that are associated with the assisted living industry.

The impact of the aging population on programs and services for older adults will likely be an increased demand for services and options to meet individual needs. It is anticipated that the increasing numbers of adults in the oldest cohort will lead to an increased demand for assisted living services, since the average age of assisted living residents is 83.7 in studies of assisted living in 
the United States published from 1993 to 2004 (Golant \& Hyde, 2008). In addition, the increasing diversity of resident culture, language, values, and preferences of older adults will test the ability of assisted living as an industry or care option to meet diverse needs and promote individuality and autonomy while providing care as health and functional abilities decline.

\section{Industry Challenges}

Stefanacci and Podrazik (2005) note the challenges facing the assisted living community are those of balancing the goals of resident independence, choice and maintaining a home-like environment in this medically, cognitively and functionally diverse aging population. ALCs need to recognize and address when the medical, functional and safety needs of older adults have outstripped their communities' capacity to provide safe, quality care. Golant (2004) recognizes that state regulators are concerned with the level of care and type of services the assisted living community can offer because they are responsible for quality assurances.

Assisted living critics have raised concerns about the quality of care provided in the assisted living community. The question is whether assisted living providers can deal 
with a very frail population's complex health care needs, including their use of medications, the management of changes in physical abilities, the detection of threatening medical conditions and the diagnosis and treatment of depression and other cognitive disorders (Golant, 1999).

The reasons leading to admission from assisted living communities to skilled nursing facilities or to hospitalization with subsequent admission to skilled nursing facilities have not been extensively explored. The most common reasons for residents of ALCs to be discharged are medical condition, cognitive decline or behavior problems, which often stem from changes in medical condition (Aud \& Rantz, 2005). However, these reasons lacked details such as the kinds of medical conditions, the extent of cognitive decline, the nature and the frequency of behavior problems (Aud \& Rantz,2005). Knowing more about the reasons for discharge is an important step in the promotion of aging in place.

Advocates of assisted living point out that in return for a more normal housing environment, autonomy and privacy, residents and their family members must assume greater responsibility and risks for their care.

Smith (2003) asks if assisted living communities are accomplishing their mission of providing quality homelike 
care at a cost lower than that of nursing homes. There is a limited, but growing amount of academic research in the area of assisted living that seeks to assess the value and contributions that assisted living communities are making. The few studies that have examined the well being of residents in assisted living communities are inconclusive. Morgan et al. (2004) note a study that compared the depressive affect of people living in an assisted living community with that of people residing in the community. They found that the depressive affect of the assisted living residents was, on average, worse than that of the community residents. However, the cross-sectional design of that study made it difficult to know whether the affective functioning of the people in the assisted living setting had improved or would improve over time, and whether the assisted living community was beneficial for residents. Another issue is whether the researchers adequately controlled for other differences between the two groups. For example, the physical health of the ALC residents could have been worse, leading to more depression.

There is limited research on the economic disparity between residents and caregivers. Smith (2003) argues that in the private-pay, high-priced assisted living 
communities, it is inevitable that there will be a strained relationship with resentment between affluent residents and low-wage workers who provide care and services to them.

Satisfaction with the quality of care received by older adults in long-term care institutions is increasingly highlighted in research and practice. This has been accompanied by increased regulations often calling for innovative interventions to address the variations in the quality of care provided by different levels and types of organizational structures (Mutran, et al., 2001).

Researchers in the area of quality of life for older adults increasingly agree that the person's perspective and that of family members and caregivers are needed to provide a balanced view of a satisfactory quality of life. Limited research has been conducted to assess the older adult's degree of satisfaction with major services and environmental factors of community residential care programs (Davis \& Gerrard, 1993).

In rural communities, older adult housing options are much more limited than in urban settings (The Assisted Living Workgroup, 2003). Housing options in these rural communities and for older adults should include assisted living communities that are affordable to low- and moderate- income persons. In rural and under served areas, 
because no other housing options with support services exist, it is not uncommon to find nursing home residents who are younger and less disabled than their urban counterparts (Stefanacci \& Podrazik, 2005).

\section{Continuing Care Retirement Communities}

Continuing care retirement communities (CCRCs), sometimes called life-care retirement communities, represent another type of living arrangement that is similar to ALCs. CCRCs specifically address the problems associated with age related disabilities. This housing option goes beyond the commitment of ALCs in responding to the needs of elderly persons as their health deteriorates and their need for long-term care services increases. CCRCs are planned communities which allow residents to age in place. As part of a long-term contract with the resident, usually for life, the CCRC provides the resident with housing, amenities and a range of services, including supportive services and, when necessary, nursing home care (Sherwood et al., 1997). This guarantee of access to nursing home care along with a commitment to reside in the community distinguishes CCRCs from virtually every other housing alternative. CCRCs incorporate a continuum of care philosophy that allows residents to age in place. 


\section{Continuum of Care}

Apart from CCRCs, the objective of providing a seamless continuum of care for older adults as their health needs change is met with much fragmentation. In many communities, the continuum of care services are often loosely connected, overlapping or leaving large gaps in the care that older adults need (The Assisted Living Workgroup, 2003). The U.S. Department of Health and Human Services (HHS) defines the continuum of care for long-term care as the entire spectrum of specialized health, rehabilitative, and residential services available to the frail and chronically ill. The services focus on the social, residential, rehabilitative and supportive needs of individuals as well as needs that are essentially medical in nature (US HHS, 2006). This concept describes levels of care and residential settings that meet the needs of older adults as they age.

Many housing and long-term care professionals view assisted living as a step along the continuum of care between independent housing and nursing home placement. However, the continuum of care paradigm is coming under scrutiny as it pertains to long-term care services. The paradigm assumes linear progression of disability and 
disease which is not always the case as residents often experience improvement in their ability to live independently with minimal amounts of services. Kane and Wilson (2001) stress that the continuum model requires older people to be slotted along a continuum at just the right level of care for their level of disability and that any deviance from the expected pattern is to be considered an inappropriate level of care, either too much or too little.

A typical linear progression of a long-term housing resident would be from an independent living facility to an assisted living facility, to a personal care home and then finally to a nursing facility. They are described as follows:

Retirement (or Independent) Living Community

These communities offer rental units in which services are not included as part of the rent. Services may be available on-site and may be purchased by residents for an additional fee. These communities offer residents freedom and privacy while creating an atmosphere of convenient comfort. Most facilites offer a variety of social, cultural and recreational activities. These communities can be either for purchase or rental. 


\section{Assisted Living Community}

These are residences that provide a home with services and that emphasize residents' privacy and choice. Residents typically have private locking rooms and bathrooms. Residents are capable of maintaining a level of independence but may need some assistance with activities of daily living and instrumental activities of dailyliving. Personal Care Home

Residents are provided with assistance in performing their activities of daily living as well as with selfadministration of medications and preparing special diets. The care needs of these residents generally result from a decline in their ability to perform activities of daily living and instrumental activities of daily living. Nursing Facility

Facilities licensed by the state to offer residents personal care as well as skilled nursing care on a 24-hour a day basis. In addition to room and board, staff provide nursing care, personal care, supervision, medication, therapies and rehabilitation. Rooms are often shared and communal dining is common. 
Aging In Place

Aging in place is a concept that is frequently referred to in assisted living policy and literature. There are many interpretations, definitions include enabling older adults to remain in their current or preferred environment, with necessary adaptations and support services, to the end of their lives (Eckert et al., 2009). There is also significant support to the preference that many older adults express to remain in their own home as they age. The advantage to aging in place is that it allows older adults to retain connections to the people and physical environments that they have established over time. By preserving these connections, older adults also maintain a sense of autonomy and security due to the familiarity of surroundings and sense of belonging in the community (Spitzer, Neuman \& Holden, 2004). These benefits are frequently lost through institutionalization, or even a move to an unfamiliar community.

Increasingly, attention is shifting to the consumer as the center of a system in which greater effort is made to maintain individuals in his or her own home. The shift serves to empower residents and enhance their dignity by encouraging self-determination and allowing them to remain in their homes. The most often cited reason, by older 
adults, is to stay with the familiar surroundings of their home or the surrounding city. Familiarity with one's environment evokes comfort and safety (Lawton, 1980a). Personal control over the environment and the meaning of home are other key factors in the aging in place phenomenon (Lawton, 1980a). To some, home means independence, success, safety and a sense of belonging. Most industry definitions of aging in place refer only to the changes that occur in the occupants over time but seldom address the changing nature of the environment itself (Frank, 2002). Lawton (1980) describes aging as a much more multidimensional phenomenon for seniors. He adds that it is a transaction between an aging individual and their residential environment that is characterized by changes in both the person and the environment over time, with the physical location of the person being the only constant. Ball et al., (2005) explain that a fundamental understanding of the concept of the assisted living community is a home for older adults that promote aging in place by maximizing resident independence and providing services that accommodate their changing needs.

Many older adults who move into senior housing facilities want to remain in their apartments and avoid any subsequent move. Residents look for services and ways that 
the physical environment can be altered to meet their changing health needs (Frank, 2002). By accommodating the residents' changing needs, the facility assists residents by adding services and if necessary allowing minor alterations to the residents' units. Examples would be adding emergency strobe lighting for the hearing impaired, wheelchair ramps and tiled or carpeted flooring.

Although the singular place implies that individuals would remain at the same precise location until the end of their lives, the assisted living sector has adopted and adapted this concept, so once an older adult moves into assisted living, the assumption is that he or she should be able to remain their apartment with growing support to meet changing needs (Eckert et al., 2009). In other words, when it is not possible or preferable for a person to continue to live in their current residence, aging in place can begin after a person moves into an assisted living environment.

Calkins (1995) explains that the definition of aging in place can be interpreted in several ways, but primarily means that residents may remain in their own home with additional services. Another way would be that once a resident moves to the ALC, they do not have to move from the facility; however, as their needs change, they move to 
another floor or wing within the facility. The concept of place could be interpreted as a facility or community rather than the more particular ideas of a suite within a facility or a private home within a community (Chapin \& Dobbs-Kepper, 2001). This is perhaps the broadest definition that includes a resident moving to an ALC on a campus that included a nursing facility. For example, when a resident declines, his or her needs are met by moving from the ALC to another facility on the campus. Using this definition, an individual could still be considered to be aging in place if they move from their home to an assisted living facility in their community, and if they move from one room to another within the same facility as their care needs increase. For those with changing care needs, aging occurs in places along the continuum of care, including home, assisted living, hospital, and/or nursing home. Chapin \& Dobbs-Kepper (2001) define aging in place functionally, as the fit between the person and their residential setting and includes programs and policies that help maintain that fit. When characteristics of a resident or facility can no longer support aging in place in an assisted living setting, the goal is to find the best available place to continue to age, or to create a new care option to meet the need. 
The understanding of aging in place as remaining in a single residence or health care setting may be too limited. The reality is that many older adults age in several places, and adapt to transitions between places such as private residence, assisted living, hospital, and nursing homes as needs change over time. Movement between settings within a continuum of care is neither linear nor predictable. While it is possible for some residents to remain in assisted living until the end of their lives, such a scenario relies on a difficult and unpredictable balancing of their changing needs and the ability of the physical, social, and care environment of the assisted living facility to meet those needs (Eckert et al., 2009). The possibility of residents aging in place in assisted living is influenced by a number of factors, including intake policies, medical and care needs of the resident, staffing, the financial capacity of the resident, the physical and social environment, and management philosophy. If there is not a good fit between resident and the community, the possibility that a resident will age in place in that setting will be affected (Eckert et al., 2009).

The model for aging in place in the ALC requires management of resident decline. Management of resident 
decline is the cornerstone of residents' ability to remain in this setting over time (Ball et al., 2005).

In their research on five ALCs, Ball et al. (2005) identify several factors upon which the residents' ability to age in place rests. This management of resident decline is based upon both resident capacity and facility capacity. Resident capacity relates to health conditions, access to financial resources, involvement of family members, strong values for independence and friendships among ALC residents:

Health condition

Residents are entering ALCs older and generally have significant deficiencies in activities of daily living. Their condition affects the nature and effectiveness of decline.

Access to financial resources

The ability to pay for needed services is one of the most significant barriers to aging in place. Not all states provide government funding to assist those in need. Involvement of family members

Residents who have families involved in their care have a better chance of remaining in the community. 


\section{Strong values for independence}

The desire to remain in the facility prompts residents to adhere to self care habits and maintain independence.

\section{Friendships}

Friendships between residents promote mutual support, which in some cases increase length of stay.

Facility capacity related to admission and discharge policies, service capacity and care strategies, and community supports.

\section{Admission and discharge policies}

These policies differentiate the boundaries for aging in place in each facility and are restricted by state regulatory requirements which specify the characteristics of residents who may be served and the types of services that may be provided.

Service capacity and care strategies

Service capacity is largely determined by staffing. Staff quality, as well as quantity, affects an ALCs ability to manage resident decline. An ALCs willingness and ability to promote residents' self-care and healthy behaviors are included in philosophy of care strategies. Community supports

Community resources such as senior centers and day programs, home health agencies, hospitals and individual 
health care providers provide critical support for management of decline in residents in ALCs.

Many states are revising regulations in order to promote the aging in place concept in their long-term care regulations. However, there is currently disagreement within the provider community as to whether aging in place is financially and operationally feasible. Also, there is disagreement about whether aging in place is possible in assisted living, and whether it should be an expected or desired outcome (Chapin \& Dobbs-Kepper, 2001). For some, the ideal scenario is that a resident ages in an assisted living community until the end of life. For others, assisted living is understood as one element in a continuum of care that includes nursing home care (Eckert et al., 2009). As assisted living has grown as an option for housing and care for older adults, it is increasingly recognized that as a residents' care needs increase, assisted living may not be the best place for that person to stay (Eckert et al., 2009).

In this context, it is possible to plan for the outcome of prolonged residence rather than aging in place in assisted living, and in fact many providers interpret the concept of aging in place as prolonged residence rather than care to end of life (Frank, 2002). 
Several states have revised regulations in recent years to allow for the provision of some skilled nursing care services in assisted living communities to support the concept of aging in place, but only under limited conditions and only if the community is able to supply appropriately trained staff.

The National Center for Assisted Living (2001) estimates that $46 \%$ of residents who move to assisted living communities come from their own home. This is due to the likelihood that the older adult or a family member will recognize a decline in physical and/or mental condition that requires housing with supportive services.

\section{Affordability}

Many state governments like the long-term care alternative provided by the ALC because it is viewed as a more affordable solution that can reduce Medicaid nursing home costs. Morgan et al. (2004) note that both state and federal governments are looking to grow the resident population of assisted living communities as a way of delaying or avoiding the more costly entry into nursing homes. However, not all experts agree that states will save money (Golant, 2004). Advocates of assisted living fear that if state governments make Medicaid assistance 
available to low-income older adults, this will invite stringent federal regulation and additional requirements. There is also considerable apprehension that greater federal and state government compliance monitoring and inspection will increase operating cost.

Because government funding for low-income residents living in an assisted living community is very limited, most assisted living developers do not market to low-income persons (Smith, 2003). Noting that public subsidies are virtually unavailable, they package their projects to more affluent seniors who can afford privately to pay for the housing and services. Many older adults and their adult children tend to have a negative view of nursing homes and try to avoid placing there. There is an image of neglect, shame and poor care in nursing homes and developers know that to sell their product they must avoid that image (Goldstein, 2001). Some high priced ALCs pay a premium to build at prestige addresses and adorn their entranceways with opulent-looking glass chandeliers. Some ALCs give the appearance of high-status affluence and liken their communities to exclusive resort hotels with extra services. Through the glossy pictures in their brochures, they associate their communities with the time-tested sales 
appeal of high social status and eternal youth (Greene et al., 1997/1998).

However, in some instances, their success in creating this illusion is generating resentment as some residents feel they have been tricked. The image of the affluence and activity often depicted in brochures and advertisements does not seem to reflect the aging in place of residents with their cognitive impairments and problems with ambulation and incontinence. This reality departs from the rhetoric of the social resort promised in the brochures (Greene, et al., 1997/1998).

Typical residents in private assisted living communities are not the affluent members of a leisure class elite as sometimes implied in assisted living brochures. For the most part, they are average people with average pensions and savings. They, and their children, are often surprised at the costs, and many live in fear of what will happen when their money runs out. Due to the cost and the uncertainty of maintaining a relative in an ALC, often the families of older adults become the caregivers themselves (Lustbader \& Hooyman, 1994). In many cases they are not always able to provide care and supervise medication and proper diet, which can lead to falls, medical problems and premature placement in nursing homes. 
In 2004, the average annual cost for nursing home accommodation was $\$ 70,080$, or $\$ 192$ per day (US HHS, 2006). The estimated cost of an assisted living facility ranged from $40 \%$ to $60 \%$ of the cost of a nursing home. Costs for assisted living residences vary greatly and depend on the size of units, services provided and location. Other considerations affecting cost are whether the room is private or shared and the frequency of services provided.

Despite the growth and popularity of the ALC, it remains largely out of reach for low- and moderate- income older adults, since most programs have been developed for and marketed to relatively affluent older adults (Schwarz \& Brent, 1999). Communities market to upper income seniors with sufficient income or assets to meet their costs. According to the 2001 National Center of Assisted Living Survey, $67 \%$ of assisted living residents paid with their own funds (see Chart 1). The average monthly cost for an assisted living facility was $\$ 1,873$, with roughly two thirds of all assisted living communities charging between $\$ 1,001$ and $\$ 2,500$ in monthly rent and service fees. Although there have been increases in rental rates and service fees, the increases have not been dramatic. An April 2004 review by Health Policy Tracking Services found 
that estimates of the average monthly cost of assisted living ranged from approximately $\$ 2,100$ to $\$ 2,900$.

Chart \#1

Sources of Funding for Residents of Assisted Living Communities

(National Center for Assisted Living, 2001)

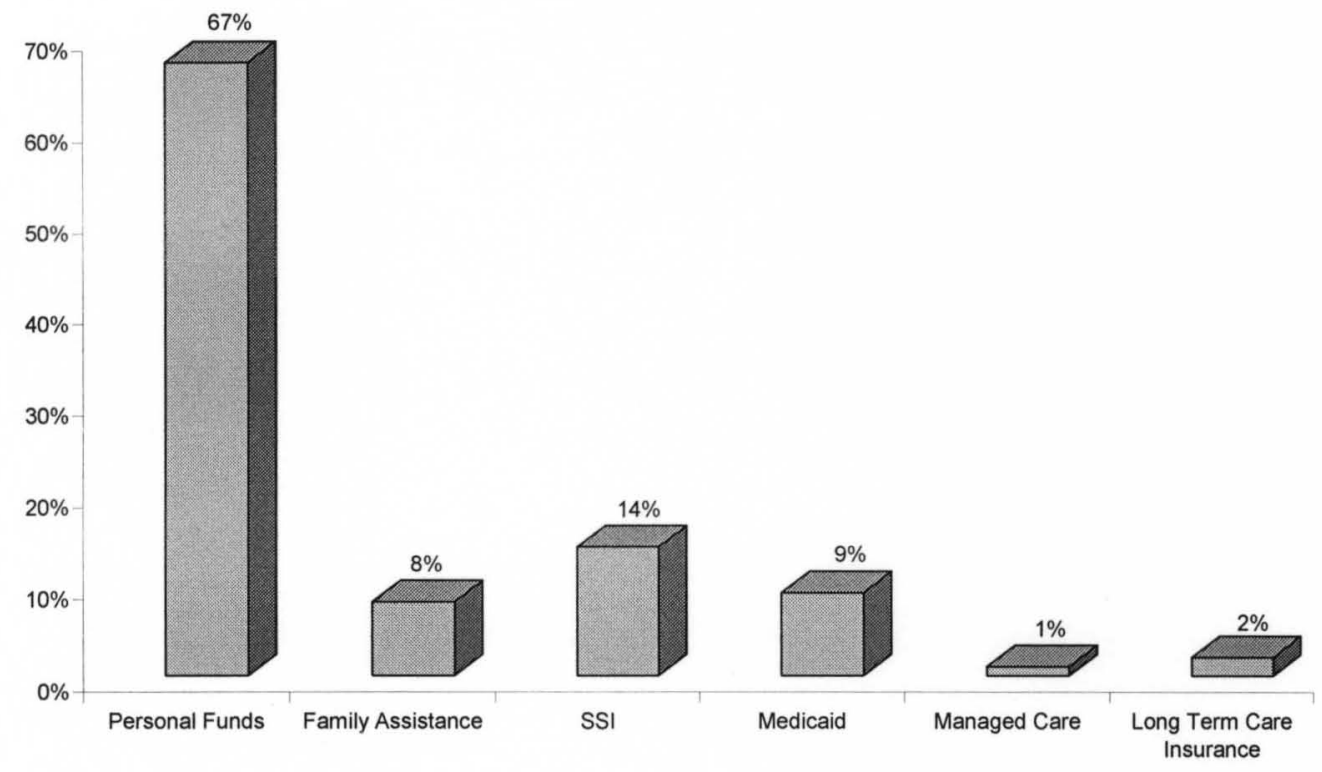

Medicare, the federal government's health insurance for persons age 65 and older, does not pay for the rent or services of persons residing in an assisted living facility. Approximately 75\% of all assisted living residents pay for the cost of assisted living from their personal funds or with the assistance of family members. Supplemental Security Income (SSI) pays for 14\% of assisted living residents, while $2 \%$ of assisted living residents are covered by long-term care insurance. 
Medicaid is a joint federal and state funded program administered by the state to provide certain health care benefits for low-income people. Each state establishes its own guidelines for eligibility and services. Across the nation, Medicaid pays the costs for about $9 \%$ of residents in assisted living communities. In contrast, Medicaid is the primary source of payment for 58\% of nursing home residents (Day, 2002).

Not all states have enacted legislation which allows Medicaid to cover the cost of residing in an assisted living facility. However, this situation is gradually beginning to change. Some states have adopted legislation which provides Medicaid coverage for low-income residents in an assisted living facility, under certain circumstances or on a limited basis. In 2002, 41 states had Medicaid legislation which helped pay for some assisted living services. Nevertheless, assisted living remains primarily paid for with private funds. The relatively high costs and the lack of public subsidies make assisted living communities largely unaffordable for older adult persons with low or moderate incomes (Wright, 2004). The Commonwealth of Kentucky is among those states that have not enacted legislation allowing Medicaid to cover the cost of services in an assisted living facility. 


\section{ALCs Size}

ALCs vary in size from small, family-like to larger, more institutional-style facilities and serve a varied population. Although most ALC residents are living in larger facilities, the majority of the homes fall into the small category of 2 to 10 apartments (Hawes, Rose \& Phillips, 1999). The average size of an ALC is 43 units and ranges from three units to 200 units. The average number of residents in a community is 40 , with a range of one to 175 residents (NCAL, 2001). The average ALC has been in operation for seven years and the physical structure that houses the assisted living residence has existed for 11 years (NCAL, 2001).

\section{Assisted Living in Kentucky}

In 2000, the Kentucky General Assembly passed laws requiring communities offering assisted living services to be certified as an Assisted Living Facility. In Kentucky, an assisted living community provides each client with a separate living unit that includes a lockable door and private bathroom. The client can receive assistance with activities of daily living as well as assistance with selfadministering his or her own medication. Meals, housekeeping, transportation, laundry and clerical services 
are also available. Each client may directly arrange with an outside agency or individual to receive health care services, subject to any related policy of the assisted living community (Kentucky Assisted Living Facilities Association, 2004).

Assisted living communities are defined and regulated differently than nursing homes, although some of the same services are provided.

For example, both assisted living communities and nursing homes can provide assistance with activities of daily living; bathing, dressing, grooming, toileting, eating and transferring. However, nursing homes must deliver these health care services, while a resident in an ALC may directly arrange with an outside agency or individual to receive health care services. Generally speaking, assisted living communities offer more privacy and independence, because each client has a separate living unit with a lockable door, private bathroom and usually an individual thermostat control. The Kentucky Department of Aging and Independent Living must certify assisted living communities in Kentucky each year. As already noted, Kentucky does not offer Medicaid funding to cover any costs of residing in an assisted living community. 


\section{CHAPTER III}

\section{RESEARCH DESIGN}

The primary aim of this research is to learn how ALCs in Louisville, Kentucky are providing supportive services to residents. I wanted to learn how they are meeting the diverse needs of older adults and examine the community characteristics that may best allow residents to age in place. Since Kentucky does not provide Medicaid funding to fund assisted living services for low-income older adults, I also wanted to learn how, if at all, ALCs are serving low- to moderate- income older adults. Since the Kentucky General Assembly passed legislation enacting the operation and certification of assisted living facilities, there are currently 104 ALCs in Kentucky and 14 in Louisville (Kentucky Department for Aging and Independent Living 2011). The subjects for this research study will be the ALCs in Louisville, Kentucky. A complete list of certified ALCs in Louisville, was obtained from the website of the Kentucky Department of Aging and Independent Living. 
Case study

The case study is one of several ways of doing social science research (Yin, 1993). It is an empirical inquiry that investigates a contemporary phenomenon within its real-life context when the boundaries between phenomenon and context are not clearly evident and in which multiple sources of evidence are used. There are five components of research design that are important for case studies: a study's question; its propositions, if any; the units of analysis; the logic linking the data to the propositions; and the criteria for interpreting the findings (Yin, 1984).

\section{Methodology}

For the ALCs that are in the Louisville, Kentucky area that are included as the subjects of this research, I made telephone calls to the community office and asked to speak with the owner and inform them of the purpose of my call and to solicit their participation in this research study. I identified myself and explained to the owner or manager the purpose of my call and asked if they were willing to participate in this research. Several owners declined and I excluded them from further consideration. I scheduled mutually agreeable time for those owners and managers that did agree to participate. 
During our meeting, I provided my documentation from the University of Louisville verifying this study as partial fulfillment of the doctoral degree for the researcher. I then gave an explanation of this research study and asked if they had any questions before proceeding. The owner or manager signed the Informed Consent (see Appendix 1) and I began the interview by taking tours of the communities and then meeting in their offices to administer the questionnaire (see Appendix 2). We scheduled additional dates and time for follow-up meetings.

\section{Grounded Theory}

The approach for this research design will be based on grounded theory. Developed in the 1960's by sociologists Barney Glaser and Anselm Strauss, grounded theory is a methodology that delineates specific guidelines for data collection and analysis with the intent of building theoretical frameworks to explain the data (Glaser \& Strauss, 1967). Proponents of grounded theory give warning to researchers to avoid premature use of theory or prior conceptual categories, although they should have a good working knowledge of the previous research literature on the topic being investigated (Yin, 1993). The use of all 
data is a fundamental property of grounded theory. Grounded theory data include everything that gets in the researcher's way when studying a certain area. Not only are interviews and observations included, but anything that helps the researcher generating concepts for emerging theory. Data also includes field notes from informal interviews, lectures, seminars, expert group meetings, newspaper articles and Internet mailing lists. During the interviews with the managers, I took their responses to my questions as well as making notes while making general observations of facility appearance and maintenance, interactions between staff and residents, interaction between supervisors and staff and the general operation of the facility.

There are four basic components in creating grounded theory including (a) concurrently gathering and analyzing data, (b) employing theoretical sampling, (c) using specific coding techniques and (d) memo writing. Theoretical sampling is the process of filling out one's theory by gathering data from sources (people, places or events) that will maximize the researcher's discovery of variations among concepts already found in the data and to make data categories more dense in terms of their properties and dimensions (Strauss \& Corbin, 1990). This 
methodology requires the researcher to analyze data while still collecting it so that gaps or underdeveloped areas of the emerging theory may be filled in.

Open coding is the process of identifying and conceptualizing phenomena in the data. This includes coding words, phrases or longer passages within the data for major content.

Memo writing consists of written ideas about the data and coded categories as they emerge in the researcher's mind. Memos serve to help the researcher sort out his or her thoughts and may include notes related to actual codes and their development. Memo writing is an ongoing process beginning with the first contacts with research and is critical in tracing the development of theory.

\section{Data Collection}

Data collection for this research will include openended interviews, direct observation, document reviews and review of archival records. Interviews will include questions on perceptions of how well the ALC is operating, policy, procedures and the care philosophy of the facility.

The interview is an interaction between an interviewer and respondent in which the interviewer has a general plan of inquiry but not a specific set of questions that must be 
asked in particular words and in a particular order (Babbie, 1998). One of the strengths of the interview is that it allows the researcher to begin with a clear idea of the subject to be studied and allows for the flexibility in the questions that are asked. Interviews will include meetings with owner, managers and other staff members relating to the long-term care of residents.

Direct observation can range from formal to casual data collection activities (Yin, 1984). Formal activity may include the observation of meetings and the performance of activity in the phenomenon being studied. Casual activity includes those observations of items or issues that may be made throughout a field visit when other evidence is being collected. Direct observation will be made by walking through and around the facility and through casual interaction with respondents.

Document reviews are the explicit data collection from letters, memoranda, announcements, policies, minutes of meetings and progress reports (Yin, 1984). Data such as applications, lease agreements, house rules, service policies and state survey inspections will be collected during this research. It is generally anticipated that copies of the application, lease agreement, house rules and service policies will be freely given for analysis. The 
state survey inspection is not a matter of public record and some administrators may be reluctant to share the report. However, assurances of confidentiality and anonymity will be given.

Design Tests

Research design for the case study can have problems with construct validity, external validity, internal validity and reliability.

Construct validity refers to establishing correct operational measures for the concepts being studied. To overcome this problem, Yin (1984) suggests that the researcher must; (1) select the specific types of changes that are to be studied; and (2) demonstrate that the selected measures of these changes do indeed reflect the specific types of change that have been selected.

For this research, I have selected specific areas of the ALC that will be examined so that the questions asked during the interviews will be consistent. For each specific area under examination, there is a general line of questioning that will measure the area under review within the ALC. A representative number of general open-ended questions that will assess the areas being examined are listed later in this chapter. 
External validity refers to problem of knowing whether the study's results are generalizable to other populations and settings. However, the goal of this research is not to establish statistical generalization but to establish analytical generalization. In analytical generalization, the researcher is striving to generalize a set of results to a broader theory (Yin, 1984). It will be anticipated that the results of this research will be generalizable to ALCs in communities of like size and population demographic and where government resources are not available to fund services.

Internal validity relates to establishing a casual relationship. However, pattern-matching logic is one method to ascertain a relationship. Such logic compares an empirically based pattern with a predicted one or with several alternative predictions. If the patterns coincide, the results strengthen the case study (Yin, 1984).

Reliability is the ability of a later investigator to follow the exact procedures as described by an earlier investigator and arrive at the same conclusions. The goal of reliability is to minimize errors and bias (Yin, 1984). 
Research Question

The questions guiding this research are: 1) How are ALCs providing supportive services to older adults? 2) What are the factors that promote an ALCs ability to best accommodate residents to age in place? 3) What information can best inform current public policy debate as federal and state governments continue to look for low-cost options for assisting older adults and their care needs?

By exploring how ALCs are operating in Louisville, Kentucky, I want to examine how residents are benefiting from the services provided in the ALC. The four specific areas that will be examined are the 1) personal services, 2) meals and social interaction, 3) facility policies and 4) physical characteristics. These four areas are chosen because the Iiterature review has determined that these areas have the greatest impact on a community's capacity to manage resident decline. I will explore how residents in these communities are being helped to live in their apartments with the needed services to remain independent. 


\section{CHAPTER IV}

\section{DATA REVIEW}

To begin my research, I completed the University of Louisville Human Subjects Protection Program. I then contacted each of the assisted living communities in the Louisville area and asked to speak with the owner or community managers. Many of these owners and managers had very busy schedules and in some cases it was difficult to speak with them directly. Either they were unavailable due to a meeting or were out of the office. Upon speaking with them by phone, identifying myself and explaining my research, I asked if I could follow up with faxing a

recruitment letter and the informed consent form (see Appendix 3)

Several communities declined to participate either because there was staff turnover with the community managers and they felt like they could not provide substantive responses to my questions or the manager simply did not want to allocate time for participation. 
For those subjects included in this research, we scheduled a mutually agreeable date to meet face to face. When I met with them, I identified myself and we exchanged greetings. I asked if they had any questions about the recruitment letter or the informed consent form. None of the owners and managers had any questions about the form, intent of the research or about proceeding with the interview. After securing their signature on the informed consent form, I either began with a tour of the community or with the interview questionnaire (see Appendix 2). Over the course of a several weeks, I met with or spoke with each community owner or manager to collect additional data or to clarify any notes that I had on a previous meeting. The owners and managers enthusiastically gave me copies of materials such as lease agreements or functional needs assessment tools and were agreeable to provide data.

During my tours of the assisted living communities, I met with and greeted several residents. Without exception, all of them appeared to be well cared for and happy to be living in their communities. They appeared to enjoy the meals and participated in various activities of the community. The communities were very neat and clean in appearance and the direct care staff was courteous, attentive and caring. 


\section{Physical Characteristics}

The front door to ALCs \#1 and \#2 open immediately into the common living room area in the community. The kitchen and dining room are next to the living room and the apartments are around the perimeter of these common areas, which makes for ease of access for residents. The laundry and community bathrooms are located on one side of the building. None of the apartments in ALCs \#1, \#2, \#4 and \#5 have kitchens in the apartments, because communities with less than 20 apartments are exempt from the requirement to provide kitchens in the apartments, however, they all have a homelike interior atmosphere and design. Figure 1 shows a comfortable sitting area for residents to socialize, play games or puzzles. The hallways in ALCs \#1, \#2, \#4 and \#5 are narrow as shown in Figure 2 .

ALC \#3 is the most institutional-looking ALC of all, with multiple floors and an elevator for residents to get to their apartment. However, apartments in ALC \#3 have kitchens in them. In ALC \#3, the entrance opens into a lobby adjacent to administrative offices and the community dining room that is elegantly decorated. The dining room is accented with a chandelier hanging from the ceiling and a piano (see Figure 3). 


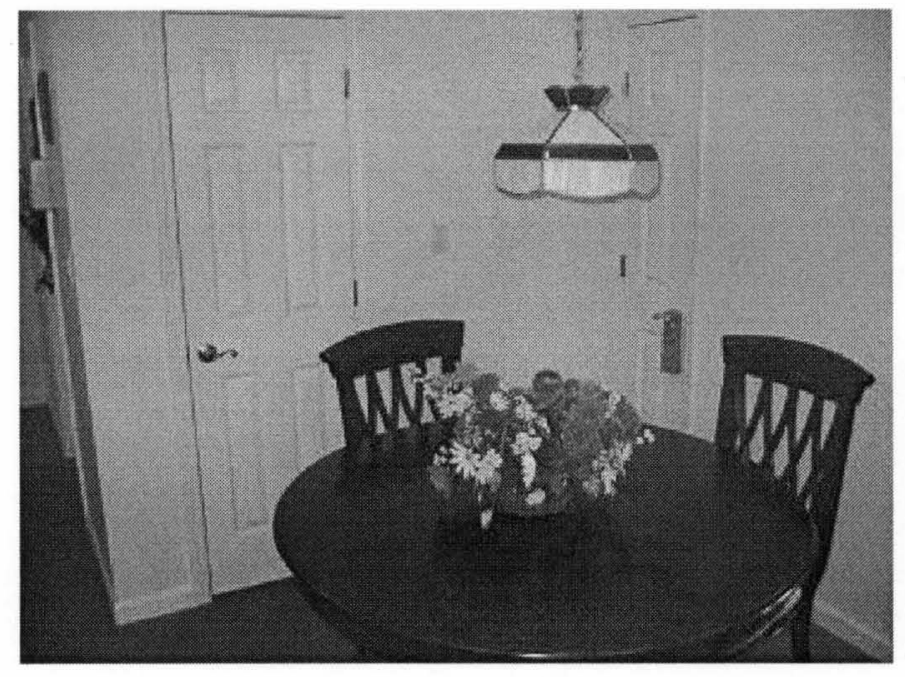

Figure 1 - ALC \#1 - Indoor sitting area

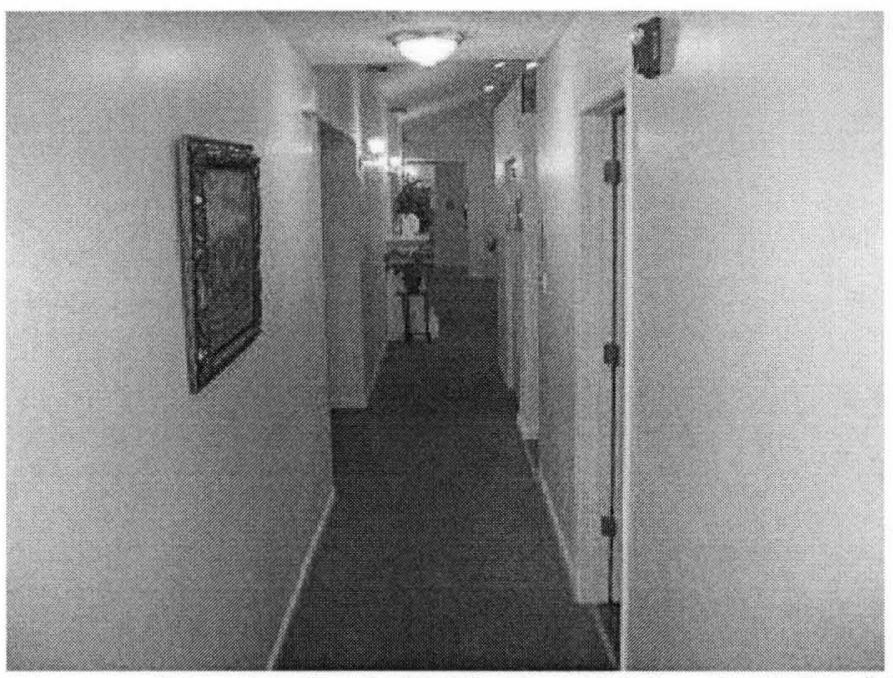

Figure 2 - Typical hallway width of ALCs \#1, \#2, \#4 and \#5 


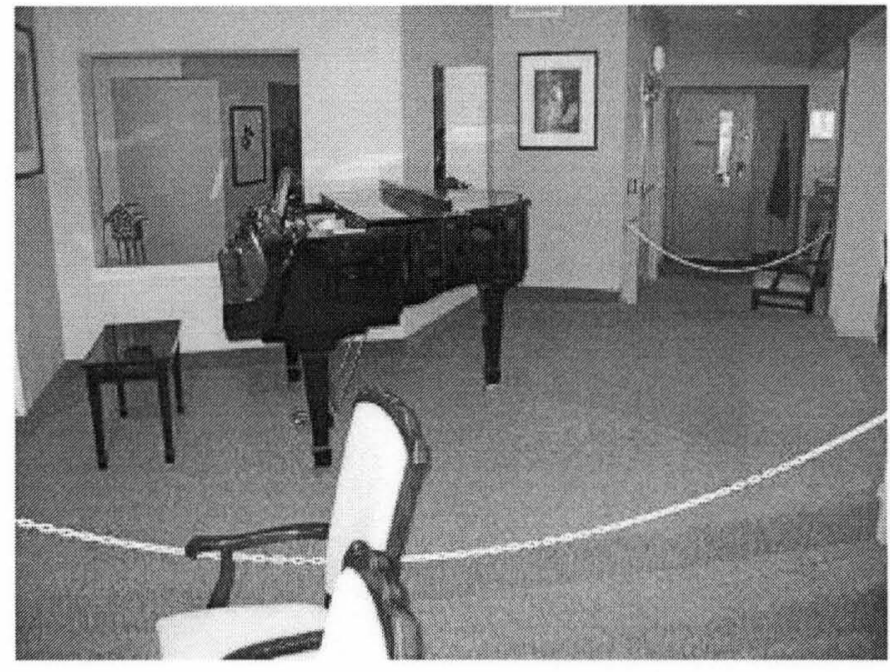

Figure 3 - ALC \#3 - Piano in dining room

All of the communities have centralized community and dining rooms. These features lend to socialization and relationship building that enriches community life. Most of the ALCs have outside patio areas that allow for additional recreational and leisure activities. All of the common areas and apartments of the communities are accessible for persons with mobility impairments. However, none of them are equipped with strobe lighting for those with hearing impairments.

The apartments in all of the ALCs are similar in design with minor variations in size and configuration. The amenities in the apartments consist of a bed, dresser, night stand, private baths, emergency pull-cords, exterior window, telephone jack, cable TV hookup, adjustable thermostat and a lockable door. ALCs \# 1 and \#2 do not 
have community bathrooms, so residents receive bathing assistance service in their apartments.

ALC \#3 has additional amenities including a movie theatre (see Figure 4), community guest rooms on each floor, beauty salon, barber shop (see Figure 5) and balcony overlooking the dining room. The hallways are long and narrow which would make it difficult for persons in wheelchairs or scooters to maneuver when traveling in opposite directions. However, the hallways and common areas are well lit and the apartments are numbered and easy to find. ALCs \#4 and \#5 have flat screen televisions with stereo, beauty salon and a handicapped accessible whirlpool tub.

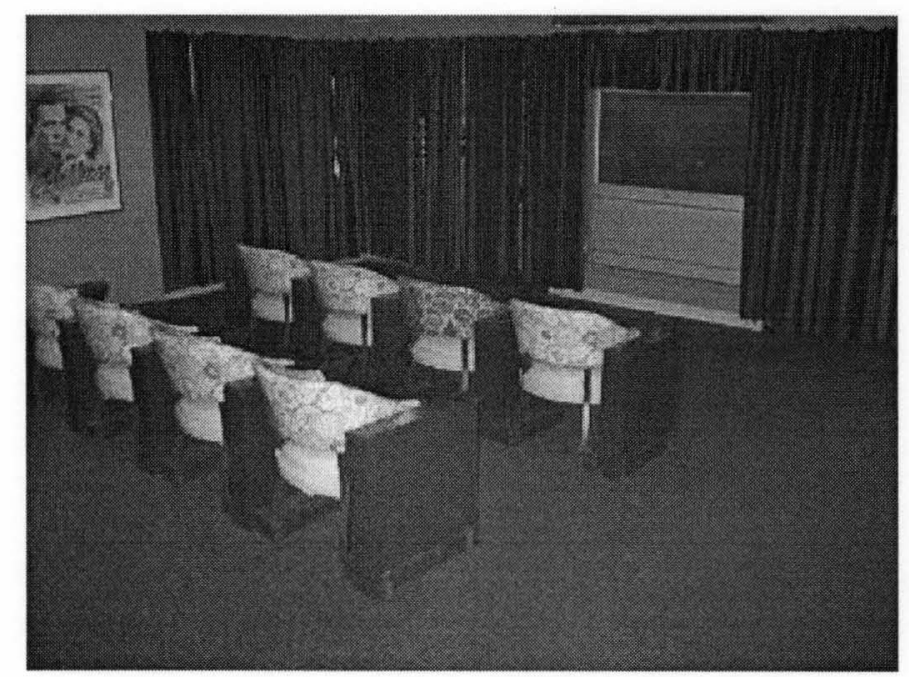

Figure 4 - ALC \#3 - Theatre

Table 1 shows the different physical characteristics of the assisted living communities reviewed in this research. 
Table 1. Physical Characteristics

1. Kitchen
Amenity
ALC\#1
ALC\#2
ALC\#3

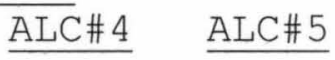

in apartment

n

n

Y

$\mathrm{n}$

$\mathrm{n}$

2. Community

Bathroom

n

$\mathrm{n}$

$\mathrm{n}$

Y

y $\quad y$

3. Elevator

4. Multiple Floors

n

$\mathrm{n}$

y

$\mathrm{n}$

5. Community Room

n

y

n $\quad \mathrm{n}$

6. Accessible Ramp

7. Beauty salon Barbershop

8. Outside patio

y

y $\quad y$

y

y

y

y

y

Y

y

9. Strobe Lighting

10. Central

Dining

$\begin{array}{lllll}\mathrm{n} & \mathrm{n} & \mathrm{y} & \mathrm{n} & \mathrm{n} \\ \mathrm{n} & \mathrm{n} & \mathrm{y} & \mathrm{y} & \mathrm{y}\end{array}$

n

$\mathrm{n}$

$\mathrm{n}$

n $\quad n$

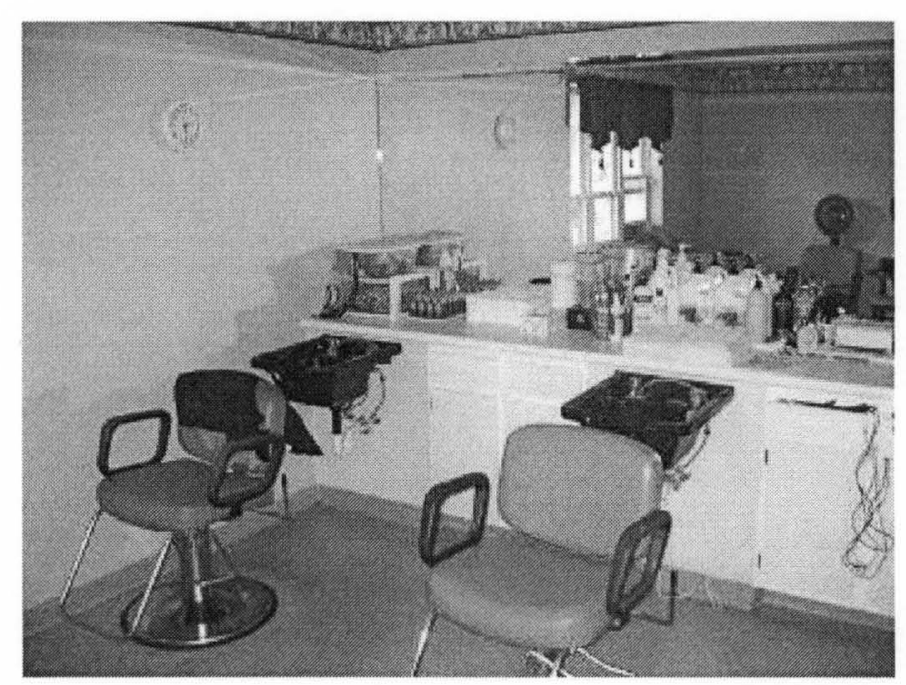

Figure 5 - ALC \#3 - Beauty salon

\section{Meals and Social Interaction}

Table 2 identifies conditions of meals and social

interaction for all assisted living communities. In ALCs

\#1, \#2 and \#3, residents are assigned seating in the dining room; social interaction is encouraged amongst the 
residents. ALC \#1 allow meals to be delivered to their private apartments for a limited amount of time before a service delivery fee is charged. Figure 6 shows a typical homelike dining room arrangement for the ALCs.

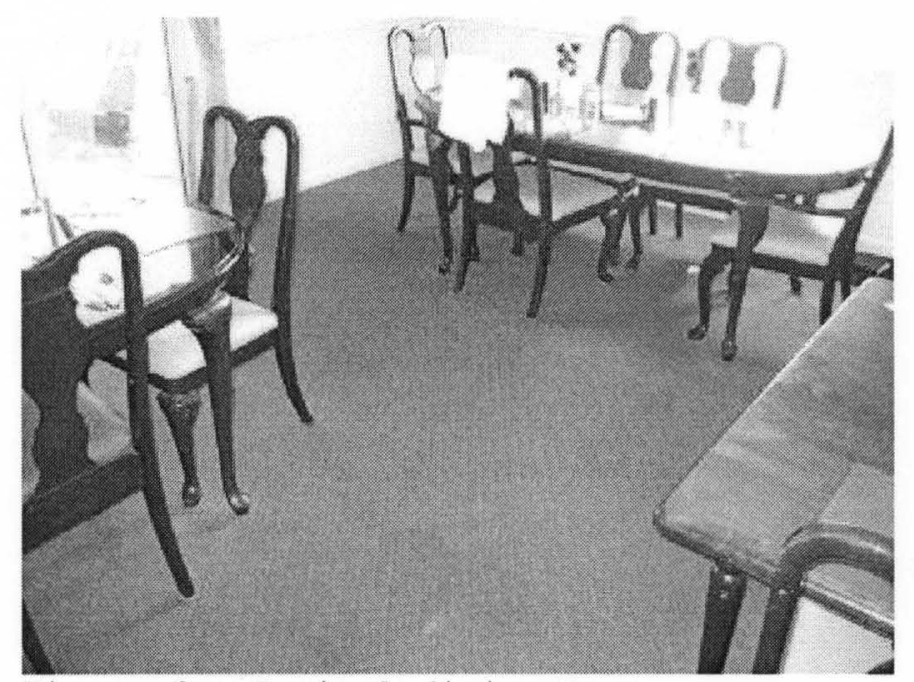

Figure 6 - Typical dining Room

ALC \#3 allow meal delivery on an unlimited basis; however, residents are strongly encouraged to eat their meals in the community dining room. Residents requesting this service frequently are closely monitored. ALC \#3 also provide residents that need additional assistance with feeding, services include cutting up of food and providing a thickener for liquids for those with difficulty in swallowing. 
Table 2. Meals and Social Interaction

\begin{tabular}{|c|c|c|c|c|c|}
\hline & ALC\# 1 & ALC\#2 & ALC\# 3 & ALC\# 4 & ALC\# 5 \\
\hline $\begin{array}{l}\text { 1. Assigned } \\
\text { seating }\end{array}$ & $y$ & $y$ & $y$ & $n$ & $\mathrm{n}$ \\
\hline $\begin{array}{l}\text { 2. Formal } \\
\text { Dining area }\end{array}$ & $y$ & $y$ & $y$ & $y$ & $y$ \\
\hline $\begin{array}{l}\text { 3. Delivery to } \\
\text { room } \\
\text { 4. Formally } \\
\text { Trained } \\
\text { Culinary }\end{array}$ & $y$ & $\mathrm{n}$ & $y$ & $y$ & $y$ \\
\hline $\begin{array}{l}\text { Staff } \\
\text { 5. Special }\end{array}$ & $y$ & $\mathrm{n}$ & $\mathrm{n}$ & $y$ & $y$ \\
\hline Dieting & $y$ & $\mathrm{n}$ & $\mathrm{n}$ & $y$ & $y$ \\
\hline
\end{tabular}

ALCs \#4 and \#5 have a council consisting of staff and residents that meets monthly to discuss matters relating to the dining services. The community offers special dieting for those residents that need them. The most common request for meal accommodation is from those with diabetes. A trained dietary manager prepares the menu and meals with a food council.

All of the ALCs emphasize the homelike feel of their communities by offering "home-cooked" meals from their dining services. In ALCs \#1 and \#2, residents regularly accompany staff to the grocery store and are welcomed to share recipes or cooking suggestions. There is no provision to accommodate residents on special diets and residents must be able to feed themselves.

In ALCs \#4 and \#5, the dining rooms are modestly decorated and accented with a scenic painting on the walls. 
Staff members that have undergone culinary training at a local university prepare meals with special dietary meals prepared for those who request them. Residents are strongly encouraged to eat their meals in the dining room but may have their meals delivered to their apartment at no additional charge.

ALCs \#1 and \#2 serve traditional breakfast items a la carte without specific beginning and ending times. Midday meal and evening meals are designed by the manager a week in advance. The ALC emphasizes the home-like environment by producing "home cooked" meals and often solicit recipe suggestions and cooking directions from residents and families. The community is able to accommodate special appetites of residents. If necessary and upon request, residents may have their food cut up by staff members. Residents are strongly encouraged to eat their meals in the dining room and socially interact with each other. However, when residents are not able or choose not to eat their meal in the dining room, staff delivers meals to their apartment without additional charge. Assigned seating is a feature that most of the communities require. The reasons for this policy include the ease of residents to find their seat and it prevents residents from conflict when two or more persons might 
desire the same seat. The manager of ALC \#3 remarked that this has been a real problem with some residents and by assigning their seats there have not been any arguments amongst residents. This policy has the added benefit of allowing the servers to more quickly serve residents with their personal meal preferences as they can anticipate where they will sit. Requiring residents to eat in the central dining room allows staff to better monitor residents. Usually, if a resident is not feeling well, it will be reflected in the amount of food remaining on his or her plate. However, if a resident has just returned from the hospital or temporary nursing home rehabilitation, there is a limited provision of delivering meals to their apartments.

Residents appear to socially interact with each other reasonably well. The manager uses discretion on approving the residency of an applicant for purposes of personality cohesion and best fit in the community. This seems to be going well for this tight-knit community as there have been no evictions or lease termination relating to resident conflict. All of the ALCs actively maintain close relationships with families of residents by inviting them to have meals at the community and to participate in activities with residents. This helps the resident 
transition into the community and allows the staff members to know the families members better.

State regulation does not require formalized training or certain qualifications for those that prepare resident meals, however, ALC \#1, does have formally trained culinary staff to prepare resident meals. The manager believes that having a cook that has had professional training enhances the quality of the meals and makes for a more enjoyable experience for the residents.

Participation in scheduled social activities is encouraged in ALCs \#4 and \#5; however, participation is low at this time. The community has a 14-passenger van that makes a variety of trips for resident activity. Transportation is provided on an emergency basis to medical facilities.

Activities that are typically held each month include exercise, bingo, spelling bees, music, movies, a variety of board games and worship services. These activities appear to adequately meet the needs of residents. The community invites and encourages residents to offer suggested activities.

A review of a typical month's calendar of activities for ALC \#3 includes worship services, exercise, arts and crafts, movies, musicals, bingo and board games. Residents 
are welcome to offer suggestions for additional recreational activities. Activities are also planned for those residents who prefer smaller groups. For ALCs \#1 and \#2, activities are scheduled at least a month in advance while the community remains flexible to postponing some activities when resident are not feeling well. Residents are invited to share suggestions for scheduled activities.

\section{Assisted Living Services}

All of the ALCs offer an array of personal care services to residents (see Table 3 ). One of the most basic and often requested services is assistance with medications, item number 7 . State regulations do not allow ALC staff to dispense medications to residents. Managers provide literature stating this prohibition to inquirers, applicants, residents and their families and emphasize this restriction to avoid later confusion should the resident need more assistance beyond their self-administration. 
Table 3. Available Services

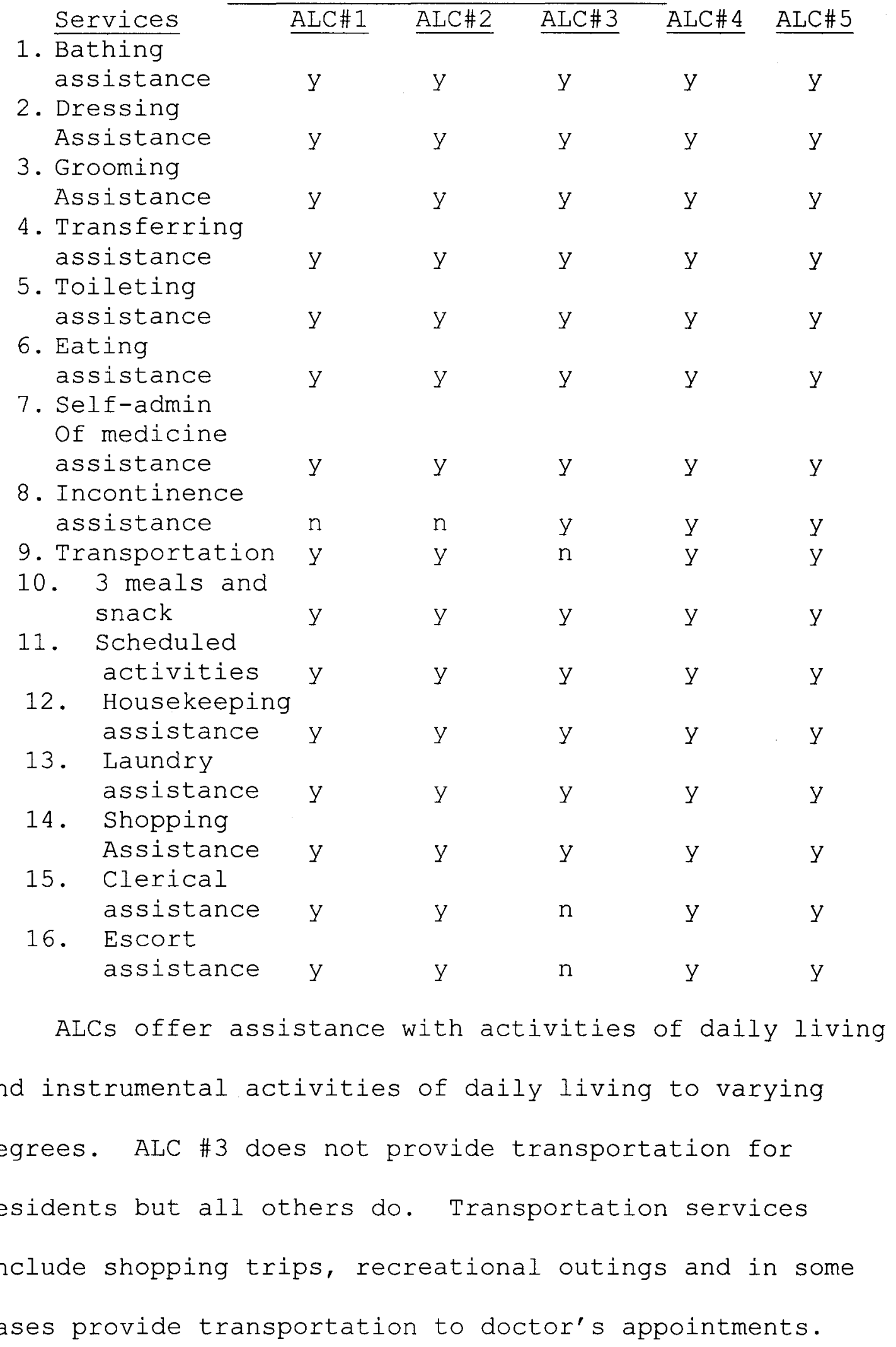


Transportation is not a required service but it does provide a significant enhancement to the value of the community and to recreational activities.

Incontinence assistance is a significant service available to residents, because its availability allows residents to remain in the community longer in than those communities that do not offer this service. Several of the managers state that this has helped them retain residents much longer while they were undergoing inpatient therapy treatment from home health agencies in the home to better control their continence. Assistance with the selfadministration is also a service that managers state is one of the most often requested services from prospective and current residents.

Clerical and escort assistance is provided by most of the communities, however, clerical assistance is not requested very often. Residents occasionally need assistance with escorting within the community. Escorting is often requested as a result frequent slips and falls. Offering this service allows managers to monitor levels of confusion with residents.

For ALC \#3, the community offers a vast array of services to meet the scheduled and unscheduled needs of the residents. Services include assistance with bathing, 
grooming, dressing, escorting, housekeeping, transferring, incontinence, laundry and meals. These services are provided by a full time staff of 13 persons, including the manager. The manager noted that staff turnover for the community is relatively high, which makes for inconsistency of service provision and makes it difficult for residents to know the staff.

In ALC \#1, all of the nine staff members that work in the ALC are employees of the community and not contracted labor. They complete their employee orientation and inservice training as provided by the owner. The ALC has nine full-time staff members providing services to the twelve residents. This allows the community to respond to resident needs very promptly and gives the residents more personalized service. All of the services are included in the monthly fees and are available 24 hours a day. However, not all residents subscribe to all of the services but know they are there when they need them. There is virtually no wait time for residents to begin receiving a service for which they are not already a recipient. Because of the high staff ratio and the relaxed, home-like environment, residents are free to ask a staff member at any time for any of the services offered by the community. 
In ALCs \#4 and \#5, there are twelve full-time employees for the communities, which provide services to the residents. Hired consultants conduct training and continuing education. Management believes this approach assures care is properly conveyed and professionally administered. The manager assesses residents for suitability and determines which are approved and granted admission to the community. All residents must meet the initial qualifications by not being a danger to themselves or to others and must be mobile non-ambulatory as defined by state regulation. There is no wait time for services once the manager and resident determine that new services are needed. Residents are also given an emergency push button to call for staff when urgent assistance is needed. Residents are assessed for their functional needs on a quarterly basis. A computerized chart allows residents, administrative staff and families to monitor health status.

There are fourteen employees that provide the personal care services to the residents for each of ALCs \#4 and \#5. The staff is very well trained and several members have qualifications beyond the state minimum.

Most of the ALCs are able to provide high levels of personalized services to the residents because of ratio of staff to apartments. All of the ratios are similar with 
the exception of ALC \#3. The numbers of staff include the manager and all other direct care staff that provides services to the residents (see Table 4).

1. Number of

$$
\text { Table 4. Units, Staff and Ratio }
$$

$\underline{\text { ALC\#1 }} \underline{\text { ALC\#2 }} \quad \underline{\text { ALC\#3 }}$ ALC\#4

units

2. Number of staff 12

12

80 12 12

3. Ratio

10

Each community offers services to meet the current and anticipated needs of residents. The fees for living in the community are virtually the same, except for the move-in fees which vary significantly (see Table 5). Figure 7 shows a typical one-bedroom apartment in the ALC.

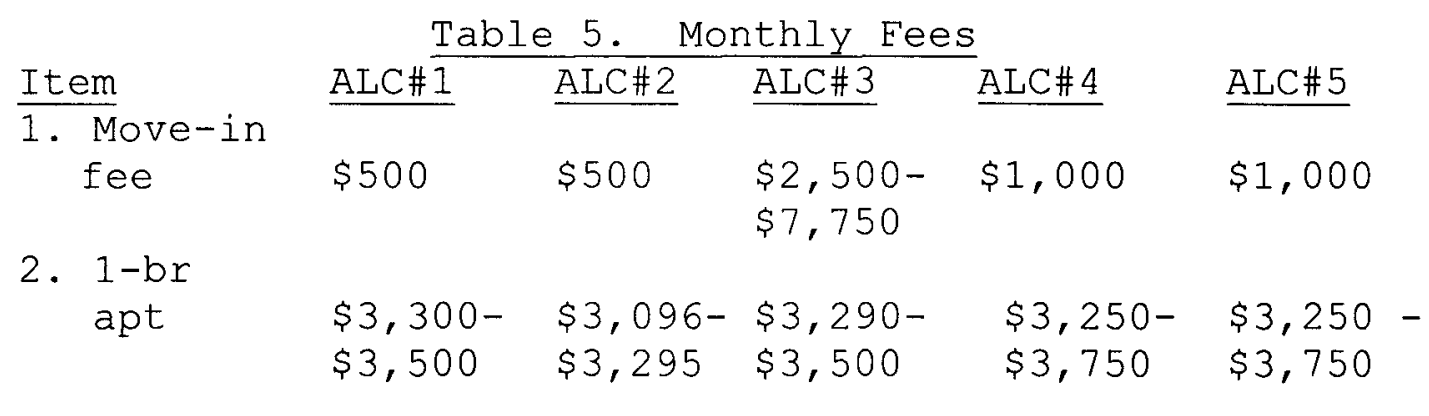

3. 0-br apt

$\mathrm{n} / \mathrm{a}$

$\mathrm{n} / \mathrm{a}$

$\$ 2,265-$

$\mathrm{n} / \mathrm{a}$

$\mathrm{n} / \mathrm{a}$

4. Alcove apt
$\mathrm{n} / \mathrm{a}$

$\mathrm{n} / \mathrm{a}$ $\$ 2,475$

$\$ 2,465-$ $\$ 2,950$

$\$ 2,950$ $\$ 2,675$ 


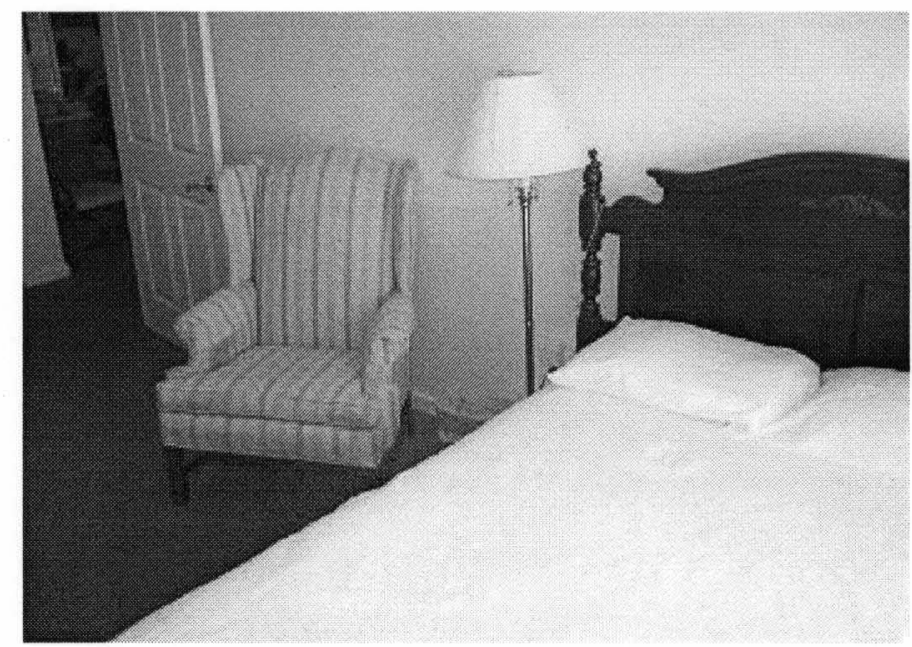

Figure 7 - Typical apartment bedroom

\section{Resident Assessments}

All of the communities are required to conduct an annual assessment of residents, however, ALCs \#2 and \#3 conduct them more frequently than others (see Table 6). ALCs \#4 and \#5 have clearly explained functional needs assessments while the remaining communities' assessment tools are vague (see Appendix 3).

\section{Table 6. Community Policies

$\underline{\text { ALC\#1 }} \underline{\text { ALC\#2 }} \underline{\text { ALC\# } 3} \quad \underline{\text { ALC\# } 4}$

ALC\# 5

1. Clearly Explained Functional Assessment

$\mathrm{n}$

$\mathrm{n}$

$\mathrm{n}$ Y

2.2 or more assessments in year n y y

$\mathrm{n}$

$\mathrm{n}$

3. Al-a cart Services
$\mathrm{n}$

y

n

$\mathrm{n}$

n

4. Allow minor Modifications

n

$\mathrm{n}$ 
As residents begin to show signs of confusion, staff members manage their risk of wandering by giving added attention and supervision. The goal is to keep them in the community as long as possible before they become a danger to themselves or to others. When residents apply for admission, they are screened for the risk of wandering. Those applicants with a history of doing so are rejected for admission. The community strictly adheres to the state regulation for those applicants and residents that might be deemed to be a danger to themselves for wandering or who are immobile (see Appendix 4). The initial assessment is conducted by the owner and manager for suitability to live in and enjoy the benefits of the community.

Any applicant or resident demonstrating signs of psychotic behavior are rejected or given a 30-day lease termination. However, attempts are made by the ALC to keep the resident in the community as long as possible with the provision of additional services or reasonable accommodations.

The manager of ALC \#2 carefully screens potential residents to assure that his or her personality will fit with the existing residents. The screening includes an inhome interview at an applicant's current place of residence to screen for signs that would indicate behavior or 
housekeeping issues. Tours for potential residents often include adult children. The manager of ALC \#2 has a very proactive assessment policy by assessing residents when they return from the hospital for any reason and periodically, when staff members observe residents exhibiting significant changes or unusual behavior.

For ALC \#3, residents are given an assessment of functional needs by the manager upon admission to determine what services are needed. Careful screening is done to detect risks for wandering and severe dementia. Assessments are conducted semi-annually and upon return from nursing stay or hospitalization. A computer system keeps track of the care plans and services that are needed by residents. Monitoring of resident decline is discussed weekly by the staff during care meetings and when needed, families are contacted to discuss the addition of services.

The manager of ALCs \#4 and \#5 conduct a very thorough assessment of residents as they move to the community and all services are available to any resident at any time of the day. There is no wait time for services to be implemented.

Physical Accommodations

ALC \#3 has clearly numbered apartments which make them easy to identify. To avoid an institutional look and to 
further facility the homelike feel, ALCs \#1, \#2, \#4 and \#5 have numbered apartments that are more discreet. If residents desire, they are allowed to personalize their apartments by choosing a paint color. The manager for ALC \#3 allows alterations to the apartment, but only when medically necessary.

The manager of ALC\#2, allows residents to make significant alterations to their apartments to better accommodate their mobility or as a matter of personal preference. Alterations include removing and adding doors to adjoining apartments, larger appliances, new flooring, additional grab bars or strobe lighting for the hearing impaired. On average, residents request to make accommodations about 6-10 times per year; however, not all of the requests are approved. As shown in Table 6, not all communities allow modification of the apartments.

Each of the managers of the assisted living communities participating in this study was generally enthusiastic about the subject of aging in place. When I asked each of them about their motive for agreeing to meet with me, in varying degrees, each expressed a desire to educate people about the benefits of assisted living communities. The manager of ALC \# 3 states, "Although assisted living is not for everyone because of the monthly 
cost, more people needed to know about them and the benefits that are available." The manager of ALC \#4 hopes that my research will "lead to a type of government assistance that will help make assisted living affordable for people that don't have a lot of money, but could live in the assisted living community very successfully." When meeting with the managers for ALCs \#1 and \#2, I visited them during normal business hours when residents were in their homes and staff members were providing services to the residents. The managers were anticipating my arrival and we conducted most of the interviews in their offices. Since the doors to their offices are right off the hallways from the community room, I could hear the chatter and busyness of what appeared to be the normal daily activity of residents talking with each other, a television show, staff preparing to provide bathing services, and other staff preparing meals. Occasionally, the office phone would ring or a staff member would need the manager's immediate attention, and she would ask me to hold while she attended to the matter. On a couple of occasions, the phone calls were from family members of prospective residents inquiring about the community and its services. The managers were assuring and pleasant to the callers and scheduled appointments with them. 
My initial meeting with the manager for ALCs \#4 and \#5 was very much unlike the meetings with the managers listed above. The first meeting was quiet as we and another staff member were in the community alone. All of the residents were away from the community. Several residents were with their respective family members while the remaining residents were away on an activity trip to the mall. The community was very clean and tidy. The manager's office was also clean, but the desk was cluttered with several papers that appeared to be lease agreements or attachments to the lease. One of the immediate items I observed in the managers office was a sophisticated computer system, video monitors and other types of electronic equipment. The manager also had a very sleek looking smart phone he was using. When I asked about all of the electronic devices, he pointed out that these devices relate to the speaker system throughout the communities, the control of the satellite community television and the security cameras in the common areas. During the tour, he was sure to point out to me the appliances in the kitchen that were state-ofthe-art and energy efficient. I could easily tell that this manager was no stranger to advanced technology. This manager believes that residents are attracted to this community because of its location and because the campus 
layout offers other living options with added security features. Also, since many family members of residents do not live very far away, it is convenient for them to visit frequently.

My initial meeting with the manager of ALC \#3 was the most challenging of all. Although she was eager to participate in this review, I sensed early on in the initial interview that she was becoming a little anxious about completing the interview and desired to tend to staff matters and other issues relating to services to the residents. During the course of our tour, I later learned that earlier in the morning several staff members had called-in, unable to work, and she needed to make preparations for staffing later in the evening, but was committing the time to me and the appointment we made for my interview with her.

The managers were experienced in other lines of work prior to coming into the assisted living industry. The managers of ALCs \#1 and \#2 are also the owners of the communities. For the managers of ALC \#1, acquiring the franchisee license to open the assisted living community was more than a business decision. They viewed this business more like their life mission of service to others. Although the managers of ALC\#2 did not share a view as 
deeply committed as the managers of ALC \#1, they express their interest as more than purely a business proposition; they wanted to be able to help older adults as they age. The managers of ALCs \#1 and \#2 believe that the strengths of their assisted living communities lie in their relative size. Because there are a small number of residents, staff is able to provide individualized attention and cultivate meaningful relationships with residents and families. Even after their loved one has moved on from the assisted living community, family members still keep in contact with staff from the community.

However, they point to the frustrating factor of those times when staff members are not able to report to work and the additional burden is placed on others to maintain the same quality of care and attention that residents and families have come to expect. They believe that residents and families are attracted to their community because of the value they receive for what they pay each month, the location in a residential neighborhood and the close-knit, sense of family that exist in the community.

Because their communities are part of a larger national franchise, there were building design features they were required to adhere to. The one feature that the managers of both communities agreed as being the most 
difficult to work with is the design of the community bathroom. The space is narrow which makes it hard for wheelchair bound persons to maneuver in them and for staff to provide services to large residents.

ALC \#3 has the highest resident to staff ratio of $8: 1$ (see Table 4), but the manager believes that the staff ratio is one of the strengths of their community. Although there are ALCs in this report that has significantly lower ratios of resident to staff, this manager comes from a skilled care background where the ratios are much higher than the community she manages and her current ratio of $8: 1$ is a good balance of human resources and resident care. Additional strengths of this community include a caring and personable staff that is experienced in providing care to residents. When I asked her about anything she thought the community would need to improve its service, without hesitation she wanted state legislators to remove the regulatory prohibition of providing health care services to residents. Her desire to provide health care related services stems from her background as a registered nurse and her previous position as a director of nursing for a nursing home. She told me she often feels conflicted when recognizing health care needs in residents, being unable to perform the necessary 
services for fear of violation of regulations and the financial penalty associated with the violation. She too believed that her community's location and value for the monthly fees paid are items that are most attractive to residents.

There have not been any cases when residents were so dissatisfied with an assisted living community that they decided to move to another one. All of the managers cite the most common reason for residents moving out of the community is to nursing home placement or death. When its time for residents to move from the community, the manager of ALC \#1 takes pride in knowing that they provided the best level of care to residents while they remained in their home. She said, "We do the best we can with what we have and try to keep them here as long as we can, but when their needs just go past our ability to care for them, our hearts want them to stay, but we know that moving on to a hospital or nursing home is the best place for them."

The managers agree in believing that assisted living communities will be the trend for the older adult population. The manager of ALC \#3 adds, "Places like ours will undoubtedly be the trend for as long as people can afford the monthly fees." The manager for ALC \#2 believes "assisted living communities are a good solution for the 
care of older adults because the nursing home industry is overwhelmed with regulation and many older adults are inappropriately placed there. It costs Medicaid too much and we can do it better and for less money." While state regulation requires various topics of inservice training to be provided to staff (see Appendix 4), the manager of ALCs \#4 and \#5 believes services could become more beneficial if regulation required more stringent training requirements for staff. He says, "The current system has too many loopholes and everyone is not doing the in-service training the way it should be done." The managers believe that assisted living communities benefit older adults more than nursing homes. Because of their relatively smaller size, no Medicaid regulation, the personalized care residents receive and the quality of life in the assisted living community far exceeds the quality of life in the nursing homes. 


\section{CHAPTER V}

\section{DISCUSSION AND ANALYSIS}

A June 2002 report to Congress from the Commission on Affordable Housing and Health Facility Needs for Seniors in the 21st Century, titled "A Quiet Crisis in America," summarized the critical problem of housing and care for older adults in this way:

...A large and growing number of seniors will face triple jeopardy: inadequate income, declining health and mobility, and growing isolation. ...For some, family supports disappear when they outlive spouses or when children move to a distant place. For others, old age is a time of discovering that, with declining or fixed income, they are simply unable to purchase the goods and services they need. ...For those fortunate enough to have caring families nearby, their caregivers may face more stress than they can endure. When family, friends or caregivers search for help, they often encounter confusing requirements and eligibility 
standards as well as exorbitant costs. Those in rural areas face a dearth of available services...

... [The] result of this could be a substantial increase in costly and premature institutionalization of older people... Nursing facilities should be places that care for the very ill and not the only alternative for people who cannot afford to live elsewhere. (Staff of the Rose Ames Senior Assisted Living Communities, 2006)

As data suggests, within the next $15-20$ years, the older adult population in the United States is going to expand significantly with persons aged 85 years and older being the largest group. The impact of a large number of older adults is going to affect all areas of society. Housing and care options for older adults are becoming an increasing concern for older adults, families, local, state and federal governments. Many local and state governments are hoping to prepare meet this need by the presence of assisted living communities and other long-term care options that, in many respects, are an alternative to institutional settings such as nursing homes and meet the diverse needs of the Baby Boomer generation.

The U.S. population of persons age 65 years and older is projected to increase dramatically, see Chart \#2. 
Chart \#2

U.S. Population, Age 65+

(In thousands)

(U.S. Census Bureau, 2011)

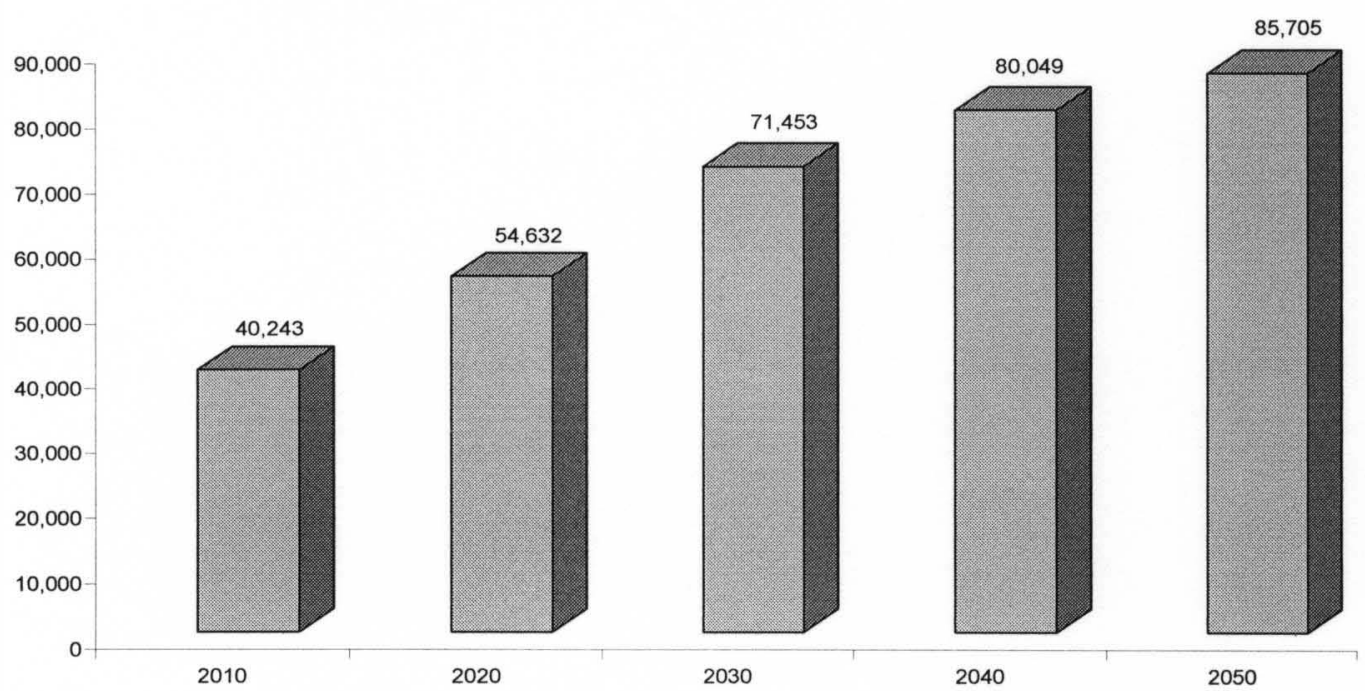

Also, the population in Kentucky of persons aged 65

years and older is projected to rise, see Chart \#3.

Chart \#3:

Kentucky Population, Age 65+

(U.S. Census Bureau, 2011)

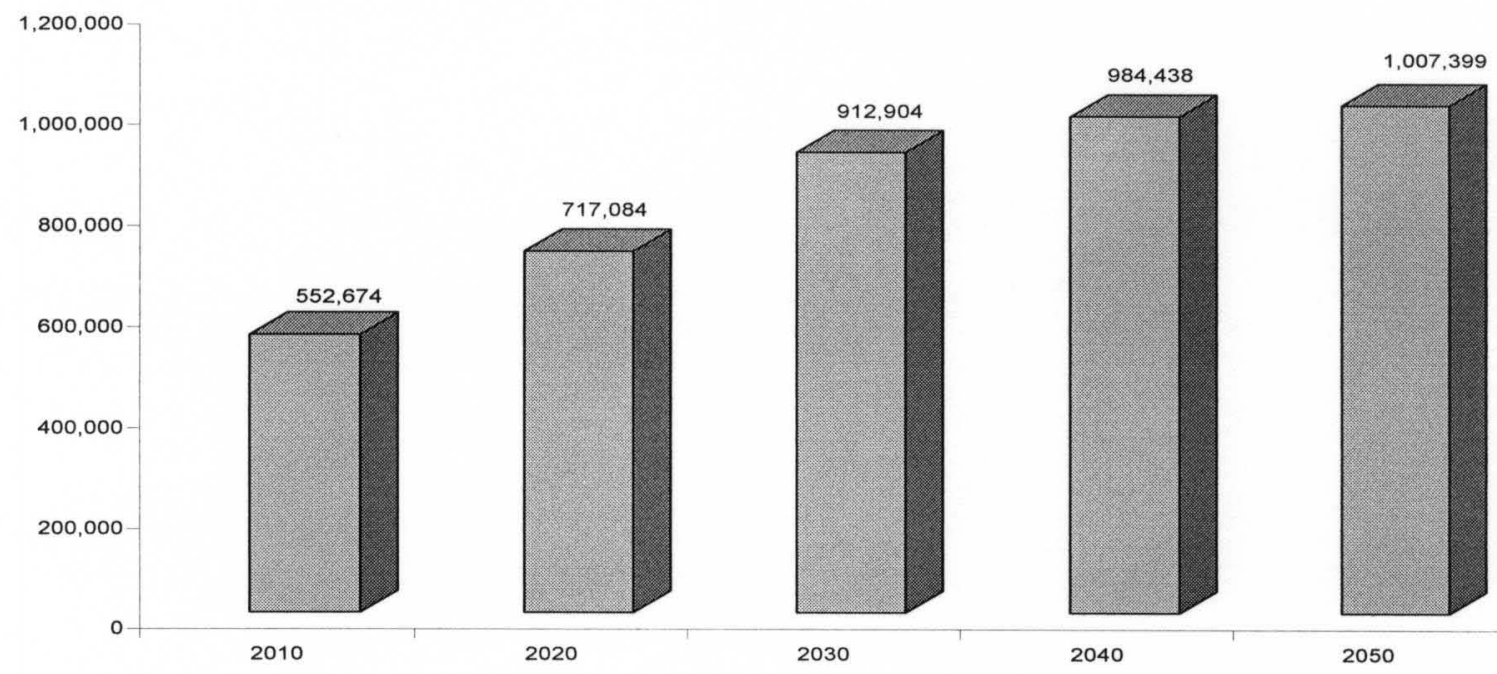

Assisted living communities are distinguished from

nursing homes in that it is typically a less costly model 
and provides a more homelike environment that tends to be less physically restrictive. One of the hallmarks of assisted living communities is its ability to delivery necessary personal services in and environment features that are non-institutional. Many assisted living communities share a common philosophy that emphasizes privacy, autonomy, flexibility of services and the ability to age in place.

To increase the general knowledge about assisted living communities in Kentucky, my research has identified several important items that provide clarity and understanding to this long-term care housing option.

Chart \#4, shows that in Kentucky, the current number of long-term care options are woefully inadequate to address current and anticipated housing and long-term care needs of persons age 65 and older. The scarcity of resources will be a challenge that many older adults, families and governments will have to address with a sense of urgency. 
Chart \#4:

2010 Comparison of Kentucky Population Age 65+

and Available Long-Term Care Units

(U.S. Census Bureau, 2011; \& KALFA, 2011)

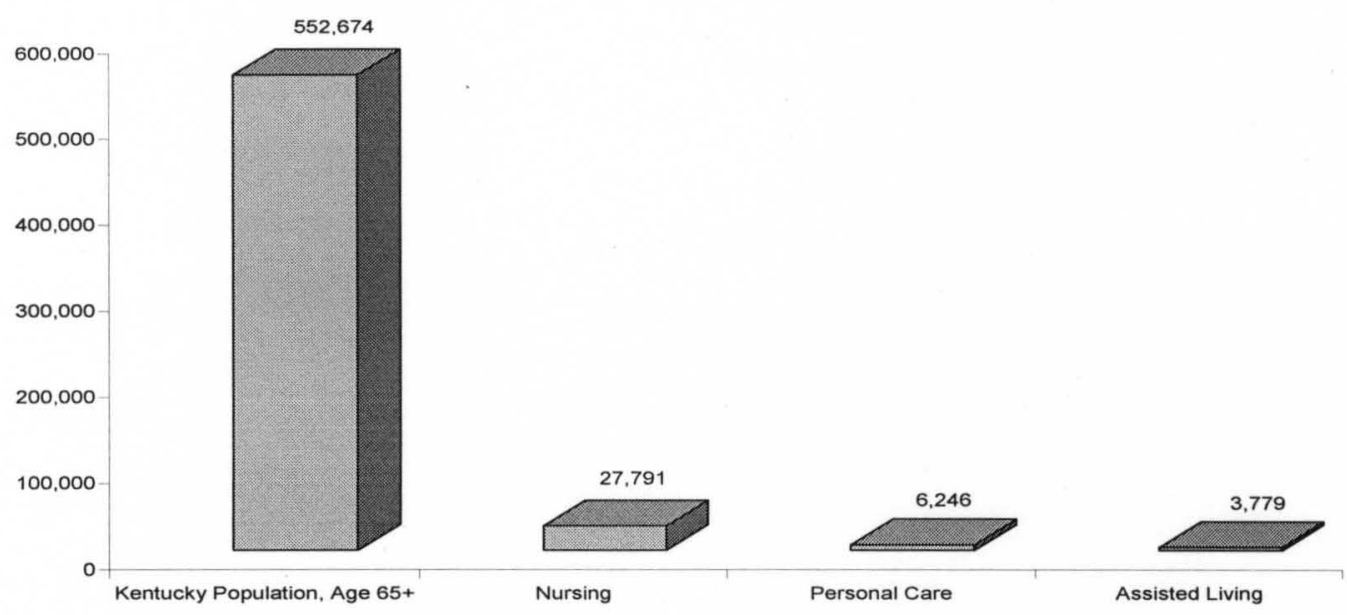

Chart \#5 shows that the 2010 population in Kentucky of persons age $65+$ with those persons in the age cohort of 65 and 69 is 176,016 or 32\% of the population. This cohort, in 20 years will place an even greater strain on the lack of long-term care options and community resources.

Chart 5:

2010 Kentucky Older Adult Population by Cohort

(U.S. Census Bureau, 2011)

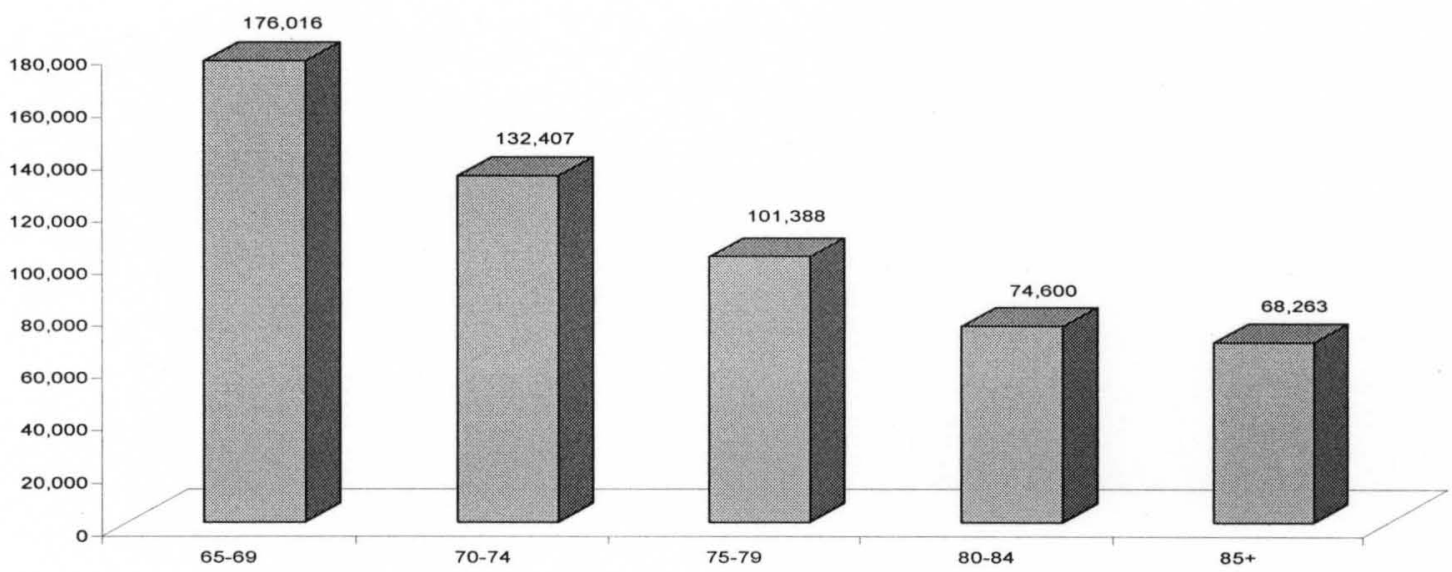


Government Assistance

Kentucky is one of a few states that currently do not allow for any portion of Medicaid assistance to provide funding for low- and moderate- income older adults. In the current political and economic environment, as states look for substantive means to provide more affordable care options for low-and moderate- income older adults, this option is sure to get more attention from state legislatures. The lack of government assistance or lowincome assisted living options dictates that assisted living communities are a long-term care option that is unavailable for many older adults.

Many older adults lack sufficient resources to live in an assisted living communities, but still have care needs, are having their needs met by a hodgepodge assortment of community or family resources, are not being met at all or may be inappropriately placed in a nursing home. Many of these older adults could enjoy a better quality of life with less strain on community and family resources and at less cost than nursing homes. In some respects, assisted living communities are an untapped community resource for older adults without the resources to pay the monthly fees for assisted living care. 


\section{Personal Care Homes}

Assisted living in Kentucky is based on a social model of care which prioritizes resident independence, privacy and autonomy. Treatment of diseases and provisions to provide health care services are restricted. State regulation provides for the existence of personal care homes, which are very similar to assisted living communities; however, they are able to provide health care services, including administration of medication. Unlike assisted living residents, residents of personal care homes may qualify for state Medicaid assistance to fund their care. Personal care offers a higher intensity of services than is available in assisted living communities, but not as intensive as intermediate and skilled nursing care. The care needs of Personal Care residents generally include a progression in the loss of activities of daily living. Residents may begin exhibiting a decrease in cognitive functioning and require extensively more help in areas such as bathing, dressing, eating, toileting and the administering of medication. To qualify for this level of care, residents must be ambulatory or wheelchair independent, remain continent and must be capable of feeding themselves. Setting the meal tray, including the 
preparation and cutting of food, is a serve that can be offered in Personal Care.

\section{Supportive Services}

Assisted living communities are required to provide services to meet residents' scheduled or unscheduled needs for activities of daily living and instrumental activities of daily living. Assisted communities are also restricted, by state regulation, from providing 'health care' related services. These services are defined as "Help with personal daily living activities such as bathing, dressing, grooming and hygiene, transferring, toileting and eating; assistance with household and related activities incidental to daily life such as housekeeping, shopping, laundry, chores, transportation and clerical/recordkeeping assistance; scheduled social activities; and help with self-administering medication.

\section{Monthly fees}

Assisted living is largely a private-pay business. Most residents living in assisted living communities pay for expenses from private money sources. These sources can include income from pensions and retirement, as well as money from savings and investment accounts. Some families 
help with covering the costs associated with assisted living. In other cases, residents use the proceeds from the sale of real estate and personal property. A long-term care insurance policy is also an option for residents to cover monthly fees.

By virtue of the full occupancy of the communities included in this research, these communities are attracting and maintaining residents with the ability to pay the monthly fees. According to the managers of these communities, most of their residents have sufficient incomes or are spending down assets from the sale of their previous homes. All of the managers of the communities emphasize that they conduct thorough interviews and financial analysis of the resources of potential residents to assure themselves, residents and families that they have sufficient resources to maintain residency in the community. The managers of these communities understand the cost on operations and the impact that an unpredictable revenue stream would have on their community if such an analysis and commitment is made. There have been very few instances when managers have had chronic problems with late payments, as residents pay their rent on time, and there has not been an instance where an eviction was necessary due to the inability or refusal to pay. The ability to pay 
the monthly fees from personal resources is significant and vital to the success of assisted living communities as there are no government resources available to help defray these expenses.

The monthly fees in ALCs included in this research study range from $\$ 2,265$ to $\$ 3,750$ a month depending on size of the apartment, making them largely out of reach for poor older adults. The assisted living communities are structured in a homelike framework which is small and lends itself to the idea that residents are paying for personalized attention that would not be otherwise available in a large nursing home.

When the inevitable time comes that these assets are insufficient, managers must look to eviction or residents must find alternative means of satisfying the monthly obligation. However, this has not been an issue that has had to be faced on a regular basis.

There is virtually no difference in the amount monthly fees the assisted living communities charge residents depending on the area of Jefferson County. These communities are located in southwestern and northeastern neighborhoods and have very similar price structures. I was anticipating a difference in price with the east end communities charging more. Aging in place is largely 
available to the extent that residents have the financial resources to remain in the community and that resident care needs do not exceed the ability of the community to meet those needs.

\section{Residents}

A key task in maintaining consistency, continuity and harmony in the assisted living community is determining interests, background and compatible personalities. Most residents are in the same age range, share similar cultures, and have religious and worldviews that are homogenous. However, the small homelike environment would seem to make it difficult for residents of vastly different religious and cultural backgrounds to be compatible. Differences could exist regarding worship services, activities and meal preferences. Significant unrest or disagreement amongst the residents could jeopardize socialization and harmony in the home.

Managers must make the community welcoming and comfortable for current and future residents. The older adults in the communities seemed to enjoy relating to others with the same frame of reference and values in these small close-knit assisted living communities. 
Most of the older adults in these homes were white women who have lived in the Louisville area for most of their lives. When I visited each of the assisted living communities and inspected various apartments, all of them were similarly decorated with artwork, furniture and household goods. There was nothing particularly unique about their appearances. Each of the communities seemed to appeal to the same cultural and racial demographic. When potential residents and families visit an assisted living community the managers want them to know that the community relates to their values, and preferences, and is a community that can meet their housing and personal care needs as well as their needs for social engagement.

However, more research will determine how the homogeneity amongst the residents may affect operation of the ALCs with regarding to social interaction and resident satisfaction.

Staff

There is a high level of homogeneity amongst the staff persons that provide the management and the day-to-day care services for the residents. Since most of the residents are women, one could infer correctly that most of the staff would also be women. Residents receive very personalized 
care from assisting with bathing and dressing to escort to and from their apartments. Resident and families are given a sense of security and comfort when the services provided are from women.

Not only is the gender of residents and staff largely the same, but the racial composition of the staff is also similar to that of the residents. Most of the staff members employed and providing services are white women. Additional research will determine if this is caused by the pool of available workers, market forces or some other variable.

Among the staff in most of the communities I noted a high sense of camaraderie. Workers support and encourage each other in providing the best service to the residents. This sense of teamwork was more present in those cases where the owner managed the community and was involved in the day-to-day work of providing care to the residents. Surprisingly, in most of the communities there was a high staff to resident ratio. In many cases there is a staff person for every resident. This high ratio allows residents to receive personalized and immediate attention for needed services. Residents are paying not only for a certain quality of service for the immediacy of that service. 
Supportive Family

There is significant engagement of families during orientation and throughout the length of stay for the resident. Assisted living communities encourage high involvement of residents' family members and they are welcomed to participate in activities including shopping trips and meals in the community. Several managers believe that the more residents' family members remain actively engaged with them, the more satisfying their experience is in the community. Management staff contacts family members when there is significant decline in a resident's health or on those occasions when there have been behavior issues. The positive, high family involvement adds to the richness and homelike feel of the community.

Adult children of potential residents mostly make the initial inquiries about the assisted living community. It is common for the adult child to visit the community with the potential resident when making their first tour. The family member involvement provides an invaluable tool in managing resident care. When there are certain behaviors of the resident or a certain preference in how and when services need to be delivered to residents, family members 
are a resource when there are disagreements or issues with which a third party might help.

\section{Assistance with Medication}

By far, the most sought out service the assisted living community provides to residents is the assistance with self-administration of medications. Management of the communities report that most residents are on a minimum of 10 to 12 prescription medications each. With prescription medications needing to be taken at various times throughout the day, managing the schedule can be complex. While state regulation prohibits the community from directly administering the medications, residents often need a reminder of when to take their medication or assistance in administering the medications.

This service is vital for the health of residents. Management reports that one of the leading causes of hospitalization is residents not taking prescription medication properly as directed by their health care providers. Before living in the community, some residents had overdosed by taking too much mediation or they forgot to take their medication at all. In the ALC, residents and families are assured that medications will be taken when prescribed. The ALC is permitted to keep the medicine in a 
locked container in the apartment of the resident provided the resident maintains a key in the apartment as well. Significant attention is given to make sure residents have sufficient doses of each prescription medication and that medications are not inadvertently given to another resident.

Managers of the assisted living communities believe that they could better serve residents if state regulation provided a broader definition regarding assistance with self-administration of medications (see Appendix 4). These managers believe that the current definition is too restrictive because it does not allow them to touch the medication. Also, state regulation prohibits the application of over the counter medicated creams and lotions as this is considered as providing a health care service.

As the assisted living communities meet the needs of residents, these managers have identified an opportunity to provide greater care while still preserving the intent of the assisted living community and differentiating it from nursing homes. 


\section{Accommodations}

I was expecting all of the communities to be accommodating to alterations to the apartments due to changes in their health or for personal preferences. All of the communities do allow some alterations on a case-bycase basis. Some communities have a broader policy in the alterations they will approve; however, these communities desire to keep the resident in their home for as long as possible. If residents have the means to afford the alterations and the alterations do not fundamentally change the character of the apartment, they are generally approved. Such as additional grab bars, changes in flooring types, lower cabinets, counter tops, etc.

\section{Intake Policies}

All of the assisted living communities follow a strict adherence to the state's minimum qualifications for eligibility. Residents must be ambulatory or mobile nonambulatory and must not be a 'danger' to themselves (see Appendix 4). The communities generally define a danger as a resident showing a high level of confusion which could lead to wandering and elopement. Because residents are not restricted from coming and going in and out of the community, there are no significant safeguards for 
preventing residents from wandering away from the community and endangering themselves. Therefore, communities are predisposed to screen for any early detection of this tendency. Communities that have a history of residents wandering might be perceived as providing insufficient care or attention to the needs of the residents and could affect desirability.

Because of the competitive nature of the business and the need to differentiate themselves from the others, I was anticipating some communities to have intake policies that were beyond the state's minimum. Such as having specially designed units for hearing impaired, dementia, etc.

\section{Meals and Social Interaction}

Because of the homelike nature of the community, most of the managers emphasize the home-cooked nature of their meals. This aspect of care appeals to residents and families that want to avoid any hint of institutionalization by bland food typically associated with nursing homes. The kitchen and dining rooms are centrally located where residents can observe meals being prepared, and, on a limited basis, participate in preparing the meal. For many residents, meal preparation, has been a significant part of their life history, and they feel a 
sense of connection with the community and contributing to it by participating in this experience.

Several of the communities are able to accommodate special dietary needs of the residents. This is particularly helpful for those residents that have special needs as their health changes or due to an acute health issue. This personalized attention is what adds to the essence of the homelike environment for the residents and seems to enhance their quality of life.

Although residents are compatible with each other and seem to enjoy each other's company during meal times, some residents occasionally request to have their meals delivered to and eaten in the privacy of their apartments. Most of the communities accommodate this personal choice with limited restrictions. However, one of the marketing aspects of the community is the quality of the resident interpersonal relationships and the value of social interaction. Allowing residents to have their meal delivered is a benefit to those that might have recently returned from the hospital or may not be feeling well enough to be with others.

There does not appear to be any discernable differences in the operation of assisted living communities according to size. The largest assisted living community 
in this research study has a ratio of direct caregivers that would still allow it to provide more personalized attention to residents than most nursing homes. Assisted living communities desire to differentiate themselves from an institutional look by emphasizing the residential character of the environment. Typically found in these communities' common areas are couches, fireplaces, television and stereo equipment that would more likely to be found in a private residence.

\section{Aging in Place Capacity}

As a person ages, providing them with a stable and familiar environment is important. A familiar environment and routine allow people to devote time to other activities, as they can perform their everyday chores and activities efficiently. The stability on which we all rely is especially important to older adults, since long time residences are more likely to fit older occupants more comfortably. Lawton (1980) pointed out that the environment can provide stability, stimulation and support, and that these three functions can be in opposition or can interchange with one another.

Living close to and/or interaction with family and friends is an important factor in the quality of life for 
older adults. Family members and friends provide older adults with a support system that is referred to as informal support. They can help an older adult cope with crisis, adjust to change in a health or facilitate a formal service such as doctor visits, annual assessments, etc. They are not necessarily paid to do anything but remain a part of the older adults life and can be a 'lifeline' at any time. These familial resources can be children, friends, peers or outside caregivers, as well.

The support needed by older adults varies from one situation to another. It may be financial, emotional or daily help that is needed. It should also be noted that older adults not only receive support but they give it as well. This is an important consideration for their esteem. Also important is that help comes from one's peers. Peer groups help their members to feel independent and confident; this can return a higher sense of self-esteem and sense of purpose in their life.

Wherever an older adult lives, it is important that appropriate facilities and services be easily accessed, such as churches, health clubs community centers, shopping, grocery and medical facilities. The location of these services may be important enough for an older adult that they will choose a community that will allow greater access 
to them or, at a minimum will discount a community that they felt made these locations inaccessible. A complete range of relevant support services must be made available to seniors in order to keep them in their homes and communities. Many times, what forces an older adult out of their community and not to age in place, is the lack of services such as snow removal, transportation or heavy house cleaning.

The four primary factors that were examined in this research study and determine to influence a community's capacity to age in place are supportive services, meals and social interaction, community policies and physical characteristics. Below is a discussion of each of these factors.

\section{Support Services}

All of the communities provide services to meet residents' scheduled and unscheduled needs for activities of daily living and instrumental activities of daily living. Due to the high numbers of staff to residents, all of the services are generally available to residents within a moment's notice. Assisted living communities are laborintensive. Staff must be attentive to changes in resident behavior and provide personal, one-on-one services to each 
of the residents. To create and foster a comfortable and satisfying homelike environment, the communities in this review have staff members that are congenial to each other and caring for the residents. The viability of he assisted living community is dependent upon competent and committed staff members who provide daily services to older adults.

\section{Meals and Social Interaction}

Cox (2005) believes that the opportunity to receive supportive personal care services while socializing with peers in a congregate type setting such as an assisted living community offers an advantage over home-based care, where residents have virtually no interaction with peers and or family members outside of their homes. Assisted living communities are challenged with fostering a genuine sense of community but also allowing residents to have their individual lives which managers do not always control or influence. Genuine community and resident autonomy includes allowing residents to express their individuality while giving back and contributing to the community at large and to relationships with other residents and with staff. However, residents' ability to engage the community does not always come to fruition in practice, since residents are living longer and are often impaired with 
chronic health conditions. They usually require assistance in one or more areas of activity of daily living, which can include mild confusion, memory loss or impaired judgment (Carder, 2002).

The move to the assisted living community itself is usually prompted by a sudden life event such as the death of a spouse or an acute illness, and is not uncommon to be facilitated by a family member with limited or no input from the individual. As a result, assisted living communities are often comprised of residents from various parts of the country with diverse histories, experiences, interests, philosophies and abilities living together with little else in common (Yamasaki \& Sharf, 2011). In many cases, the transition to an assisted living community or other long-term care option represents a significant turning point in an older adult's life. Adjustment involves finding a suitable ALC, downsizing to a new ALC, settling in, and establishing new social relationships. This residential transition triggers unfolding path, with some individuals having sufficient resources to navigate successfully in to a new setting, whereas others face less satisfactory outcomes (Burge and Street, 2009). 
Health is likely to impact residents' ability to form friendships in their new facility. For example, residents who suffer from health conditions may lack the energy or the desire to be sociable. Furthermore, limited mobility may present a barrier to friendship formation. If residents have a hard time navigating their community it may restrict their opportunities to interact with others. Additionally, residents with hearing impairments may have a difficult time communicating with other residents.

The mealtime and social engagement is a significant part of the communities' appeal and residents' satisfaction. The managers of these assisted living communities believe it is important for current and potential residents to have a greater number of factors in common than differences. To that end, in addition to determining a potential resident's ability to consistently pay the monthly fees, managers are highly subjective in choosing residents to live in the community. Residents that have a history or show signs of being combative can be detrimental to the operation of the community.

\section{Community Policies}

The ALCs in this research study all have community policies that very closely follow the minimum guidelines 
established by the Kentucky Department of Aging and Independent Living. Particular emphasis is placed on the resident not being a danger to themselves or to other residents in the community. The frequency and quality of training differ from the ALCs as well as the frequency and in-depth analysis of the functional needs assessments.

\section{Physical Characteristics}

The communities are located in residential neighborhoods and generally appear to blend in with the construction types of the single-family homes in the area. • The communities centralize the main living and dining areas. Most of the communities allow for some minor types of alterations to better accommodate needs of the residents. The communities are accessible to persons with disabilities and typically have amenities that make it easy for persons with disabilities to enjoy all aspects of the community. The environments are small enough to foster a homelike atmosphere but have sufficient common and community spaces for the administration and delivery of supportive services and for social activities and interaction. The homes are decorated well and avoid the institutional look. 
Limitations of study

The primary limitation of this study is in the number of assisted living communities that participated. Although there are fourteen assisted living communities that are currently in Jefferson County, several of the communities declined to participate.

The managers that did participate in this study did so with a good level of enthusiasm and generally wanted to contribute to increasing the knowledge of and potential benefits of assisted living. The managers provided me with ample information and time to meet with them and to review data that I had collected from them. The assisted living communities in Jefferson County were selected because I believe reviewing these communities would be an adequate reflection of assisted living communities throughout the Commonwealth of Kentucky. While I believe that is substantially true, there may be some nuanced differences due to the urban and non-urban setting. Louisville is, by far, Kentucky's largest metropolitan area with a plethora of community resources for residents and families. The managers of these communities tell me that most of the residents have lived in Louisville or some other similarly sized metropolitan city for most of their lives and chose 
assisted living communities that are relatively close to their former neighborhoods or are close to family members.

In rural environments such as in Kentucky, where communities do not have the types of resources that could be found in Louisville, there may be substantive differences in how assisted living communities operate. Another limitation of this study is that I am employed as the administrator of two assisted living communities in Louisville that were not included in this study. These communities were excluded due to the possible conflict of interest there might be when conducting research in communities that I oversee.

Finally, this study was designed to examine the communities' ability to accommodate aging in place based on interviews with managers, tours of communities and a review of data that focused on four areas that research has deemed to be critical in this area. However, I did not have any conversation with residents or family members to discuss their perspective and how residing in the community may or may not have enhanced their quality of life and helped them to age in place. 


\section{CHAPTER VI}

\section{ASSISTED LIVING COMMUNITY AFFORDABILITY AND COST}

As the older adult population increases and ages, the need for alternative housing options which include supportive services will continue to accelerate. The rapidly increasing numbers of the population over age 65 is a well-established phenomenon. With increasing longevity, there is also a greater likelihood that older adults will need assistance with activities of daily living. While our society has placed great emphasis on the institutionalization of older adults (Gilderbloom, 2008), this is a model that is no longer financially sustainable for governments nor is desirable for older adults. Many state governments like assisted living communities, as a long-term care alternative to nursing homes, largely due to anticipated cost savings to Medicaid. While Medicaid assistance is offered to low-income older adults to help cover some the cost of living in an ALC, it is available on a limited scale and there are significant 
waiting lists. To make assisted living communities accessible to low- and moderate- income older adults and families, developers and governments should seek creative means of providing housing and services to meet the growing demand for assisted living type services.

One of the reasons why assisted living is unaffordable for most low- and moderate- income older adults is because assisted living has significant costs associated with the real estate side("bricks and sticks") and service intensity which equate to relatively high costs.

Universal design features which promote safety, convenience and comfort in residential settings are purposed to minimize accidents in the home and to make facilitate aging in place. Senior apartment communities that are being built and remodeled should build and renovate their homes using these concepts which should greatly prepare them to help older adult residents age and delay having to move on to other long-term care options. Universal design features usually include no-step entry ways, slip resistant flooring in kitchens and bathrooms, front loading washers and dryers, interior doors that are between $32^{\prime}$ to $36^{\prime}$ wide, hallways that are $48^{\prime}$ wide and removable cabinet fronts at bathroom and kitchen sinks. 
One possible way to develop affordable assisted living is to concentrate on real estate costs and 'soft' costs, such as food, services, etc. Separating these two significant components could allow developers to focus on ways of identifying and mitigating those cost factors that influence assisted living affordability.

An effective means of developing affordable housing is through the Low-Income Housing Tax Credit Program. Tax credit financing allows developers to receive tax credits in exchange for promising to provide affordable rental units for a specified period of years, usually 15 to 30 years. Developer's sale these tax credits to for-profit institutions such as banks, corporations, or individuals and apply the proceeds of the sale to lowering the cost of the mortgage. This process allows the development to transfer the savings in the form of lower rents to residents.

The rental rates in the tax credit housing community must be maintained at or below a set amount based on the median area income for the county in which the housing development is located.

The tax credit program requires that services, including supportive services, that are mandatory for residents to pay must be included in the rent. This would 
likely create a housing burden for low- to moderate- income older adults.

However, using this model, all of the assisted living services that would be purchased would be optional. Older adults may rent apartments in the facility and either obtain the optional services from the building owner or its affiliates, or obtain them from any provider they choose. The same is true with meals: Residents may purchase a flexible meal plan from communities that offer this service, cook on their own, or have meals catered to them. To assist with the cost of services, residents could access their states' Medicaid Waiver Program or other subsidies for the elderly to cover assisted services. In-home support services are often used by older adults living in housing communities specifically designed for older adults and/or by those individuals who are participants in senior center activities. In-home support services constitute care along a continuum - from the least medical, more chore oriented types of services, i.e., shopping, errands, housecleaning, light cooking, to personal care services including assistance with ambulation, bathing, dressing, meal preparation and feeding, and supervision, to the most highly skilled and highly regulated nursing services provided by registered 
nurses. In-home support services range in intensity from a few hours a week to full-time live-in care and are provided both on an informal as well as a formal basis.

Cost could also be reduced in the provision of services by carefully scrutinizing the offering of basic services. Some hospitality services can incrementally increase labor costs and encourage dependency. Other techniques, such as integrating job functions and doing volume purchasing affect affordability.

Regulations also might affect a provider's ability to tailor services to people's needs rather than to unrealistic regulatory mandates. 24-hour coverage may not be necessary for some ALC, yet this could be an expensive and unnecessary service. To save money in assisted living, providers must ultimately work with families, older adults and regulators to try to moderate expectations that may not be necessary or infeasible to incorporate into daily operations.

Another component in the affordability equation is regulatory requirements. Thoughtful regulations are important for the assisted living industry. Overregulation can increase costs without improving quality of life. When new regulations are proposed, it is important for legislators to weigh each one to determine if there is true 
consumer benefit or just an additional cost to the consumer and provider.

Long-term care insurance is a special type of insurance plan that can help pay for the supportive services in an ALC. Long-term care insurance policies usually pay a certain sum of money to the facility for a certain period of time.

The cost of long-term care insurance varies widely depending on the policy. There are many different options to choose from, and the price often is determined by the age, medical condition and services needed by the resident applying for the policy. Usually, the younger the applicant is, the less expensive the policy. Many policies have set rates that do not increase as the insured ages.

The U.S. Department of Veterans Affairs (VA) is another possible funding source to extend assisted living services to low- and moderate- income older adults (U.S. Department of Veterans Affairs, 2011). The VA was authorized to provide this level of care for the first time on a pilot demonstration basis in Public Law 106- 117, The Veterans Millennium Health Care and Benefits Act. This law authorized the VA to establish a pilot program to determine the "feasibility and practicability of enabling eligible veterans to secure needed Assisted Living services as an 
alternative to nursing home care." The Act designed the pilot as a clinical demonstration program whereby VA would contract with existing community facilities to provide care rather than establish its own program. To address the concern about the potentially high cost to the VA of paying for assisted living, the VA Assisted Living Pilot Program (ALPP) was developed as a transitional benefit designed to facilitate VA patients transitioning to other sources of funding, such as private pay or Medicaid, at the end of a VA payment period.

Most of the public activity for independent planned housing specifically for older adults took place with the enactment of the 1956 Housing Act when Congress enacted the Public Housing Administration to provide units specifically for low-income elderly. Since then, many older adult housing communities have been built under by local housing authorities but with financing and operating expenses provided by the federal government. The Housing Act of 1959 authorized, among other housing programs, the section 202 housing for low-income elderly. Through the program, the government loaned funds to private nonprofit developers so that they could build housing for elderly families and individuals. Unlike most of its loan programs, HUD made 
the Section 202 loans directly to developers rather than insuring loans from private lenders.

The 1974 Housing and Community Development Act authorized the section 8 program, which provided rent subsidies for people with limited income. Under this Act, Section 202 housing was linked with Section 8 housing assistance. In 2000, the U.S. Department of Housing and Urban Development offered the Assisted Living Conversion Program. This funding source provides to private nonprofit owners of eligible developments with a grant to convert some or all of the dwelling units in the project into an assisted living community for the frail elderly. The purpose of the program is to convert existing HUD financed, older adult housing communities into assisted living communities.

Typical funding will cover basic physical conversion of existing project units, common and services space. The ALCP provides funding for the physical costs of converting some or all of the units of an eligible development into an assisted living community, including the unit configuration, common and services space and any necessary remodeling, consistent with HUD or the state's statute/regulations (whichever is more stringent). There must be sufficient community space to accommodate a central 
kitchen or dining facility, lounges, recreation and other multiple-areas available to all residents of the project, or office/staff spaces (HUD, 2011).

The below table 7 lists the number of units that have converted to assisted living communities since the inception of the program. The number of units demonstrates the attempts by the federal government to look for ways to address the aging of older adults in affordable housing communities. Although, HUD funding conversion covers the capital cost, there are still significant burdens in providing supportive services in a consistent manner. In Kentucky, there have only been two HUD financed housing only communities for older adults, totaling 103 units that have converted to offer assisted living services.

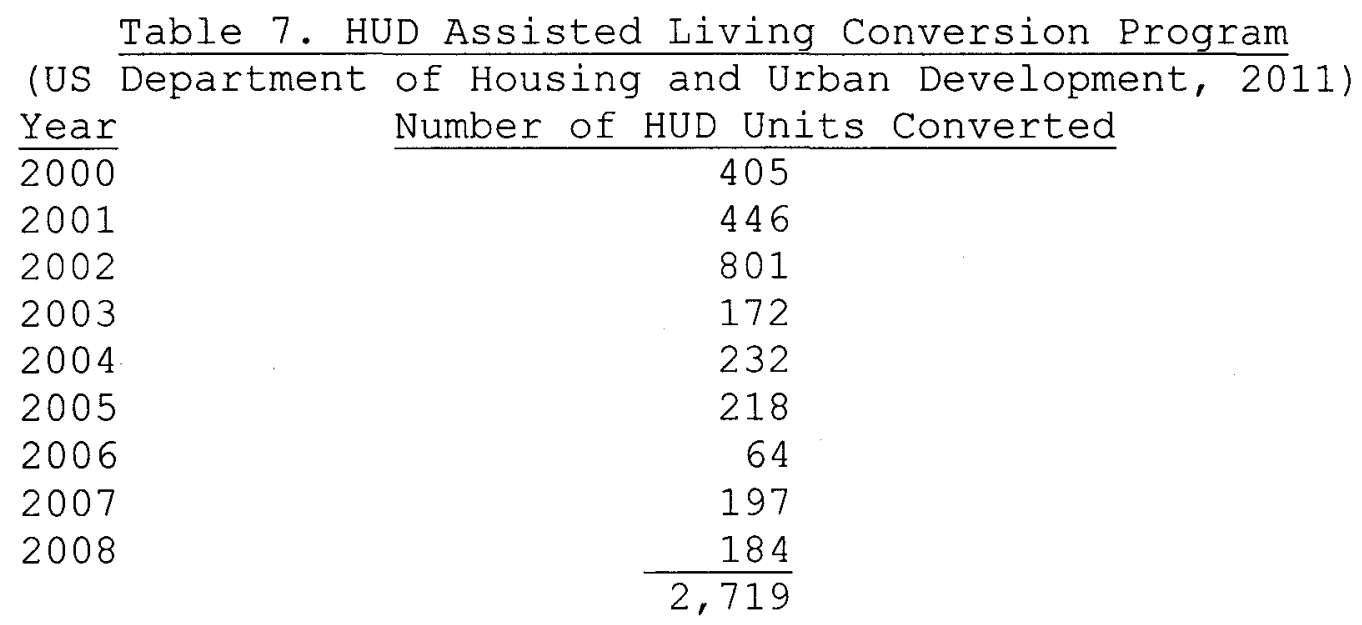

Funding for the supportive services must be provided by the owners, either directly or through a third party, 
such as Medicaid, SSI payments, State or Area Agency on Aging, etc. (HUD, 2011).

The Medicare program is a federal health insurance program for individuals 65 and over and certain disabled individuals under 65. Eligibility for Medicare requires that either the individual or the individual's spouse has worked enough months to qualify for Social security benefits.

Medicare covers home health care, and the same Medicare rules apply whether the individual is at home or in an assisted living facility. The Medicare program can pay for home health care only if the beneficiary is considered "homebound," based on the reasoning that a resident who is not homebound could travel to a hospital or clinic for routine health care. An assisted living resident is considered "homebound" if leaving the facility is a very difficult process. In determining whether a resident qualifies as "homebound," the resident is not penalized for leaving the facility to receive health care treatment or to attend an adult day care program.

The Medicare home health care benefit generally requires a need for skilled nursing care, or physical or speech therapy. Nursing care is considered "skilled" if a nursing service requires the expertise of a licensed nurse. 
For example, treatment of a wound or administration of an injection are skilled nursing services that qualify for Medicare reimbursement. On the other hand, bathing a resident, or helping a resident get dressed, are services that do not qualify for Medicare reimbursement. Medicare covers only those skilled nursing facility services that help a resident recover from an acute illness or injury. Medicare will not cover permanent, daily skilled nursing care. Generally nursing care must be needed six days a week or less. If nursing care is needed every day, Medicare can pay only if the daily nursing care will be needed for only a limited time-period - three or four weeks, for example.

As mentioned above, therapy services also must be "skilled" in order to qualify for Medicare payment. The expertise of a licensed physical therapist or certified speech therapist must be required.

If a resident requires skilled nursing services or skilled therapy, the Medicare home health benefit also may be able to provide the part-time assistance of a home health aide, as appropriate given the resident's care plan. Also, the Medicare home health benefit may provide medical supplies (such as catheters) or durable medical equipment 
(such as walkers), if the supplies or equipment also are part of the care plan.

Therefore, practically speaking, the Medicare program does not cover day-to-day assisted living costs. However, Medicare can be a useful benefit that may pay for certain services provided at the assisted living facility by a home health care agency, the same way that Medicare would pay for those same services if the individual resided in his or her own home.

The Assisted Living Federation of America encourages the promotion of affordable and accessible assisted living by teaming up with state and local governments in creating affordable housing innovations, such as tax credits or bond issues, and at the federal level using Housing and Urban Development (HUD) programs. Providers are also working with foundations, churches and other not-for-profit organizations to create affordable housing and services to help older adults. 


\section{CHAPTER VII}

\section{POLICY RECOMMENDATIONS}

The following policy recommendations for assisted living communities are intended to enhance the benefits that communities are providing to current and potential residents. The policy recommendations for these communities will increase their ability to accommodate aging in place and removing barriers to providing substantive and quality care.

\section{Expansion of Assistance with Self-Administration of}

\section{Medications}

Assisted living communities could offer more services and provide more help to residents by expanding on the types of assistance that communities can offer to residents with the self-administration of medications. Currently, state regulations prohibit communities from dispensing, measuring or handling the medication of a client. A regularly occurring example of the type of restriction this 
regulation prohibits is that if a pill were to fall from a residents' hand and accidentally drop on the floor, staff from the assisted living community are not allowed to pick the pill up and place it in the residents' hand. It must be placed in a container and the resident must pick it up and place it in their hand. Staff may steady or guide the hand of the resident, but may not touch the medication, as this would be seen as conveying a health service. By allowing assisted living communities greater latitude in providing assistance with self-administration of medications, this allows the community to better serve residents that may have an intermittent condition for which greater assistance with self-administration is needed. When greater assistance is needed, the burden of care for providing this assistance is placed on family members, hospitals or nursing homes. Implementation of this policy would benefit families of residents by alleviating the need to come by the community to administer a relatively small task.

Broadening the definition of assistance by allowing staff to better serve residents will enhance the quality of life and will foster longer aging in place in the assisted living communities. It includes: reminding and observing medications taken; opening medication's dosage packaging or 
pill planner to tip medication into the resident's hand, steadying the resident's hand and assisting with refills via telephone, fax or other electronic device. It does not include scheduling appointments, lab tests, X-rays or transportation. Staff may not touch the actual medication nor tip the medication from the original container. Staff may not put on medicated lotions, eye, ear or nasal drops.

\section{Personal Care Homes}

Kentucky should consider combining regulations for Personal Care Homes and Assisted Living Communities. As current regulations exist, the substantive distinction between the two long-term care options is the ability of the Personal Care home to directly administer medications to residents. Combining these regulations would remove a barrier that creates confusing in the industry as many other assisted living communities in other states are able to direction administer medications to residents (Legislative Budget and Finance Committee, 2008) (see Table 8). 
Table 8. States Allowing ALC Medication Administration (Legislative Budget and Finance Committee, 2008)

Arkansas

California

Connecticut

Delaware

District of Columbia

Florida

Idaho

Indiana

Iowa
Kansas

Maine

Maryland

Minnesota

Mississippi

Montana

Nebraska

Nevada

New Hampshire
New Jersey

New Mexico

North Dakota

Ohio

Rhode Island

South Dakota

Washington

wisconsin

Wyoming

\section{Financial Assistance and Affordability}

State and federal governments should provide

additional funding to assist lower income older adults with

the cost for housing and services in the assisted living

community. Kentucky state legislature allocates funding to

various community agencies through the Home and Community

Based Waiver Program (HCBW) to provide services to income

qualified older adults living in private homes throughout

the community. The services to these older adults in their

private homes are services typically provided in assisted

living communities. However, greater economies of scale

could be achieved by providing the same services to older

adults in a congregate living arrangement such as the assisted living community. Reallocating a significant

portion of HCBW funding for services to assisted living

communities could serve as an incentive for older adults

living in their home alone to move into an assisted living 
community and experience all the benefits, including socialization that an assisted living community offers. Savings on economies of scale, however, would be offset by the additional cost of housing more adults in the ALC.

The benefits of the assisted living community are largely unknown to older adults that cannot afford the monthly fees. Providing funding for service provision in the assisted living community could also delay hospitalization and nursing home placement and enhance the quality of life for the older adult.

Greater understanding and dialogue should take place between the assisted living and the nursing home community with regard to Medicaid funding. Many administrators and proponents of the nursing home industry argue that providing government assistance to assisted living communities will affect funding allocated to nursing homes. However, discussion should focus on removing barriers that are confusing to the general public and reserving nursing homes for those residents that truly need the care and services it provides. In a period of scarce resources when legislators and government bureaucrats are looking for cost-effective strategies to optimize housing and care for older adults, an assessment of the fiscal impact of changes in health benefit structures is advisable. 
There are currently no safeguards available to residents who deplete their assets and do not have sufficient income to pay the monthly assisted living fees. Aging in place in the community is no longer an option if the resident cannot pay.

There are many older adult housing communities which are owned and operated by local housing authorities or have financial assistance through the U.S. Department of Housing and Urban Development (HUD). Many of these communities have older adults who could benefit from assisted living services. Because of the unavailability of supportive services, many of these older adults are neglected or are required to move to alternative housing options to receive care. Without supportive services to assist residents through physical and mental decline, portions of HUD and local housing authority units are underutilized. Greater utilization could be achieved if HUD and the Department of Health and Human Services, which administers Medicare, could reach an agreement that would achieve mutually beneficial goals.

\section{Quality Meals}

Assisted living communities do not require the preparer of the meals to have any qualifications in food 
preparation or formal dietary training. While many residents in the assisted living communities appear to enjoy their meals and the social interaction during meals, there are no standards for the quality of meals prepared for the residents. Assisted living communities promote choice and independence and residents can choose not to have a meal if it is not appealing to them. However, assisted living communities could better serve residents by having staff that are formally trained. Better quality meals prepared by skilled cooks could aid in better health for residents and impacting their quality of life and aging in place.

\section{Consistent Diagnosis and Functional Needs Assessments}

Assisted living communities independently develop their assessment tools for selecting residents based on state regulation criteria; however, there is not a uniform consistent assessment tool used (see Appendix 3). State regulation identifies a minimum set of criteria that a potential resident must meet in order to be considered for admission, but, these criteria are vague and each community uses its own discretion in defining them. For example, one criterion to be met by a resident is that they must not be a danger to themselves. The definition of danger is 
defined as the physical harm or threat of physical harm to one's self or others which can have any number of inferences and implications. This vagueness causes confusion about what determines assisted living suitability. Having a uniform, consistent assessment tool and a clearly defined list of criteria will benefit potential residents, families and the general public in understanding what expectations the community has for residents.

\section{Skill Training}

The education requirements for managers of assisted living communities are, at a minimum, a high school diploma. There are ongoing requirements for annual inservice training, but the quality of training programs is at the discretion of the community. Assisted living communities can improve their capacity to manage resident decline by having standardized training for caregivers and managers. As residents decline and experience certain cognitive impairments, community staff can better identify potential residents and current residents that may have a tendency to wander. Aging in place is enhanced by the communities' ability to recognize the signs and provide better care. 
Hypotheses

The three hypotheses that guided this research study are as follows.

a. Supportive services to older adults are a benefit to the residents who live in ALCs.

b. Some ALCs are more accommodating to allow aging in place than others.

c. ALCs interpret their services apart from the continuum of care and accommodate aging place.

\section{Supportive services to older adults are a benefit the}

residents who live in AlCs. My research concludes that assisted living communities provide a benefit to the older adults who live in them. The benefits include 1)

socialization, 2) individualized attention for services relating to activities of daily living and 3) instrumental activities of daily living. Assisted living communities also benefit older adults with a secure, homelike environment that delays institutionalization for as long as possible. Each of the assisted living communities provides significant assistance to the quality of life for the older adults that would not otherwise be gained by living in the nursing home or some other living arrangement. The advantages of residing in an assisted living community are 
unique to its living arrangement, configuration of services and promotion of independence and self determination. The residents benefit from the assisted living community because of the promotion of independence while providing services to meet their needs. The unique, personalized attention that each resident receives is superior to independent living homes without personal care services and nursing homes.

\section{Some ALCs are more accommodating to allow aging in}

place than others. My research concludes that there are assisted living communities that are more accommodating to helping residents age in place within the community in which they reside. There are physical characteristics, management philosophy and the ratio of staff to residents that allow residents to maintain their home in some assisted living communities better than others. Although the most significant determinant in a community's ability to accommodating aging in place is state regulation, all of the communities in this research abided by it, there are some communities who are better positioned to provide both formal and informal supports. State regulation allows communities to provide services that meet the scheduled and unscheduled needs in activities of daily living and instrumental activities of daily living. Each community 
completes functional needs assessments of residents on, at a minimum, an annual basis. Frequently, functional needs assessments are completed whenever a resident returns from hospitalization, nursing home placement, or when staff observes out of the ordinary changes in their behavior. The purpose of these assessments is to more accurately determine what services are needed, how frequently, and, if residents have become a danger to themselves and have needs beyond the ability of the assisted living community to meet. State regulation largely determines what services assisted living communities are allowed to provide and what services are strictly prohibited. All assisted living communities provide the minimum services as required and several communities offer additional services such as incontinence care. While incontinence is a medical condition that often requires hospitalization or nursing home placement for treatment, the communities that do not offer this incontinence cleaning service do not require lease termination of their residents. There is no significant ability of any assisted living community to provide more accommodation to aging in place than any other community.

ALCs interpret their services apart from the continuum of care and accommodate aging place. My research concludes 
that managers interpret the role of their assisted living community as part of the continuum of care with nursing home placement as the next level of care needed for residents. The continuum of care model suggests a linear progression of disability. However, managers agree that residents do need temporary nursing home placement and frequently become better and return to the assisted living community. State regulation prohibits assisted living communities from providing health care related services to residents thereby predetermining their slot along the continuum. Notwithstanding their slot along the continuum, managers of the assisted living communities believe that they could provide some health care related services to residents better than nursing homes and further delay institutionalization. This increased move along the continuum would leave nursing home placement for those older adults whose health care needs are dire. 


\section{CHAPTER VIII}

\section{SUMMARY AND CONCLUSION}

Residents in the assisted living communities participating in this review have a high level of attention and personalized care as evidenced by numbers of staff, information gathered from the functional needs assessment and responses from managers. However, the quality of care in the assisted living community would need further evaluation. This is especially the case in light of state regulation having no qualification requirements for direct caregivers other than that the manager must have a high school diploma or GED. The quality of care in the assisted living community appears to be satisfactory as residents and families of residents maintain occupancy in these communities. But a review to evaluate quality outcomes is needed to determine if there could be better ways of providing care to residents.

Assisted living communities are labor intensive and are dependent upon direct caregivers to provide the daily 
services that residents need. Assisted living regulation does not require certain qualifications of staff nor are there requirements for certain numbers of direct caregivers per number of residents. Numbers of staff persons are determined by the manager of the community to meet the scheduled and unscheduled needs of the residents.

Assisted living communities are largely unaffordable to low- and moderate-income older adults. However, the monthly fees for residing in the assisted living community are substantially lower than the monthly cost of residing in a nursing home. Further evaluation is needed to determine the cost savings, if any, for residents that are inappropriately placed nursing homes and are receiving Medicaid assistance, but may benefit from the services in the assisted living community. Medicaid assistance could be provided to assisted living residents at lower rates than nursing home rates and the cost savings to Medicaid could be substantial.

Assisted living is unavailable to older adults who do not have the resources but who could benefit from this long-term care option. Literature review raises the question that some low- to moderate-income residents are inappropriately placed in nursing homes due to unavailability of assisted living communities or the lack 
of Medicaid funding for them. The lack of government assistance renders assisted living communities a beneficial yet unattainable resource for some in the long-term care industry.

While residents are able to age in place, to the extent of their financial resources, the quality of care in the assisted living community is undetermined. Regulation does not provide for benchmarks or quality outcome measures for the performance of the assisted living communities. This matter is further exacerbated by the absence of quality control measures for the ongoing in-service requirements as required by regulations.

In 2000, Kentucky legislators passed regulation authorizing assisted living communities. The regulation is enforced by the Kentucky Department of Assisted and Independent Living (DAIL). DAIL reviews compliance of regulation by annually reviewing all assisted living communities in Kentucky. To meet current and anticipated needs of older adults living in these communities, DAIL develops and proposes changes to regulations and recommends them to state legislators. In 2010, a revision to the regulation has expanded the concept and definition of providing assistance with self-administration of medications. This expansion will make additional benefits 
available to residents and will allow communities to better meet resident needs.

Assisted living communities can improve their benefit to older adults by providing government assistance to older adults without the financial resources to pay the monthly fees. Currently, the difference between personal care homes and assisted living communities is the administration of medications. This difference can be eliminated, thereby providing a more streamlined continuum of care for older adults that preserves nursing home placement for those that need more intensive services. Assisted living communities can improve by expanding diversity within the communities. Although most residents appear to be satisfied with living amongst other older adults that share the same values, culture and beliefs, it is not a reflection of a multicultural society where the differences are varied and complex. Assisted living communities appear to be a benefit for only a certain demographic and could expand by appealing to other groups who could benefit from the services in these communities.

Assisted living regulation in Kentucky is based on a social model which makes no allowance for assisted living communities to provide any medical services, including applying medicated ointments or lotions to residents. 
Residents in the assisted living communities appear to be happy and appreciative for the care and services they receive from the staff in these communities. Residents have the independence to come and go as they choose but very few residents have automobiles and most are dependent upon family or community transportation to medical appointments or social activities.

The services offered by the assisted living communities meet the personal care needs of the residents and allow them to remain at a high level of independence. By providing meals, bathing services, transportation to and from medical appointments, and assisting with the selfadministration of medications, these services aid residents to age in place. Two of the more fundamental tenets of the assisted living industry are that of independence and personal autonomy. These characteristics allows for resident choice with regard to their personal activities and to leave and enter the assisted living community at their own discretion. But due to the gradual onset of confusion and disorientation, it is important for assisted living communities to carefully screen and evaluate residents that may endanger themselves.

Managers of the assisted living communities expressed frustration at not being able to provide more assistance to 
residents when they become confused. Many believe that allowing assisted living communities to better assist with medications would allow many more residents to live safely within the community. Managers generally believe that their assisted living homes are helping residents have a much better quality of life as opposed to living at home or becoming institutionalized. They believe that they offer a better quality of care and are not encumbered by restrictive regulations such as those in the nursing home. Assisted living communities with few apartments and low resident to staff ratio are favored by these managers. Not only does it allow for staff to provide more personalized care and assistance to residents, managers believe the staff members enhance the family-like atmosphere in the community.

Despite the low resident to staff ratio that is common in the assisted living communities with fewer apartments, one of the administrative frustrations for managers are those occasions when a staff person is not able to work their shift. There is not a very large pool of ALC employees to choose from, to avoid overtime wages, while the community is required to have 24 -hour staff coverage to meet both scheduled and unscheduled needs of residents. 
Several managers note that Kentucky does not provide any Medicaid funding of services for residents. While they have not had to terminate any lease agreements with residents because of their inability to pay, they acknowledge that the benefit of living in the community is largely available to those residents and or their families that can afford the monthly fees.

Assisted living communities in Kentucky are making a significant impact to residents by providing access to those with sufficient means to afford the monthly fees. However, this impact is limited to the extent that resources allow residents to remain in the community. Communities are allowed to provide residents with services that assist with activities of daily living and instrumental activities of daily living: three meals and a snack available each day, schedule daily social activities and assist with the self-administration of medications. Kentucky's Medicaid program does not provide any funding for services for residents of assisted living communities, so monthly service fees are all privately paid. Assisted living communities provide housing and care services to residents who can no longer live at home alone, need some level of assistance to care for their personal needs, but 
do not require intensive therapy and care from nursing home placement.

Low resident to staff ratio and a centralized community and dining area with individual bedrooms along the perimeter and on the ground level floor appear to be the floor plan that is best to meet the scheduled and unscheduled needs of the community. Community staff is able to promptly respond to in a more efficient manner. The décor of these communities provides a homelike atmosphere for residents that help them to become acquainted with and to better adapt to community life. These communities also seem to be better suited to accommodate residents that have a high level of assistance with activities of daily living.

Kentucky regulation provides strict guidelines on the types of residents that are suited for the community. The Kentucky State Department of Aging and Independent Living annually reviews all certified assisted living communities and inspects for adherence to admission qualifications. Communities are prohibited from providing any medically related service to residents. Communities may offer assistance in self-administration of medication which range from reading instruction, opening of containers, steadying of the hand and placing medicine in the resident's open 
hand. However, staff is prohibited from organizing pill organizer or in anyway touching the medication.

The provision of some minor level of medically related service might help residents to live in the community longer or to prevent hospitalization, particularly when residents are mentally alert and otherwise mobile, but unable to hold medications in their hand.

Admission of residents is highly subjective and is based on the skill level and intuition of the administrator evaluating the resident for suitability. Evaluation of residents is usually done at the initial intake and not conducted over a period of time. It is possible for a resident to be at a substantial risk for wandering but might be having a relatively good day during an evaluation interview and might be deemed suitable for living in the community.

Residents in the community all appear to be happy and cared for by the staff. All of the communities were fully occupied which might infer that the assisted living communities are meeting a substantial need for these residents and their families.

Each of the assisted living communities was evaluated on the basis of their capacity to accommodate aging in place by asking questions as it relates to Personal 
Services, Meals and Social Interaction, Facility Policies and Physical Characteristics. Meals and social interaction, while important, appear to have less of an impact on aging in place than the other three areas. Each of the community administrators emphasized their desire to help residents maintain a high level of independence while keeping them safe and respecting their privacy. 


\section{REFERENCES}

Assisted Living Workgroup Steering Committee. 2003. Assuring Quality In Assisted Living: Guidance for Federal and State Policy, State Regulations and operations. Washington, D.C. American Association of Homes and Services for the Aging.

Aud, M.A. \& Rantz M. J. 2005. Admissions to Skilled Nursing Facilities From Assisted Living Facilities. Journal of Nursing Care Quality. 20, 1:6-25.

Ball, M.M., Perkins, M.M., Whittington, F.J., Hollingsworth, C., King, S.V. \& Combs, B.L. 2005. Independence in Assisted Living. Journal of Aging Studies. $18: 467-483$.

Barton, L. 1997. A Shoulder to Lean on: Assisted Living in the U.S. American Demographics. July, 44-51.

Babbie, E. 1998. The Practice of Social Research $\left(8^{\text {th }}\right.$ Edition). Belmont, CA: Wadsworth Publishing Company.

Burge, S. \& Street, D. 2009. Advantage and Choice: Social Relationships and Staff Assistance in Assisted Living. Journal of Gerontology: Social Sciences. 65B:358-369

Calkins, M. 1995. From Aging In Place To Aging In Institutions: Exploring Advances in Environments for Aging. The Gerontologist. 35:568-570.

Carder, P. C. 2002. The Social World of Assisted Living. Journal of Aging Studies, 16, 1:1-18.

Chapin. R., \& Dobbs-Kepper, D. 2001. Aging in Place in Assisted Living: Philosophy versus policy. The Gerontologist. $41: 43-50$. 
Cox, C. B. 2005. Community Care For an Aging Society: Issues, Policies and Services. New York, Spring Publishing Company.

Davis, A.H. \& Gerrard, C. 1993. Resident Satisfaction with Community Residential Care Placement. Research on Social Work Practice. 3, 1:91-103.

Day, T. 2002. About Assisted Living. Assisted Living Federation of America. Available. http://www.longtermcarelink. net/about_assisted_living. html

Eckert, J. K., Carder, P., Morgan, L., Frankowski C., \& Roth, E. 2009. Inside Assisted Living: The Search for Home. Baltimore, John Hopkins University Press.

Eckert, J. K., Zimmerman, S. \& Morgan, L. 2001. Connectedness in residential care: A qualitative perspective. Pp 292-316 in Zimmerman, S., Sloane, P. D. and Eckert, J. K. (Eds.). Assisted Living Needs, Practices and Policies in Residential Care for the Elderly. Baltimore: Johns Hopkins University Press.

Feingold E. \& Werby E. 1990. Supporting the Independence of Elderly Residents Through Control Over Their Environment. In Leon Pastalan (Ed.), Aging in Place: The Role of Housing and Social Supports. Binghamton, NY: The Hawthorne Press.

Frank J.B. 2002. The Paradox of Aging in Place in Assisted Living. Westport, CT: Bergin \& Garvey.

Gilderbloom, J. I., and Mullins, R. L. Jr. 1995. Elderly Housing Needs: An Examination of the American Housing Survey. International Journal of Aging and Human Development. 40, 1:57-72.

Gilderbloom, J. I. 2008. Invisible City: Poverty, Housing, and New Urbanism. Austin: University of Texas Press.

Gillespie, A.E. and Sloan, K.S. 1990. Housing Options and Services for Older Adults. Santa Barbara, CA: ABCCLIO. 
Glaser, B., \& Strauss, A. 1967. The Discovery of Grounded Theory. Chicago, IL: Aldine. Golant, S. 1992. Housing America's Elderly: Many Possibilities Few Choices. Newbury Park, CA: Sage Publications.

Golant, S. 1999. The Promise of Assisted Living. In B. Schwarz \& R. Brent (Eds.), Aging, Autonomy and Architecture: Advances in Assisted Living. Baltimore: The Johns Hopkins University Press.

Golant S. 2004. Do Impaired Older Persons With Health Care Needs Occupy U.S. Assisted Living Facilities? An Analysis of Six National Studies. Journals of Gerontology Series B: Psychological Sciences \& Social Sciences. 59B, 2:S68-S80.

Golant, S. \& Hyde, J., 2008. The Assisted Living Residence: A Vision for the Future. Baltimore. John Hopkins University Press.

Goldstein, A. 2001. Better than a nursing home? Time. August $13: 48-53$.

Greene, A., Hawes, C., Wood, M., and Woodsong, C. Winter 1997/1998. How do family members define quality in assisted living facilities? Generations. 21, 4:34-37.

Hawes, C. \& Phillips, C.D. 2000. High Service or High Privacy Assisted Living Facilities, Their Residents and Staff: Results from a National Survey. Beechwood, $\mathrm{OH}$ : Myers Research Institute. U.S. Department of Health and Human Services.

Hawes, C., Rose, M. and Phillips, C.D. 1999. National Study of Assisted Living for the Frail Elderly: Results from a National survey of Facilities. Beechwood, $\mathrm{OH}$ : Myers Research Institute. U.S. Department of Health and Human Services.

Kane, R. A. 2001. Long-Term Care and a Good Quality of Life: Bringing Them Closer Together. The Gerontologist. 41, 3:293-304.

Kane, R. \& Wilson, K. B. 2001. Assisted Living at the Crossroad: Principles for Its Future. Portland, OR; Jessie F. Richardson Foundation. 
Kentucky Assisted Living Facilities Association. 2010. Association Website http://www. kentuckyassistedliving.org/Requirements

Kentucky Department of Aging and Independent Living. 2010. Department Website. http://chfs.ky.gov/agencies/os/dail/ALC.htm

Kentucky Department of Medicaid Services. 2006. Department website. http://chfs.ky.gov/dms/

Lawton, M. 1980a. Environment and Aging. Monterey, CA: Brooks/Cole.

Lawton, M. 1980b. Housing for the Elderly: Residential Quality and Residential Satisfaction, Research on Aging. 2:309-328.

Legislative Budget and Finance Committee. 2008. State Efforts to Fund Assisted Living Services. Harrisburg, PA: Joint Committee of the Pennsylvania General As sembly.

Lustbader, W., \& Hooyman, N. 1994. Taking Care of Aging Family Members: A Practical Guide. New York: The Free Press.

Mollica. R. 2002. State Assisted Living Policy. Portland, ME: National Academy for State Health Policy.

Morgan, L.A., Eckert, J.K., Gruber-Balini, A.L. \& Zimmerman, S. 2004. Policy and Research Issues for Small Assisted Living Facilities. Journal of Aging \& Social Policy. 16, 4:1-16.

Mutran, E.J., S. Sudha, T. Desai and K. Long. 2001. Satisfaction with Care Among Elderly African American and White Residents of Adult Care Facilities. Research In Aging. 23, 1:61-82.

National Center for Assisted Living. 2001. Facts and Trends: The Assisted Living Sourcebook 2001. Washington, DC: National Center for Assisted Living. 
Regnier, V. 1999. The Definition and Evolution of Assisted Living within a Changing system of Long-Term Care. In B. Schwarz \& R. Brent (Eds.), Aging, Autonomy and Architecture: Advances in Assisted Living. Baltimore: The Johns Hopkins University Press.

Schwarz, B. \& Brent, R. 1999. Emerging Themes, Further Reflections. In B. Schwarz \& R. Brent (Eds.), Aging, Autonomy and Architecture: Advances in Assisted Living. Baltimore: The Johns Hopkins University Press.

Sherwood, S., Ruchlin H., Sherwood C. \& Morris S. 1997. Continuing Care Retirement Communities. Baltimore: The Johns Hopkins University Press.

Smith, D. B. 2003. Reinventing Care: Assisted Living in New York City. Nashville: Vanderbilt University Press.

Spitzer, W. J., Neuman, K. \& Holden, G. 2004. The Coming of Age for Assisted Living: New Options for Senior Housing and Social Work Practice. Social Work in Health Care. 38, 3:21-46.

Staff of the Rose Ames Senior Assisted Living Communities. www. nursinghomesmagazine.com. April 2006.

Stefanacci, R. G. \& Podrazik P.M 2005. Assisted Living Facilities: Optimizing Outcomes. Journal of the American Geriatrics Society. 53, 3:538-541.

Strauss, A. and Corbin J. 1990. Basics of Qualitative Research: Grounded Theory Procedures and Techniques. Newbury Park, CA: Sage Publications.

Struyk, R. J. 1976. The Housing Situation of Elderly Americans. Washington, D.C.: The Urban Institute Press.

The Assisted Living Workgroup, Assuring Quality in Assisted Living: Guidelines for Federal and State Policy, State Regulations and Operations. Report to the US Senate Special Committee on Aging. April 2003. http://www. alworkgroup.org 
Tinsley R. and Warren K. 1999. Assisted Living: The Current State of Affairs. In B. Schwarz \& R. Brent (Eds.), Aging, Autonomy and Architecture: Advances in Assisted Living. Baltimore: The Johns Hopkins University Press.

U.S. Census Bureau. 2011. Census Bureau Website. http://www.census.gov

U.S. Department of Health and Human Services. 2006. Centers for Medicare and Medicaid Website. http://www.cms.hhs.gov

U.S. Department of Housing and Urban Development, 2011. Department of Housing and Urban Development Website. http://www.hud.gov/offices/hsg/mfh/progdesc/alcp.cfm

U.S. Department Veterans Affairs, 2001. Department of Veterans Affairs Website. http://va.gov.

Wright, B. 2004. Assisted Living in the United States. AARP Public Policy Institute, Research Report. October, 2004.

Yamasaki, J. \& Sharf, B. 2011. Opting Out While Fitting In: How Residents Make Sense of Assisted Living and cope with Community Life. Journal of Aging Studies, $25,13-21$.

Yin R. 1984. Case Study Research: Design and Methods. Applied Social Research Methods Series, Volume 5. Beverly Hills: Sage Publications.

Yin, R. 1993. Application of Case Study Research. Applied Social Research Methods Series, 34. Newbury Park, CA: Sage Publications.

Zimmerman, S. Scott, A.C., Park, N.S., Hall, S.A., Wetherby, M.M., Gruber-Baldini, A.L., and Morgan, L.A. (March 2003). Social Engagement and its Relationship to Service Provision in Residential Care and Assisted Living. Social Work Research, Volume 27 1:6-18. 


\section{APPENDICES}

Appendix 1 - Informed Consent

Appendix 2 - Assisted Living Questionnaire

Appendix 3 - Functional Needs Assessments

Appendix 4 - Kentucky Assisted Living Regulation

Appendix 5 - Consumer Checklist 
Appendix 1 - Informed Consent 


\section{INFORMED CONSENT FORM}

You are invited to participate in a study of Aging in Place in Assisted Living Communities in Louisville, Kentucky. I hope to examine the policies and practices in each community that allow and accommodate residents to age in place. You were selected as a possible participant in this study because your community is certified by the Department of Aging and Independent Living as a state certified assisted living community in Louisville.

If you decide to participate, I will meet with you and or other staff that you designate and complete a questionnaire; take a tour of the facility while making general observations. I would ask questions of you and take hand written notes regarding the policies and practices of operating your assisted living community. The time for participating in this study would be a series of 3 to 5 interviews lasting approximately one hour each over a period of one to two weeks. The interviews will be conducted at a setting that is mutually agreeable to the participant and me.

There are no risks or discomforts that are anticipated from your participation in this study. Potential risks or discomforts include feelings while discussing the decline of aging residents care and those occasions when their decline would require a higher level of care beyond the assisted living community.

The benefits of participating in this study would be to advance the awareness and improve the understanding of how assisted living communities benefit the long-term care industry. Any information obtained in connection with this study and that can be identified with you will remain confidential and will be disclosed only with your permission.

Taking part in this study is voluntary. You may choose not to take part at all. If you decide to be in this study you may stop taking part at any time. You will be told about any changes that may affect your decision to continue in the study. Your decision whether or not to participate will not prejudice your future relationship with the 
Kentucky State Department of Aging and Independent Living (DAIL).

If you have any questions, please do not hesitate to contact me.

If you have any additional questions later, please contact me, James Wilson at 502-415-1248 or Dr. Steve Bourassa, Chair/Director, Department/School of Urban and Public Affairs at 502-852-5720.

You will be offered a copy of this form to keep.

You are making a decision whether or not to participate. Your signature indicates that you have read the information provided above and have decided to participate. You may withdraw at any time without penalty or loss of benefits to which you may be entitled after signing this form should you choose to discontinue participation in this study.

Signature

$\overline{\text { Date }}$

Signature

Date 
Appendix 2 - Assisted Living Questionnaire 


\section{Assisted Living Community}

\section{Subjective \& Research Questions}

The question guiding this research is:

\section{How are ALFs in Louisville aiding the long-term care industry by helping residents}

\section{to age in place.}

By exploring how ALFs are operating in Louisville, Kentucky, I want to examine how they allow residents to age in place. The four specific areas that will be examined are the personal services, nutritional/meals, facility policies and physical characteristics. These four areas are chosen because literature review has determined that these areas have the greatest impact on a facilities capacity to managing aging in place. I will explore how residents in these facilities are being helped to live in their homes with the need services to remain independent.

\section{Typical Field Questions for Four Areas}

\section{Personal services}

For ALFs to offer assistance with activities of daily living, having sufficiently qualified staff is essential. The questions in this area are design to reflect the capacity of the ALF to sufficiently serve residents in the facility. The administrators and directors of service coordination will be interviewed.

- What types of services do you provide?

- How are staff provided?

- What are the skill level and experience of staff?

- What is staff to resident ratio?

- How do residents request services?

- How often are services available?

- How can services be approved? 
- What staff are available overnight and weekends?

\section{Meals/Social Interaction}

Nutritional meals are vital for a residents' health. These questions reflect the ability of the ALF to provide adequate nourishment for residents. The setting for the provision of meals also encourages social interaction which aids in the residents' sense of well being. Healthy meals and social interaction help residents to feel comfortable in the ALF, thereby aiding aging in place. For these questions the administrators will be interviewed.

- How are meals prepared?

- How do track provision of meals for residents on special diets?

- Do you deliver meals to private apartments?

- How do you assist residents with feeding themselves?

- What are the qualifications of those preparing meals?

- How do residents interact?

- How are social activities scheduled for residents?

\section{Facility policies}

Policies governing admission and retention identify the boundaries for aging in place in each facility. These policies specify the characteristics of residents who may be served and the types of services that may be provided. Administrators and owner representatives will be interviewed for this section.

- What are your intake and retention policies?

- How do you evaluate the suitability of residents?

- Is it possible for a resident or their family member to request waiver or permission to keep the resident in their home when their needs are beyond what your policy allows?

- What are factors that have influenced the implementation of these policies?

Physical characteristics

The physical characteristics of the facility can promote or deter aging in place by design, accessibility and level of difficulty or ease to make structural modifications. 
- How accessible are common areas (recreation rooms, dining, laundry, etc.)?

- How do you allow alterations to the apartments?

- How are individual units identified?

- How many floors are in the building?

- What is the width of hallway and doorways?

- Are wheelchair accessible units available?

- Are their elevators in the facility? If so, where are they? 


\section{Research Question}

The questions guiding this research are as follows:

\section{Is this assisted living facility aiding the long-term care industry by helping} residents to age in place?

\section{Are some factors more important than others in promoting aging in place?}

When this research has been has been completed, it is anticipated that this study will inform the public policy debate on long-term health care and will increase the knowledge about assisted living facilities industry in Louisville and be generalizable throughout the state of Kentucky.

By exploring how ALFs are operating in Louisville, Kentucky, I want to examine how they allow residents to age in place. The four specific areas that will be examined are the personal services, nutritional/meals, facility policies and physical characteristics. These four areas are chosen because literature review has determined that these areas have the greatest impact on a facilities capacity to managing aging in place. I will explore how residents in these facilities are being helped to live in their homes with the need services to remain independent.

Subjective Questions for Interviewees

The questions in this section are designed to get some subjective view of how well the interviewees feel the facility is responding to the needs of residents.

a. How well or poorly do you think your assisted living facility helps residents to age in place?

\section{$\begin{array}{lllll}\text { Very Well Well } & \text { Adequate Poorly }\end{array}$}

b. What do you think are the areas of strength of your facility?

1. Very suitable community for persons with short-term mobility.

2. Small hallways.

3. Very low resident to staff ratio.

4. Individualized care and attention for residents.

5. Socialization with staff and other residents. 
6. Home cooked meals.

7. Low staff turnover.

8. Staff are allowed to eat with residents to enhance the dining experience.

c. What do you think are the areas of weakness of your facility?

d. How would you rate the adequacy of your staff experience?

Very well Well Adequate Poor Very poor

e. How often are you requested to make changes in facility policies?

1-5/year 6-10/year 11-15/year 15-20/year 21+/year

f. How often are you requested to make changes in physical characteristics of your facility?

1-5/year 6-10/year 11-15/year $15-20 /$ year $21+/$ year

g. How would you rate the quality of life of residents in your facility?

Verywell Well Adequate Poor Very poor

h. How would you rate the provision and delivery of meals in your facility?

Verywell Well Adequate Poor Very poor

i. How would you rate the provision personal services to residents?

Very well Well Adequate Poor Very poor

j. What do you think of the policies of the facility?

Verywell Well Adequate Poor Very poor

k. What changes, if any, do you feel need to be changed?

1. Why do you think residents chose to live in your facility?

i. Price

ii. Services

iii. Meals

iv. Amenities

v. Activities

vi. Location

vii. Residents

viii. Other

m. What do you think of the physical characteristics of the facility? Verywell Well Adequate Poor Very poor

n. What is your sense that residents feel that they are members of a community in your facility?

Very Favorable Favorable Neutral Unfavorable Very Unfavorable 
o. What are the most common reasons residents are discharged from your assisted living facility?

i. Death

ii. Hospitalization

iii. Other ALF

iv. Home

v. Other

p. What improvements do you feel like should be made in the laws governing Kentucky's assisted living facilities industry?

q. Do you see assisted living facilities as a trend for the future?

r. Do you see it as a good solution for the care of older adults?

s. What are major benefits of assisted living facilities from a national public policy perspective? 
Appendix 3 - Eunctional Needs Assessments 


\section{Functional Needs Assessment}

Applicant Name:

Date:

Interviewer Name:

Where do you live?

How long have you lived there?

Are you married?

Do you have children (names and addresses)?

- Nos
Single
Widowed
Yes

How often do you see your children?

Who helps the most?

Are you able to dress yourself?

Do you need help putting on any article of clothing?

Do you need help with TED hoses?

Do you need help tying your shoes?

Do you need help with buttons, zippers?

Are you able to bathe yourself?

Do you need help getting in and out of the tub?

Do you need help with washing your back?

Do you need help with washing your feet?

Do you have trouble feeding yourself?

Do you need food cut up for you?

Do you need a special diet?

Do you have trouble walking? o Wheelchair

Can you walk a block?

Can you climb stairs?

Are you able to move from your bed to a chair without assistance?

Do you have any trouble controlling your bowels

or bladder? (If yes, specify:

Occasional accidents?

Difficulty getting to the bathroom on time?

If pads are worn, can you handle these yourself?

Does this problem keep you from going places

you want to go?

Do you have a problem with your memory?

What is the day of the week?

What date is it?

What is the name of this building?

What is your telephone number or address?

How old are you?

When were you born?

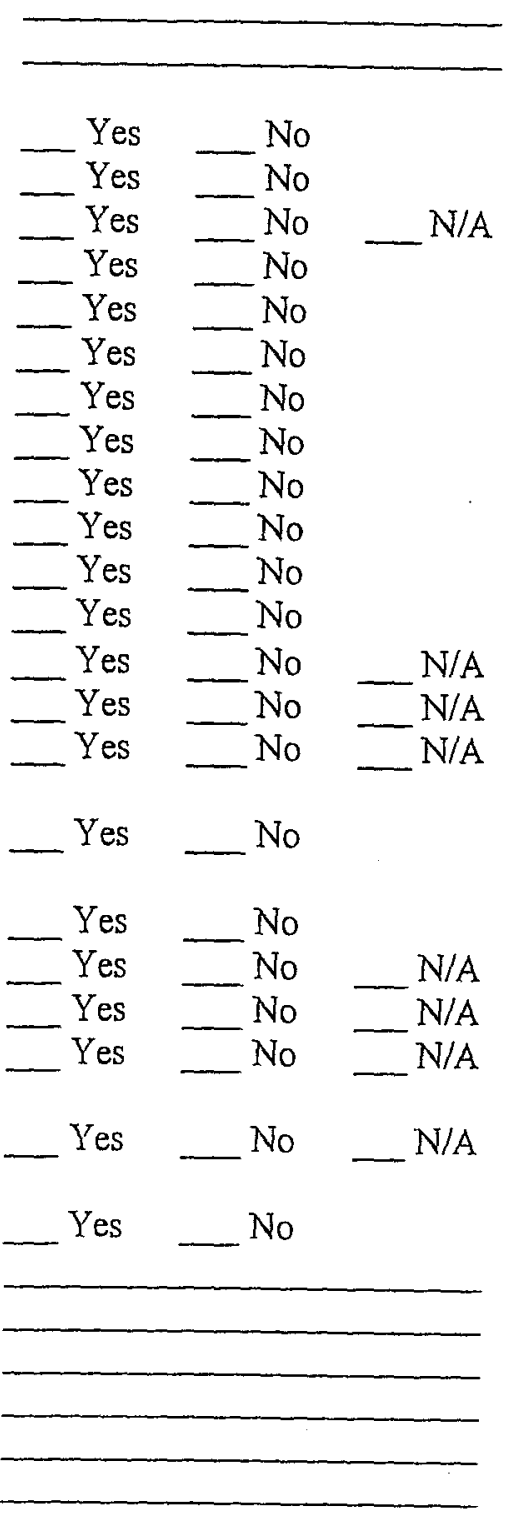


Who is the President of the United States?

What is your mother's maiden name?

Subtract 3 from 20 and keep subtracting 3 from

each new number. $(20,17,14,11,8,5,2)$

Who is your doctor?

How often do you see your doctor?

How do you get to the doctor?

Do you take medicines?

Do you order your own medicines?

Do you set up a pill box or does someone else?

Are you able to remember to take your medicines as prescribed?

Do you take insulin?

If yes, do you fill your own syringes?

Do you do your own injections?

Have you had any recent hospitalizations?

Have you ever been hospitalized for emotional problems?

Do you do your own shopping?

Do you drive a car?

Do you do your own housekeeping?

Do you do your own laundry?

If no, who helps you?

Do you do your own cooking?

Do you receive assistance from an outside agency?

If yes, what agency or agencies?

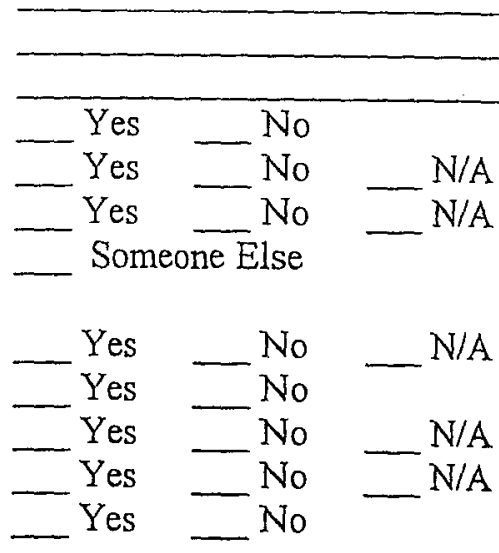

Y Yes _ No

\begin{aligned} Yes & No \\ Yes & No \\ No & \\ Yes & $-{ }^{\text {No }} \\$\hline Yes & - No $_{\text {No }}$ N/A \\ \hline Yes & N/A \end{aligned}

Observations \& Recommendations: 
CLIENT :

Mobility

- 1. Independent

- 2. Requires stand-by assist during ambulation in hallway.

- 3. Requires stand-by assist and/or minimal intermittent Weight bearing assist during ambulation.

\section{Transfers}

(moving in and out of bed or chair)

- 1. Independent

- 2. Requires stand-by assist during transfers.

- 3. Requires weight-bearing support of one during transfers.

Dining/eating

- 1. Independent

- 2. Requires minimal assistance with cutting food, open containers.

- 3. Requires intermittent physical or verbal cueing during meals.

\section{Grooming}

(includes shaving, shampooing hair, \& nail care)

- 1. Independent

- 2. Requires monitoring/reminders for general appearance.

- 3. Requires assistance but participates with direction \& supervision.

Medications

- 1. Independent

- 2. Reminders -
Assessment by:

Date:

Personal Hygiene (partial bath, oral hygiene)

- 1. Independent

- 2. Requires monitoring

- 3. Requires assistance but participates with direction and supervision.

Bathing

- 1. Independent.

- 2. Only requires assistance to get in and - out of tub or shower.

- 3. Requires partial assistance with bathing, i.e., one part of body.

- 4. Requires assistance with bathing more than one part of body.

Dressing

- 1. Independent

- 2. Requires assistance with clothing selection and/or getting clothes out for dressing.

- 3. Requires minimal assistance with dressing, i.e., buttons, zippers, tying shoes, socks/stockings.

- 4. Requires assistance with dressing and undressing.

Toileting

- 1. Independent.

- 2. Requires directions/supervision to get to toilet on time.

- 3. Requires assistance in bathroom with protective undergarments used for incontinence and/or requires assistance with managed incontinent care. 
Instrumental Activities of Daily Living

- 1. Independent

- 2. Requires assistance with

- 


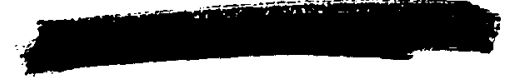

Activity

$\begin{array}{lll}\text { Client does } & \text { Needs } & \text { Other } \\ \text { Alone } & \text { Assistance }\end{array}$

Self Administration of medication

Transportation

Other

Frailty - Overall Physical ability

Behavior - Physical/Verbal

Wandering risk? yes no moderate 


\section{CLIENT ASSESSMENT}

Client Name: Prefers to be called:

Background Information:

Attitude toward move to ALC:

Living situation prior to moving into ALC:

Occupation:

Education:

Military service:

Former places of residence/travel:

Community involvement:

Daily activities: From the list below, mark the activities that the client can regularly accomplish alone. Mark the activities where assistance is needed; indicate if adaptive devices are needed.

Activity

Client

Dressing

Bathing

Eating

Grooming

Bowel care/maintenance

Bladder care/maintenance

Ambulation

Transfers: bed to chair, etc.

Communication

Safety

Socializing with peers
Does Alone

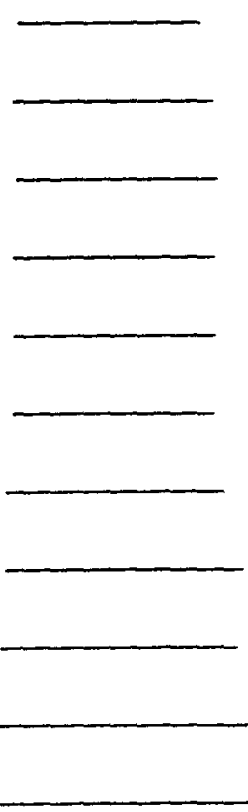

Needs

Assistance

Other

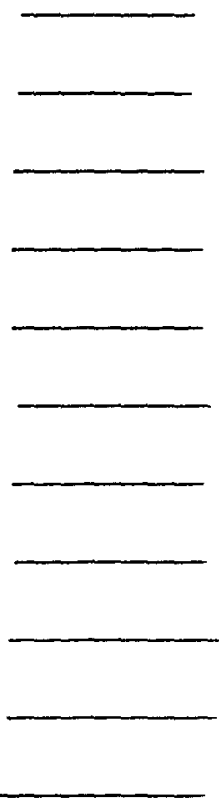

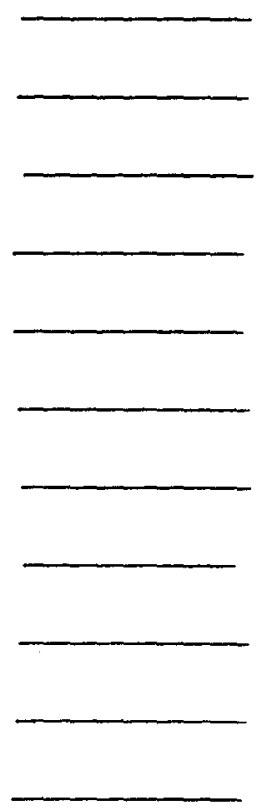




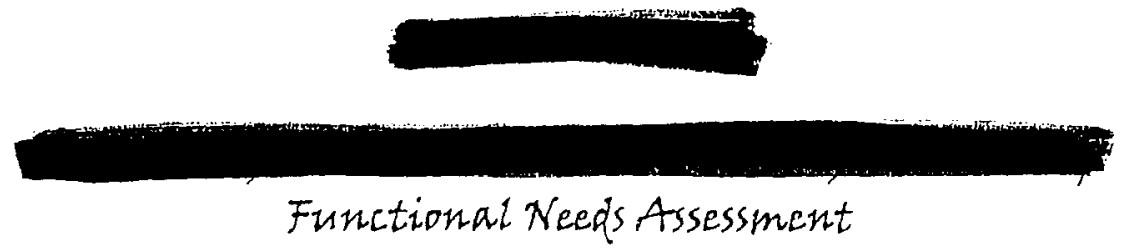

Name of Client:

Suite \#:

Date:

\section{GROOMING}

Please check here if the Client needs assistance but declines this service:

Client initials:

Please check here if the Client is independent and doesn't need this service:

Assistance Definitions:

Reminders - Staff reminds client to perform grooming.

Setup - Staff makes ready' grooming items and products.

Physical Hands-on or Standby Assistance - Staff provides reminders, setups, and physical hands-on or standby assistance.

, Type of Assistance $\square$ Reminders $\square$ Setup $\square$ Physical Hands-on or Standby Assistance

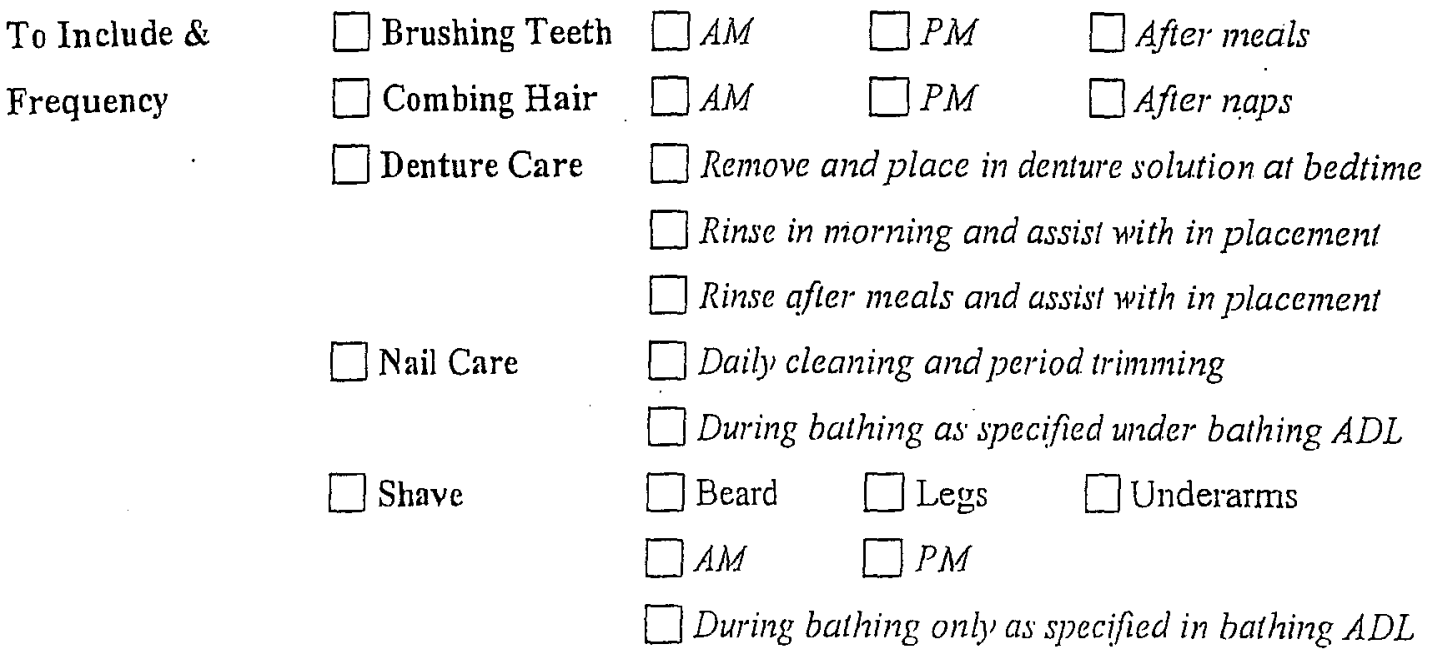

Comments/Special Instructions for Grooming: 


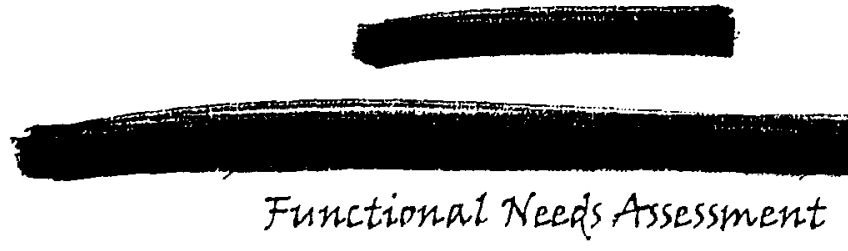

Name of Client:

Suite \#:

Date:

\section{TRANSFERRING}

Please check here if the Client needs assistance but declines this service:

Client initials:

Please check here if the Client is independent and doesn't need this service:

Assistance Definitions:

Reminders - Staff reminds client to use handrails, grab bars, etc. when transferring, or to use equipment, such as walker.

Set-up - Staff places transfer aid, such as a walker or wheelchair, next to the client for easy access.

Physical Hands-on or Standby' Assistance - Staff provides reminders, setups, and physical hands-on or standby assistance.

Type of Assistance $\square$ Reniinders $\square$ Setup $\square$ Physical Hands-on or Standby Assistance

To Include \& $\quad \square$ Daily when client is out of living unit

Frequency $\quad \square$ Daily per client requests

$\square$ Getting in and out of bed

$\square$ Getting in and out of the shower/whirlpool tub

$\square$ Other, specify:

Equipment used $\square$ None $\square$ Wheelchair $\square$ Walker $\square$ Scooter $\square$ Other:

Comments/Special Instructions for Transferring: 


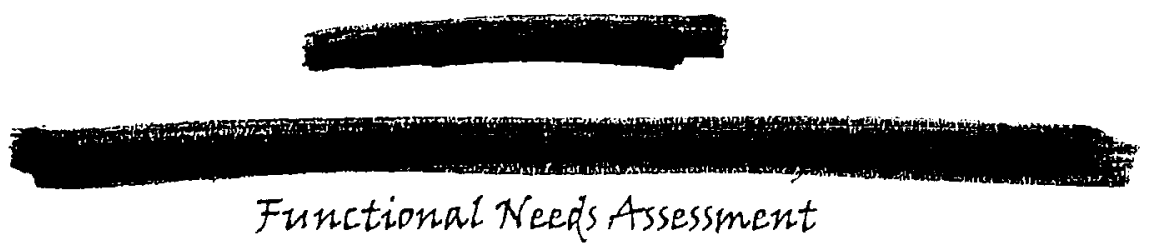

Name of Client:

Suite \#:

Date:

\section{TOILETING}

Please check here if the Client needs assistance but declines this service:

Client initials:

Please check here if the Client is independent and doesn't need this service:

\section{Assistance Definitions:}

Reminders -Staff reminds client from time to time.

Setup - Staff opens and closes doors, assures that toilet paper is available and within reach, and makes ready the client's own continence care products and supplies.

Physical Hands-on or Standby Assistance - Staff provides reminders, setups and physical hands-on or standby assistance.

Type of Assistance $\square$ Reminders $\square$ Setup $\square$ Physical Hands-on or Standby Assistance

Frequency $\quad \square$ During each loileting activity made know'n to staff

Per client's own established schedule as indicated below'

Schedule

$$
\begin{array}{ll}
\square \text { Upon rising in morning } & \square \text { Prior to retiring in evening } \\
\square \text { Before meals } & \square \text { Afler meals } \\
\square \text { During the night only } & \square \text { Other, specify: }
\end{array}
$$

Continence products: $\quad \square$ None $\quad \square$ Pads $\quad \square$ Briefs

When are products used: $\square$ Daytime $\square$ Night only $\square$ Day and Night $\square$ Outings Comments/Special Instructions for Toileting: 


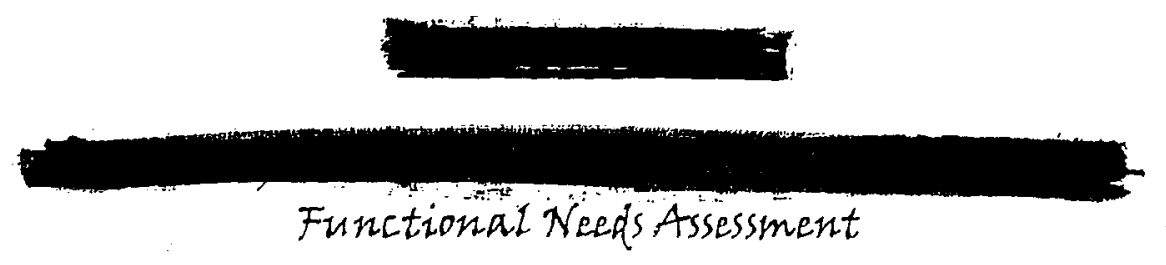

Name of Client: Suite \#: Date:

\section{EATING}

Please check here if the Client needs assistance but declines this.service: Client initials: Please check here if the Client is independent and doesn't need this service:

\section{Assistance Definitions:}

Reminders - Staff reminds client about meal times, snack times and location.

Setup - Staff sets up items, including opening containers, placing straw in beverage, placing hot beverages in specified location, cutting up food, or other make-ready' directions the client may specify'. Physical or Standby Assistance - Staff provides reminders, setup and physical hands-on or standby assistance. This may include lifting cups and spoons, wiping the mouth, or other similar assistance needed to complete the meal or snack.

Type of Assistance $\square$ Reminders $\square$ Setup $\square$ Physical Hands-on or Standby Assistance

Frequency $\square$ Daily each meal $\square$ Dailybreakfast $\square$ Dailylunch $\square$ Dailydinner $\square$ Snacks $\square$ Upon client request only

Add food likes/dislikes here from Application:

Comments/Special Instructions for Eating: 


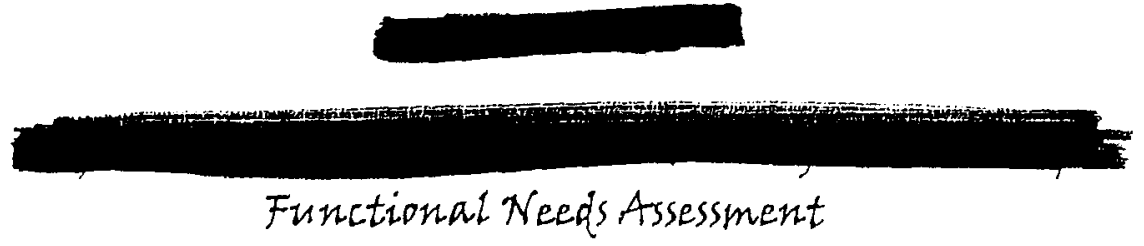

Name of Client:

Suite \#: Date:

\section{Assistance with Self-Administration of Medication}

Please check here if the Client needs assistance but declines this service: Client initials:

Please check here if the Client is independent and doesn't need this service:

\section{Assistance Definitions:}

Reminders - Staff reminds the client to take medications.

Reading the Label - Staff reads the medication's label.

Confirmation - Staff confirms the medication is being taken by the client for whom it is prescribes.

Opening - Staff opens the dosage packaging or medication container, but does not removing or handling the actual medication.

Storage - Staff stores the medication in a mamer that is accessible to the client. Pursuant

policy and procedure, storage shall be in the bathroom vanity drawer which is lockable, and for which the client shall have a key to ensure continuous accessibility to his/her medication.

Communication - Staff makes available the means of communicating with the client's physician and pharmacy for prescriptions by telephone, facsimile, or other electronic device.

\section{PHYSICIAN PRESCRIBED MEDICATION}

List all physician-prescribed medication the client takes and with which he/she will need assistance with self-administration. Please include the following information:
a. Name of the medication;
b. Route (i.e., by mouth)
c. Dosage;
d. Frequency to be taken; and,
e. Time of day it is to be taken.

1. $\square$ Reminders $\square$ Reading the Label $\square$ Confirmation $\square$ Opening $\square$ Storage $\square$ Communication 2. $\square$ Reminders $\square$ Reading the Label $\square$ Confinmation $\square$ Opening $\square$ Storage $\square$ Communication 3.

$\square$ Reminders $\square$ Reading the Label $\square$ Confinmation $\square$ Opening $\square$ Storage $\square$ Communication 
Functional Needs Assessment

Name of Client:

Suite \#:

Date:

4.

$\square$ Reminders $\square$ Reading the Label $\square$ Confirmation $\square$ Opening $\square$ Storage $\square$ Communication Playsician-prescribed medication, continued...

5.

$\square$ Reminders $\square$ Reading the Label $\square$ Confirmation $\square$ Opening $\square$ Storage $\square$ Communication

6.

Reminders $\square$ Reading the Labe] $\square$ Confirmation $\square$ Opening $\square$ Storage $\square$ Communication

7.

$\square$ Reminders $\square$ Reading the Label $\square$ Confirmation $\square$ Opening $\square$ Storage $\square$ Communication

8.

$\square$ Reminders $\square$ Reading the Label $\square$ Confirmation $\square$ Opening $\square$ Storage $\square$ Communication 9.

$\square$ Reminders $\square$ Reading the Labe] $\square$ Confirmation $\square$ opening $\square$ Storage $\square$ Communication 10.

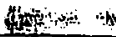

$\square$ Reminders $\square$ Reading the Label $\square$ Confirmation $\square$ Opening $\square$ Storage $\square$ Communication

\section{NON PHYSICIAN-PRESCRIBED OVER-THE-COUNTER MEDICATIONS}

Assistance definitions are the same as stated above.

List all over-the-counter medications, including topical ointments and medicated lotions, with

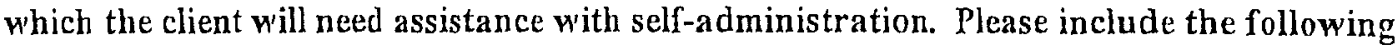
information:

a. Name of the medication;

b. Route (i.e., by' mouth)

c. Quantity/dose to be taken;

d. Frequency to be taken; and

e. Time of day it is taken.

1

$\square$ Reminders $\square$ Reading the Label $\square$ Confirmation $\square$ opening $\square$ Storage $\square$ Communication

2.

$\square$ Reminders $\square$ Reading the Label $\square$ Confirmation $\square$ Opening $\square$ Storage $\square$ Communication 


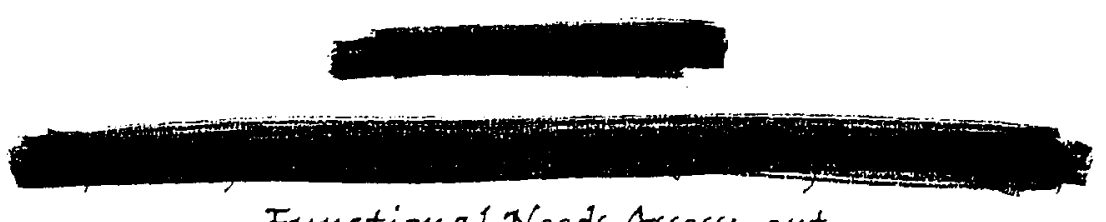

Functional Needs Assessment

Name of Client:

Suite \#:

Date:

3.

$\square$ Reminders $\square$ Reading the Label $\square$ Confirmation $\square$ Opening $\square$ Storage $\square$ Communication

4.

$\square$ Reminders $\square$ Reading the Label $\square$ Confirmation $\square$ Opening $\square$ Storage $\square$ Communication 5.

$\square$ Reminders $\square$ Reading the Label $\square$ Confirmation $\square$ Opening $\square$ Storage $\square$ Communication 6.

$\square$ Reminders $\square$ Reading the Label $\square$ Confirmation $\square$ Opening $\square$ Storage $\square$ Conmunication 7.

$\square$ Reminders $\square$ Reading the Label $\square$ Confirmation $\square$ Opening $\square$ Storage $\square$ Communication

\section{Comments/Special Instructions for Assistance with Self-Administration of Medication:}




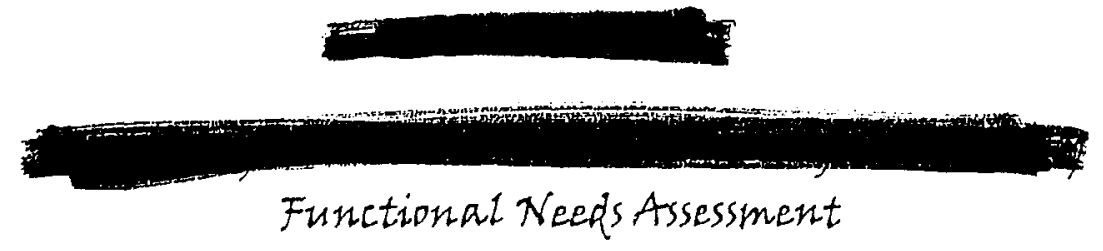

Name of Client:

Suite \#:

Date:

\section{INSTRUMENTAL ACTIVIES OF DAILY LIVING (IADLs)}

Please check each of the applicable IADLs with which the client will require assistance under the Monthly Fee and, if applicable, as an additional service under the Fee Structure.

Housekeeping: $\quad \square$ Under Monthly Fee

Additional Service - please specify:

Laundry: $\quad \square$ Under Monthly Fee

Additional Service - please specify:

Transportation: $\square$ Under Monthly Fee

Additional Service - please specify:

Chores:

Under Monthly Fee (as mutually agreed upon between and client)

Additional Service - please specify: 


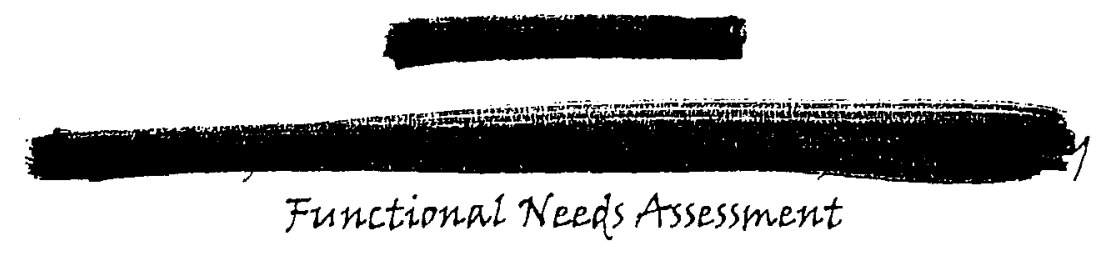

Name of Client:

Suite \#:

Date:

Clerical Assistance: $\square$ Under Monthly Tee

Additional Service - please specify:

Shopping: $\quad \square$ Under Monthly Fee

Additional Service - please specify:

FUNCTIONAL NEEDS ASSESSMENT ACKNOWLEDGEMENT:

I acknowledge this completed FNA is an accurate account of my assistance needs and my desires as represented by miy' signature below.

Client signature: Date:

Staff signature: Date:

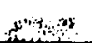


Appendix 4 - Kentucky Assisted Living Regulation 
194A.700 Definitions for KRS 194A.700 to 194A.729.

As used in KRS 194A.700 to 194A.729:

(1) "Activities of daily living" means normal daily activities, including bathing, dressing, grooming, transferring, toileting, and eating;

(2) "Assistance with activities of daily living and instrumental activities of daily living" means any assistance provided by the assisted-living community staff with the client having at least minimal ability to verbally direct or physically participate in the activity with which assistance is being provided;

(3) "Assistance with self-administration of medication," unless subject to more restrictive provisions in an assisted-living community's policies that are communicated in writing to clients and prospective clients, means:

(a) Assistance with medication that is prepared or directed by the client, the client's designated representative, or a licensed health care professional who is not the owner, manager, or employee of the assisted-living community. The medication shall:

1. Except for ointments, be preset in a medication organizer or be in a single dose unit;

2. Include the client's name on the medication organizer or container in which the single dose unit is stored; and

3. Be stored in a manner requested in writing by the client or the client's designated representative and permitted by the assisted-living community's policies;

(b) Assistance by an assisted-living community staff person, which includes:

1. Reminding a client when to take medications and observing to ensure that the client takes the medication as directed;

2. Handing the client's medication to the client, or if it is difficult for the client or the client requests assistance, opening the unit dose or medication organizer, removing the medication from a medication organizer or unit dose container, closing the medication organizer for the client, placing the dose in a container, and placing the medication or the container in the clients hand;

3. Steadying or guiding a client's hand while the client is self-administering medications; or

4. Applying over-the-counter topical ointments and lotions;

(c) Making available the means of communication by telephone, facsimile, or other electronic device with a licensed health care professional and pharmacy regarding a prescription for medication;

(d) At the request of the client or the client's designated representative, facilitating the filling of a preset medication container by a designated representative or licensed health care professional who is not the owner, manager, or employee of the assisted living community; and

(e) None of the following: 
1. Instilling eye, ear, or nasal drops;

2. Mixing compounding, converting, or calculating medication doses;

3. Preparing syringes for injection or administering medications by any injection method;

4. Administrating medications through intermittent positive pressure breathing machines or a nebulizer;

5. Administrating medications by way of a tube inserted in a cavity of the body;

6. Administrating parenteral preparations;

7. Administrating irrigations or debriding agents used in the treatment of a skin condition; or

8. Administrating rectal, urethral, or vaginal preparations;

(4) "Assisted-living community" means a series of living units on the same site certified under KRS 194A.707 to provide services for five (5) or more adult persons not related within the third degree of consanguinity to the owner or manager;

(5) "Client," "resident," or "tenant" means an adult person who has entered into a lease agreement with an assisted-living community;

(6) "Danger" means physical harm or threat of physical harm to one's self or others;

(7) "Department" means the Department for Aging and Independent Living;

(8) "Health services" has the same meaning as in KRS 216B.015;

(9) "Instrumental activities of daily living" means activities to support independent living including but not limited to housekeeping, shopping, laundry, chores, transportation, and clerical assistance;

(10) "Living unit" means a portion of an assisted-living community occupied as the living quarters of a client under a lease agreement;

(11) "Mobile nonambulatory" means unable to walk without assistance, but able to move from place to place with the use of a device including but not limited to a walker, crutches, or wheelchair;

(12) "Plan of correction" means a written response from the assisted-living community addressing an instance cited in the statement of noncompliance;

(13) "Statement of danger" means a written statement issued by the department detailing an instance where a client is a danger; and

(14) "Statement of noncompliance" means a written statement issued by the department detailing an instance when the department considers the assisted-living community to have been in violation of a statutory or regulatory requirement.

Effective: July 15,2010

History: Amended $2010 \mathrm{Ky}$. Acts ch. 36, sec. 1, effective July 15, 2010. -- Amended $2007 \mathrm{Ky}$. Acts ch. 24, sec. 7, effective June 26, 2007. -- Amended 2005 Ky. Acts ch. 99, sec. 161, effective June 20, 2005. -- Created $2000 \mathrm{Ky}$. Acts ch. 141, sec. 1, effective July 14, 2000. 


\section{A.703 Requirements for living units.}

(1) Each living unit in an assisted-living community shall:

(a) Be at least two hundred (200) square feet for single occupancy, or for double occupancy if the room is shared with a spouse or another individual by mutual agreement;

(b) Include at least one (1) unfurnished room with a lockable door, private bathroom with a tub or shower, provisions for emergency response, window to the outdoors, and a telephone jack;

(c) Have an individual thermostat control if the assisted-living community has more than twenty (20) units; and

(d) Have temperatures that are not under a client's direct control at a minimum of seventy-one (71) degrees Fahrenheit in winter conditions and a maximum of eighty-one (81) degrees Fahrenheit in summer conditions if the assisted-living community has twenty (20) or fewer units.

(2) Each client shall be provided access to central dining, a laundry facility, and a central living room.

(3) Each assisted-living community shall comply with applicable building and life safety codes as determined by the building code or life safety code enforcement authority with jurisdiction.

Effective: Iuly 15,2010

History: Amended $2010 \mathrm{Ky}$. Acts ch. 36, sec. 2, effective July 15, 2010. -- Created 2000 Ky. Acts ch. 141, sec. 2, effective July 14, 2000. 
194A.705 Services to be provided to assisted-living community clients.

(1) The assisted-living conmunity shall provide each client with access to the following services according to the lease agreement:

(a) Assistance with activities of daily living and instrumental activities of daily living;

(b) Three (3) meals and snacks made available each day;

(c) Scheduled daily social activities that address the general preferences of clients; and

(d) Assistance with self-administration of medication.

(2) Clients of an assisted-living community may arrange for additional services under direct contract or arrangement with an outside agent, professional, provider, or other individual designated by the client if permitted by the policies of the assisted-living community.

(3) Upon entering into a lease agreement, an assisted-living community shall inform the client in writing about policies relating to the contracting or arranging for additional services.

(4) A client issued a move-out notice shall receive the notice in writing and the assisted-living community shall assist each client upon a move-out notice to find appropriate living arrangements. Each assisted-living community shall share information provided from the department regarding options for alternative living arrangements at the time a move-out notice is given to the client.

(5) An assisted-living community shall complete and provide to the client:

(a) Upon move-in, a copy of a functional needs assessment pertaining to the client's ability to perform activities of daily living and instrumental activities of daily living; and

(b) After move-in, a copy of an updated functional needs assessment pertaining to the client's ability to perform activities of daily living and instrumental activities of daily living.

Effective: July 15, 2010

History: Amended $2010 \mathrm{Ky}$. Acts ch. 36, sec. 3, effective July 15, 2010. -- Amended $2007 \mathrm{Ky}$. Acts ch. 24, sec. 8, effective June 26, 2007. -- Amended $2005 \mathrm{Ky}$. Acts ch. 99, sec. 162, effective June 20, 2005. -- Created 2000 Ky. Acts ch. 141, sec. 3, effective July 14, 2000. 
194A.707 Certification -- Administrative regulations -- Accreditation by other organizations - Fees -- Compliance.

(1) The Cabinet for Health and Family Services shall establish by the promulgation of administrative regulation under KRS Chapter $13 \mathrm{~A}$, an initial and annual certification review process for assisted-living communities. This administrative regulation shall establish procedures related to applying for, reviewing, and approving, denying, or revoking certification, as well as the conduct of hearings upon appeals as governed by KRS Chapter 13B.

(2) An on-site visit of an assisted-living community shall be conducted by the cabinet:

(a) As part of the initial certification review process;

(b) On a biennial basis as part of the certification review process if during or since the previous certification review an assisted-living community has not received:

1. Any statement of danger, unless withdrawn by the cabinet; or

2. A finding substantiated by the cabinet that the assisted-living community delivered a health service; and

(c) Within one (1) year of the date of the previous certification review if during or since the last certification review an assisted-living comnunity has received:

1. Any statement of danger that was not withdrawn by the cabinet; or

2. A finding substantiated by the cabinet that the assisted-living community delivered a health service.

(3) No business shall market its service as an assisted-living community unless it has:

(a) Filed a current application for the business to be certified by the department as an assisted-living community; or

(b) Received certification by the department as an assisted-living community.

(4) No business that has been denied or had its certification revoked shall operate or market its service as an assisted-living community unless it has:

(a) Filed a current application for the business to be certified by the department as an assisted-living community; and

(b) Received certification as an assisted-living community from the department. Revocation of certification may be grounds for the department to not reissue certification for one (1) year if ownership remains substantially the same.

(5) No business shall operate as an assisted-living community unless its owner or manager has:

(a) Filed a current application for the business to be certified as an assisted-living community by the department; and

(b) Received certification as an assisted-living community from the department.

(6) The department shall determine the feasibility of recognizing accreditation by other organizations in lieu of certification from the department. 
(7) Individuals designated by the department to conduct certification reviews shall have the skills, training, experience, and ongoing education to perform certification reviews.

(8) Upon receipt of an application for certification, the department shall assess an assisted-living community certification fee in the amount of twenty dollars (\$20) per living unit that in the aggregate for each assisted-living community is no less than three hundred dollars $(\$ 300)$ and no more than one thousand six hundred dollars $(\$ 1,600)$. The department shall submit to the Legislative Research Commission, by June 30 of each year, a breakdown of fees assessed and costs incurred for conducting certification reviews.

(9) The department shall submit to the Legislative Research Commission and make available to any interested person at no charge, by June 30 of each year, in summary format, all findings from certification reviews conducted during the prior twelve (12) months.

(10) Notwithstanding any provision of law to the contrary, the department may request any additional information from an assisted-living community or conduct additional on-site visits to ensure compliance with the provisions of KRS 194A.700 to 194A.729.

(11) Failure to follow an assisted-living community's policies, practices, and procedures shall not result in a finding of noncompliance unless the assisted-living community is out of compliance with a related requirement under KRS 194A.700 to 194A.729.

Effective: July 15, 2010

History: Amended $2010 \mathrm{Ky}$. Acts ch. 36, sec. 4, effective July 15, 2010. -- Amended $2007 \mathrm{Ky}$. Acts ch. 24, sec. 9, effective June 26, 2007. -- Amended $2005 \mathrm{Ky}$. Acts ch. 99 , sec. 163, effective June 20, 2005. -- Created $2000 \mathrm{Ky}$. Acts ch. 141, sec. 4, effective July 14, 2000.

Legislative Research Commission Note (6/20/2005). $2005 \mathrm{Ky}$. Acts chs. 11, 85, 95, 97, $98,99,123$, and 181 instruct the Reviser of Statutes to correct statutory references to agencies and officers whose names have been changed in 2005 legislation confinning the reorganization of the executive branch. Such a correction has been made in this section. 
194A.709 Delivery of health services by staff - Abuse, neglect, and exploitation of clients, policies and reporting.

(1) The department shall report to the Division of Health Care Facilities and Services any alleged or actual cases of health services being delivered by the staff of an assisted-living community.

(2) An assisted-living community shall have written policies on reporting and recordkeeping of alleged or actual cases of abuse, neglect, or exploitation of an adult under KRS 209.030. The only requisite components of a recordkeeping policy are the date and time of the report, the reporting method, and a brief summary of the alleged incident.

(3) Any assisted-living community staff member who has reasonable cause to suspect that a client has suffered abuse, neglect, or exploitation shall report the abuse, neglect, or exploitation under KRS 209.030.

Effective: July 15,2010

History: Amended 2010 Ky. Acts ch. 36, sec. 5, effective July 15, 2010. -- Amended $2007 \mathrm{Ky}$. Acts ch. 24, sec. 10, effective June 26, 2007. -- Amended $2005 \mathrm{Ky}$. Acts ch. 99, sec. 164, effective June 20, 2005. -- Anended $2001 \mathrm{Ky}$. Acts ch. 81, sec. 1, effective June 21, 2001. - Created $2000 \mathrm{Ky}$. Acts ch. 141, sec. 5, effective July 14, 2000. 
194A.711 Criteria to be met by clients.

A client shall meet the following criteria:

(1) Be ambulatory or mobile nonambulatory, unless due to a temporary condition; and

(2) Not be a danger.

Effective: July 15, 2010

History: Amended $2010 \mathrm{Ky}$. Acts ch. 36, sec. 6, effective July 15, 2010. -- Created 2000 Ky. Acts ch. 141, sec. 6, effective July 14, 2000. 


\section{A.713 Contents of lease agreement.}

A lease agreement, in no smaller type than twelve (12) point font, shall be executed by the client and the assisted-living community and shall include but not be limited to:

(1) Client data, for the purpose of providing service, to include:

(a) Emergency contact person's name;

(b) Name of responsible party or legal guardian, if applicable;

(c) Attending physician's name;

(d) Information regarding personal preferences and social factors; and

(e) Advance directive under KRS 311.621 to 311.643, if desired by the client.

(2) Assisted-living community's policy regarding termination of the lease agreement;

(3) Terms of occupancy;

(4) General services and fee structure;

(5) Information regarding specific services provided, description of the living unit, and associated fees;

(6) Provisions for modifying client services and fees;

(7) Minimum thirty (30) day notice provision for a change in the community's fee structure;

(8) Minimum thirty (30) day move-out notice provision for client nonpayment, subject to applicable landlord or tenant laws;

(9) Provisions for assisting any client that has received a move-out notice to find appropriate living arrangements prior to the actual move-out date;

(10) Refund and cancellation policies;

(11) Description of any special programming, staffing, or training if an assisted-living community is marketed as providing special programming, staffing, or training on behalf of clients with particular needs or conditions;

(12) Other community rights, policies, practices, and procedures;

(13) Other client rights and responsibilities, including compliance with KRS 194A.705(2) and (3); and

(14) Grievance policies that minimally address issues related to confidentiality of complaints and the process for resolving grievances between the client and the assisted-living community.

Effective: July 15, 2010

History: Amended $2010 \mathrm{Ky}$. Acts ch. 36, sec. 7, effective July 15, 2010. -- Created $2000 \mathrm{Ky}$. Acts ch. 141, sec. 7, effective July 14, 2000. 
194A.715 Duty of assisted-living community to provide copy of KRS 194A.700 to 194A.729 and relevant administrative regulations to interested persons.

An assisted-living community shall provide any interested person with a copy of KRS 194A.700 to 194A.729 and relevant administrative regulations.

Effective: July 15, 2010

History: Amended $2010 \mathrm{Ky}$. Acts ch. 36, sec. 8, effective July 15, 2010. -- Amended $2007 \mathrm{Ky}$. Acts ch. 24, sec. 11, effective June 26, 2007. -- Amencled $2005 \mathrm{Ky}$. Acts ch. 99, sec. 165, effective June 20, 2005. -- Created $2000 \mathrm{Ky}$. Acts ch. 141, sec. 8 , effective July 14, 2000. 
194A.717 Staffing requirements -- Prohibition against employing staff member with active communicable disease.

(1) Staffing in an assisted-living community shall be sufficient in number and qualification to meet the twenty-four (24) hour scheduled needs of each client pursuant to the lease agreement and functional needs assessment.

(2) One (1) awake staff member shall be on site at all times.

(3) An assisted-living community shall have a designated manager who is at least twenty-one (21) years of age, has at least a high school diploma or a General Educational Development diploma, and has demonstrated management or administrative ability to maintain the daily operations.

(4) No employee who has an active communicable disease reportable to the Department for Public Health shall be permitted to work in an assisted-living community if the employee is a danger to the clients or other employees.

Effective: July 15, 2010

History: Amended $2010 \mathrm{Ky}$. Acts ch. 36, sec. 9, effective July 15, 2010. -- Created 2000 Ky. Acts ch. 141, sec. 9, effective July 14, 2000. 
194A.719 In-service education for staff and management.

(1) Assisted-living community staff and management shall receive orientation education on the following topics as applicable to the employee's assigned duties:

(a) Client rights;

(b) Community policies;

(c) Adult first aid;

(d) Cardiopulmonary resuscitation unless the policies of the assisted-living community state that this procedure is not initiated by its staff, and that clients and prospective clients are informed of the policies;

(e) Adult abuse and neglect;

(f) Alzheimer's disease and other types of dementia;

(g) Emergency procedures;

(h) Aging process;

(i) Assistance with activities of daily living and instrumental activities of daily living;

(j) Particular needs or conditions if the assisted-living community markets itself as providing special programming, staffing, or training on behalf of clients with particular needs or conditions; and

(k) Assistance with self-administration of medication.

(2) Assisted-living community staff and management shall receive annual in-service education applicable to their assigned duties that addresses no fewer than four (4) of the topics listed in subsection (1) of this section.

Effective: July 15, 2010

History: Amended $2010 \mathrm{Ky}$. Acts ch. 36, sec. 10, effective July 15, 2010, -- Created $2000 \mathrm{Ky}$. Acts ch. 141, sec. 10, effective July 14, 2000. 
194A.721 Exemptions from space and bathing facilities requirements for living units of certain assisted-living communities.

(1) Any assisted-living community that was open or under construction on or before July 14,2000 , shall be exempt from the requirement that each living unit have a bathtub or shower.

(2) Any assisted-living community that was open or under construction on or before July 14,2000 , shall have a minimum of one (1) bathtub or shower for each five (5) clients.

(3) Any assisted-living community that was open or under construction on or before July 14,2000 , shall be exempt from the requirement that each living unit shall be at least two hundred (200) square feet for single occupancy, or for double occupancy if the room is shared with a spouse or another individual by mutual agreement.

Effective: July 14, 2000

History: Created $2000 \mathrm{Ky}$. Acts ch. 141, sec. 11, effective July 14, 2000. 
194A.723 Penalties for operating without certification.

Any business that operates or markets its services as an assisted-living community without filing a current application with the department or receiving certification by the department may be fined up to five hundred dollars $(\$ 500)$ per day.

Effective: July 15, 2010

History: Amended $2010 \mathrm{Ky}$. Acts ch. 36, sec. 11, effective July 15, 2010. -- Amended $2007 \mathrm{Ky}$. Acts ch. 24, sec. 12, effective June 26, 2007. -- Amended $2005 \mathrm{Ky}$. Acts ch. 99, sec. 166, effective June 20, 2005. -- Created $2000 \mathrm{Ky}$. Acts ch. 141, sec. 12, effective July 14, 2000. 
194A.724 Statements of danger -- Penalty for receipt.

An assisted-living community that is issued more than two (2) statements of danger on separate dates within a six (6) month period that are not withdrawn by the department may be fined up to five hundred dollars $(\$ 500)$.

Effective: July 15, 2010

History: Created 2010 Ky. Acts ch. 36, sec. 12, effective July 15, 2010. 
194A.725 Religious orders exempt from KRS 194A.700 to 194A.729.

Religious orders providing assistance with activities of daily living, instrumental activities of daily living, and self-administration of medication to vowed members residing in the order's retirement housing shall not be required to comply with the provisions of KRS 194A.700 to 194A.729.

Effective: July 14, 2000

History: Created 2000 Ky. Acts ch. 141, sec. 13, effective July 14, 2000. 
194A.727 Ineligibility for certification of businesses not in full compliance with KRS 194A.700 to 194A.729.

Any business, not licensed or certified in another capacity, that complies with some provisions of KRS 194A.700 to 194A.729 but does not provide assistance with any activities of daily living or assistance with self-administration of medication shall not be eligible for certification as an assisted-living community under KRS 194A.700 to 194A.729.

Effective: July 14, 2000

History: Created $2000 \mathrm{Ky}$. Acts ch. 141, sec. 14, effective July 14, 2000. 
194A.729 Requirement for division to provide information to lending institutions relative to financing for assisted-living community projects -- Fee.

If a person or business seeks financing for an assisted-living community project, the department shall provide written correspondence to the lender, upon request, to denote whether the architectural drawings and lease agreement conditionally comply with the provisions of KRS 194A.700 to 194A.729. The department may charge a fee of no more than two hundred fifty dollars $(\$ 250)$ for the written correspondence to the lender.

Effective: June 26, 2007

History: Amended $2007 \mathrm{Ky}$. Acts ch. 24, sec. 13, effective June 26, 2007. -- Amended 2005 Ky. Acts ch. 99, sec. 167, effective June 20, 2005. -- Created 2000 Ky. Acts ch. 141 , sec. 15 , effective July $14,2000$. 
Appendix 5 - Consumer Checklist 
EMPLOYEE QUALIFICATIONS (CONT'D)

The Assisted Living Community ensures that no employees are listed on Kentucky's nurse aide abuse registry

\section{FOOD SERVICES}

- Three meals and snacks are made available seven days a week*

․ Meals and snacks should be nutritionally balanced

- Special foods may be requested

- The meal schedule and menus are posted

ㄷ Clients are permitted to dine in their living units

\section{SOCIAL, RECREATIONAL \& SPIRITUAL}

\section{ACTIVITIES}

- There is an activities program that addresses the general preferences of clients*

- Acrivities are posted in advance

G Volunteers and families are encouraged to participate in activities

C Clients have access to religious activities at their churches or within the Assisted Living Community

FREQUENTLY ASKED QUESTIONS Can someone help me take my medication?

Yes, to an extent. If you request, employees can assist you in taking your pre-dosed medication. If the medication is not pre-dosed, staff can read the labels, help open your medication containers, and remind you to take your medication. However, employees cannot touch or give you the actual pills unless they are pre-dosed. Staff cannot give advice about medication, measure liquid medication, or give injections. You must arrange with an outside agency or person for those services, i.e. a pharmacist, doctor, home health agency, a health professional or another qualified person of your choice. You may name a designated representative regarding medication decisions.
Does Medicare and/or Medicaid pay for services in an Assisted Living Community in Kentucky?

No. Assisted Living Communidies in Kentucky are social models and do not provide health services. However, you might qualify for Meclicare and/or Medicaid coverage for health care services you are receiving from an outside licensed health care agency.

Do long-term care insurance policies pay for services in Assisted Living Communities? Some long-term care insurance policies provide coverage for services in Assisted Living

Communities. However, because coverage provisions vary, carefully read and compare policies before purchase. For more information, you may contact the Kentucky Department of Insurance at (502)564-6088 to request a copy of their guide for selecting a long-term care insurance policy, or contact the Kentucky Assisted I iving Facilities Association (KALFA) at (502)225-5201 or toll frec at 1-877-905-2001.

Can someone with Alzheimer's, Dementia or Parkinson's disease live in an Assisted Living Community?

Yes. Some Assisted Living Communities have special program units that accommodate the needs of clients with Alzheimer's, Dementia or Parkinson's. However, individuals would need to meet the client criteria for assisted living. In addition, Assisted Living Communiries are required to ensure staff receives specialized training when these services are marketed to the public.

\section{DEPRTMENT FOR AGING AND INDEPENDENT LIVING C.ABINET FOR HEALTH AND Family SERVICES 275 E. MAIN ST., 3 E-E FRANKFORT, KY 40621 PHONE: (502) 564-6930
FAX: (502) 564-4595 HTTP:/LCHES. KY.GOV/DAIL/AL.C.HTM PRNIEDIWTH STATTEFINDS} ANEQULALOPPORTUNTTY EATPLOYER M/F/D

\section{SELECTINGAN}

ASSISTED LIVING

\section{COMMUNITY}

\section{IN KENTUCKY}

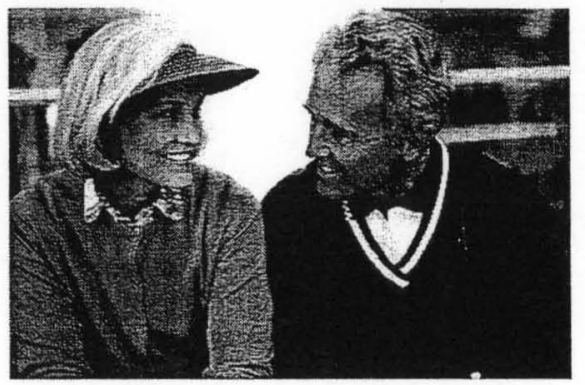

A Checklist for Consumets

Kentucky Department for Aging and Independent Living

$$
\text { (DAIL) }
$$

Kentucker lan requires certification of Assisted Liring Commannities by the Department for Aging and Independent Lining (DAIL), Cabinet for Health and Fumify Sernices. KRS 194A.700-729 and 910 KAR 1:240 specify requirements for certificution. This information includes some of those requirements as well as other jeatures and issues of interest to prospective clients.

\section{Kentucky}




\section{Your Personal Checkt IST. . .}

Choosing an Assisted I.iving Community that firs your personal preferences and care needs can be a challenging and sometimes overwhelming process. This checklist was designed to assist you as a consumer in identifing a quality residence that meets nor only the requirements bur also "best practices" of an Assisted Iiving Community in Kentucky. Ath asturisk follows a cbecklist iton that addiesses a requirment under Kenlanck.) lan or regulation (*).

\section{ASSISTED LIVING COMMUNITY}

\section{CERTIFICATION}

The Assisted I iving Community has received or applied for Certification by the Department for Aying and Independent l.iving (D.MIL) and information is available for my review.

\section{SERVICES OfFERED BY THE ASSISTED LIVING}

\section{COMMUNITY}

D Assistance with acdirites of daily living including bathing, dressing, grooning, mobility assistance, roilering and earing

a Assistance with instrumental activities of daily; living which includes, but is noc limited to, housekeeping, shopping, laundry; chores, transportacion and clerical assistance*

- Three meals and snacks made available each day*

- Scheduled daily social activities that address my general preferences *

- Assistance with self-adminiscration of medication*

\section{ATMOSPHERE}

a This is a convenient locarion

a The grounds and décor are attractive

$\square$ The employees treat risitors, clients and other employees in a friendly manner

a Clienrs socialize with each other and appear happy

V Visitors are welcome in the Assisted living Communiry:

COMMUNITY Features
- Individual living units (i.e. apartments) are at least 200 square feet (exceptions allowed)*

a Each living unit has a private bathroom (exceptions allowed)*

- Each living unit has a lockable door

a There is a window to the outdoors in each living unit*

a A telephone jack is available in each living unit*

There are provisions for emergency response in each living unir (i.e. pull cord, alarm, etc.)*

a Each living unit has thermostat control (exceptions allowed)*

a Access to a laundry facility is provided*

C.entral dining is available

D There is a common living room area*

$\square$ Doorways, hallways and living units acconmodate wheelchairs and walkers

D Elevators are available if the Assisted Living Community has more than one story

a There is a kicchenerte with a refrigerator, sink and microwave in each living unit

- Clients can access shared bitchen space for individual snacks (to the extent allowed by Local Health Department requirements)

- There is good natural and artificial lighting

It is easy to find my way around the community

- Clients can bring furniture and furnishings

a It is possible to share a room with a spouse or another individual under mutual agreement

\section{LEASE AGREEMENT}

The kease agrement is a contract between the client and the Assisted Laing Comminnity. It must be made wiailable to the chent for mevien before sizning, and be printed in 12-point tope.

\section{Client information must include:}

口 An assessment of my ability to perform activities tor daily living and instrumental activicies of daily living*

a Emergency contact person's name*
- Name of responsible party or legal guardian*

口. Atending physician's name

- Personal and social preferences*

- Advance directive if I choose*

O Other infomation that would help meet my needs*

Other information required:

- Policy regarding teminarion of the lease agreement*

口 Terms of occupancy*

( General services and fee stucuure*

- Information abour specific services provided, descripuion of the living unit and fees*

a Minimum 30-day notice for a change in fees*

a Minimum 30-day move-out nodice for nonpayment*

a Assistance in finding approptiate living arrangements prior to actual move-out date*

ㅁ Refund and cancellation policies*

Description of any special proyramming, staffing or training*

Other community rights, policies, practices and procedures*

口. Written policies about contracting or arranging to receive additional services from an outside agenc: or individual*

口 Grievance policies related to complaints*

\section{EMPLOYEE QUALIFICATIONS AND}

REQUTREMENTS

C The Assisted Living Community has a designated manager with management or administrative ability*

a There is sufficient staff to meet the 24-hour scheduled needs of clients*

C Criminal records checks are applied for within seven days of hire on all employees:

a Employee orientation and in-service education is completed within 90 days of employmenr*

a No employee who has an active communicable disease is permitted to work* 


\title{
CURRICULUM VITAE
}

\author{
James L. Wilson \\ 9507 Mozart Court \\ Prospect, KY 40059
}

Email: 1jwilsoneinsightbb.com

\begin{abstract}
Highly qualified housing executive with expertise in housing development and affordable housing policy analysis. Over eighteen years of asset and property management \& development. Results oriented with proven track record. Career reflects housing development and/or renovation in urban, suburban and rural communities. An effective communicator with an ability to work with ethnically and culturally diverse individuals and families.
\end{abstract}

\author{
EDUCATION : \\ PhD, Candidate, University of Louisville \\ Emphasis: Urban Planning and Development \\ Master of Arts, Spalding University \\ Emphasis: Religion
}

Bachelor of Science, University of Louisville Emphasis: Business Administration/Accounting

Christian Care Communities

\section{CAREER:}

Director of Assisted Living Services (January 2008 - present). Responsible for directing operations of two assisted living communities.

- Providing housing and assisted living services for older adults.

- Posses strong technical knowledge in areas relating to Kentucky state assisted living regulations.

- Oversees quality assurance programming to ensure optimum service delivery.

Director of Housing (June 1996 - present). Responsible for the development and oversight management compliance of rental 
housing programs across Commonwealth of Kentucky.

- Possess strong technical knowledge in areas relating to federal, state and local housing regulations and policy.

- Proven track record of developments with funding from U.S. Department of Housing and Urban Development (HUD), Kentucky Housing Corporation (KHC), Federal Home Loan Bank (FHLB).

- Written housing grant for construction/renovation of housing developments exceeding $\$ 16$ Million.

- Direct operational frontline employees for subsidy compliance with government authorities from HUD, KHC and FHLB, included Section 202, Section 8, Section 236 and Housing Credits.

- Direct annual revenue growth for all facilities including approval of budgets submitted to HUD.

- Advised for proper maintenance and qualitative appearance of properties.

- Review contract bids for maintenance and renovation work

- Development of new construction, renovations of facilities and expansions of programs and services.

United States Department of Housing and Urban Development (HUD), Asset Manager (June 1990 - May 1996). Assuring the compliance of policy, regulations, physical integrity and financial viability of insured, subsidized and unsubsidized multifamily properties in the scope of HUD programs.

- Review and analyze current and historical financial data for anomalies.

- Compare previous audited financial statements with recent financial information.

- Analyze current operating expenses and project financial data for the basis of approval of denial of the following actions: rent increases, refinancing, prepayment of mortgage.

COMMUNITY INVOLVEMENT:

Oakland Community Development Corporation (OCDC), Chair, (2004 - present)

Bates Memorial Community Development Corporation, Board Member (1998 - 2004)

Canaan Community Development Corporation, Board Member (1999 - 2001)

Central District Baptist Association, Department Director (1987 - 1996) 
AFFILIATIONS \& ORGANIZATIONS:

Institute of Real Estate Management (IREM):

- Certified Property Manager, CPMB

- Local Chapter 59 President, 2003

National Center for Housing Management (NCHM) :

- Certified Occupancy Specialist, COS

- Senior Housing Specialist, SHS

- Tax Credit Specialist, TCS

- Louisville Business First Magazine's "Forty Under 40" 1998

- Who's Who Among Students in American Universities and Colleges, 1998

- Leadership Louisville, Class of 2001

- Phi Beta Sigma Fraternity, Inc.

- Alpha Epsilon Lambda Graduate Honors Society for Outstanding Scholarship, Academics and Leadership - Spalding University

- Jefferson County Medical Society - 2001 Intern 